Research Division

Federal Reserve Bank of St. Louis

Working Paper Series

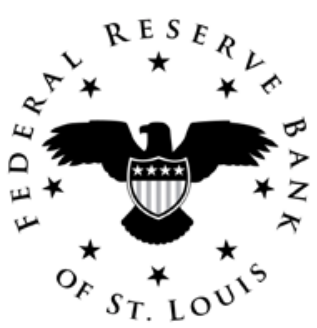

\title{
Informal Unemployment Insurance and Labor Market Dynamics
}

\author{
Kyle F. Herkenhoff
}

Working Paper 2012-057A

http://research.stlouisfed.org/wp/2012/2012-057.pdf

November 2012

FEDERAL RESERVE BANK OF ST. LOUIS

Research Division

P.O. Box 442

St. Louis, MO 63166

The views expressed are those of the individual authors and do not necessarily reflect official positions of the Federal Reserve Bank of St. Louis, the Federal Reserve System, or the Board of Governors.

Federal Reserve Bank of St. Louis Working Papers are preliminary materials circulated to stimulate discussion and critical comment. References in publications to Federal Reserve Bank of St. Louis Working Papers (other than an acknowledgment that the writer has had access to unpublished material) should be cleared with the author or authors. 


\title{
Informal Unemployment Insurance and Labor Market Dynamics (Preliminary, Do Not Cite)*
}

\author{
Kyle F. Herkenhoff ${ }^{\dagger}$ \\ UCLA \\ and \\ Federal Reserve Bank of St. Louis
}

October 29, 2012

(First Draft: July, 2012)

\begin{abstract}
How do job losers use default - a phenomenon $6 \times$ more prevalent than bankruptcy - as a type of "informal" unemployment insurance, and more importantly, what are the social costs and benefits of this behavior? To this end, I establish several new facts: (i) job loss is the main reason for default, not negative equity (ii) people default because they are credit constrained and cannot borrow more, and (iii) the value of debt payments is a significant fraction of a defaulter's earnings. Using these facts, I calibrate a general equilibrium model with a frictional labor market similar to Burdett and Mortensen (1998) and Menzio and Shi (2009, 2011) and individually priced debt along the lines of Eaton and Gersovitz (1981) and Chatterjee et al. (2007). After proving the existence of a Block Recursive Equilibrium, I find that the extra selfinsurance job losers obtain by defaulting outweighs the subsequent increase in the cost of credit, and as a result, protectionist policies such as the Mortgage Servicer Settlement of 2012 or the CARD Act of 2009 improve overall welfare by .1\%. The side effect of the policies, however, is a $.2-.5 \%$ higher unemployment rate during recessions that persists throughout the recovery.
\end{abstract}

*I am grateful for support from my advisors Gary Hansen, Lee Ohanian, and Pierre-Olivier Wiell. I received helpful comments from Aloisio Araujo, Paco Buera, Ariel Burstein, Pablo Fajgelbaum, Carlos Garriga, Alex-Monge Naranjo, Seth Neumuller, Juan Sanchez, Gabriel Ulyssea and seminar participants at the St. Louis Fed, IMPA, IPEA, FGV, and the UCLA Macro Seminar. This paper was written in part at the St. Louis Fed during the summer Dissertation Fellowship Program, and I am especially grateful for their hospitality and financial support. I also thank the UCLA Ziman Center for Real Estate for funding this research. The views expressed in this article are those of the author(s) and do not necessarily reflect the views of the Federal Reserve System, the Board of Governors, or the regional Federal Reserve Banks.

${ }^{\dagger}$ Correspondence: kfh@ucla.edu 


\section{Introduction}

How do job losers use default - a phenomenon $6 \times$ more prevalent than bankruptcy — as a type of "informal" unemployment insurance, and, taking into account the costs and benefits of this behavior, should society protect default? Ex-ante, both the positive and normative parts of this question are central to understanding past business cycles that coincided with excessive defaults, for example the 1992 Saving \& Loan Crisis and the 2005 housing bust, and to understanding the myriad current policies designed to ease the punishments for those missing payments. ${ }^{1}$ Given the importance and breadth of documenting and drawing welfare conclusions of default, I divide the task into several steps. Firstly, I define default to be $90+$ days late without filing for bankruptcy in the prior year (when possible), and secondly, I use new sources of data to determine who defaults, on how much, and why. Thirdly, I build a model that captures the labor incentives effects of default. And lastly, I simulate the model economy under various degrees of default protection, designed to capture current and past policies, in order to compare welfare and labor market dynamics.

As a preview of the empirical work, I present new evidence that a significant number of households miss payments on a certain fraction of their accounts, and that by selectively missing payments, households maintain a significant portion of their disposable income. Moreover, I show that this type of 'informal' self-insurance is commonly used by job losers and that the typical defaulter is credit constrained and unable to borrow more. ${ }^{2}$ To be precise, I use the Equifax database, the PSID Mortgage Distress Supplement, and the SCF 2007-2009 Panel to establish several new stylized facts (see below for the complete list): (i) default, which I define to be $90+$ days late without filing for bankruptcy within a year, dwarfs bankruptcy on a quarterly basis, occurring $5 \times$ to $6 \times$ times more often (ii) job loss is the most important cause of default, more so than negative equity or health shocks (iii) default is a business cycle event, roughly twice as cyclical as bankruptcy (iii) the median defaulter is credit constrained with a utilization rate of $92 \%$ (iv) the default decision boosts disposable income significantly, e.g. $34 \%$ for the median homeowner, and (v) the fraction of accounts on which consumers default is continuous, meaning that they selectively default on a non-trivial number accounts (which will be measured in 3 different ways). ${ }^{3}$

\footnotetext{
${ }^{1}$ For unsecured credit, the Credit CARD Act of 2009 imposes restrictions on punishments for defaulters (6month maximum rate increases), limits the rate increases on defaulting credit cards during the inaugural year of opening an account, and imposes many other restrictions. For secured credit, the foreclosure moratoria imposed by various states in 2008-2009 (see California and Massachusetts for example) stopped the typical default punishment of foreclosure; likewise, the robo-signing scandal of 2010 resulted in court imposed nationwide open-ended foreclosure moratoria for the largest servicers; and finally, the Mortgage Servicer Settlement of 2012 made renegotiation mandatory, banned simultaneous foreclosure and renegotiation, and forced banks to abide by HAMP modification rules that include 60+ days late as an eligibility requirement. See Appendix D for more details.

${ }^{2}$ See Sullivan [2008] for more on the way unemployed persons borrow in normal times.

${ }^{3}$ On a methodological note, the continuous default decision allows me to solve the endowment version of the economy using perturbation methods thus estimate the economy (done in a separate paper Herkenhoff [2012]), and in the extended model, high frequency job loss allows me to match observed levels of default.
} 
Using these new stylized facts, I create a unique and simple model of default in which credit constrained agents default on a non-trivial fraction of their debt to smooth higher frequency income changes. ${ }^{4}$ The model features individually priced debt as in Eaton and Gersovitz [1981] and endogenous credit scores similar to Chatterjee et al. [2008b], but in my model the drop in credit scores and subsequent punishment is determined by the fraction of debts in default. After demonstrating some properties of the model with exogenous endowments, I nest the continuous default choice in a general equilibrium model with a frictional labor market similar to Burdett and Mortensen [1998] and Menzio and Shi [2009, 2011], and aggregate risk in order to analyze the two competing effects on welfare. ${ }^{56}$ The first effect is that by defaulting after job loss, agents are able to maintain sufficient income while they look for hard-to-find high-pay jobs, even after formal unemployment benefits expire. ${ }^{7}$ The second effect is the higher costs of borrowing due to the fact that creditors must recoup their default losses on average. ${ }^{8}$ Since agents do not internalize their default actions on the overall cost of credit, this acts as a negative externality over and above the redistributional effects. After calibrating the model to match the moments of the new data, I find that the first effect of being able to find better jobs trumps the increase in the cost of credit and thus protecting defaulters improves overall welfare, lending some credence to the policies in Appendix D. Since the model is in general equilibrium and calibrated to match the true magnitude of default, it provides a plausible environment for normative analysis. ${ }^{9}$ Netting the opposite gross welfare changes associated with of the two effects, I find that protecting default improves welfare by $.1 \%$.

In addition to the welfare calculation, I feed the model the observed productivity and job destruction paths beginning in 2007-IV, the NBER dated peak of the Great Recession, through 2010-II, one year after the official trough, and I find that a policy which unexpectedly and permanently protects defaulters increases the unemployment rate by $1 / 3$ to $3 / 4 \%$ (i.e. the unemployment rate is $7.75 \%$ with default as opposed to $7 \%$ without) and that this increase is persistent. The resulting Beveridge curve from the simulation features a distinct

\footnotetext{
${ }^{4}$ With exceptions of Dubey et al. [2005], Dubey et al. [1990], Araujo and Monteiro [1996], Benjamin and Wright [2009], Seccia and Mateos-Planas [2011], [Benjamin and Mateos-Planas, 2011], and [Athreya et al., 2011], the theoretical literature on default has restricted its attention to binary bankruptcy.

${ }^{5}$ I will use several simplifying assumptions to Menzio and Shi [2009, 2011] similar to Karahan and Rhee [2011].

${ }^{6}$ For partial equilibrium search models with bankruptcy, see Athreya and Simpson [2006] and Chen [2012a].

${ }^{7}$ Using a cross-section of 6,000 respondents at various points in the possible 99 weeks of unemployment, Krueger and Mueller [2011] find that the reservation wage is fairly stable over the duration of unemployment except for those with more than $\$ 10,000$ in savings, but that "the reservation wage and job search time predict early exit from UI."

${ }^{8}$ Default raises the cost of credit among all agents, transferring wealth from borrowers to defaulters (which tends to make everyone better off), but default also strongly dissuades others from borrowing, which tends to weakly decreases welfare

${ }^{9} \mathrm{See} \mathrm{Li}$ and Sarte [2006] for a steady state general equilibrium welfare analysis of bankruptcy in a production economy with indivisible labor. See Gordon [2011] for a general equilibrium analysis of bankruptcy during business cycles with inelastically supplied labor.
} 
shift outward, with vacancies being posted but well-insured unemployed persons waiting for higher paying jobs.

While the literature that my paper intersects is expansive (see below), my contribution is threefold. To begin, I provide a consistent definition and method for measuring default as opposed to bankruptcy, and I am the first, to my knowledge, to conduct a default event study using the Equifax consumer credit panel, the Panel Study of Income Dynamics, and the Survey of Consumer Finances in order to explain why people default, and understand how default is a response to higher frequency employment changes. ${ }^{10}$ Secondly, I am the first to build a low-state general equilibrium model that incorporates the wage setting mechanisms of Burdett and Mortensen [1998] and Menzio and Shi [2009, 2011], individually priced debt along the lines of Eaton and Gersovitz [1981], endogenous credit scores as in Chatterjee et al. [2008b], and aggregate risk. And, lastly but most importantly, I make normative conclusions about the current regalia of pro-debtor default policies.

\section{Relation to the Literature}

Regarding the 'default-not-bankruptcy' aspect of the present study, the first author to provide a stylized model of default as opposed to bankruptcy is White [1998]. Building on that work, Dawsey and Ausubel [2002] obtain private visa data in order to build an empirical nested logit model used to analyze the different determinants of default and bankruptcy. Independently, Benjamin and Wright [2009] are to first to put some form of default (they model default as a renegotiation process), in a sovereign debt model which merges features from Eaton and Gersovitz [1981] and the bargaining literature. More recently, on the consumer side of the literature, Chatterjee [2010] proposes a game theoretic model to analyze the interactions between creditor collection efforts and late borrowers, and Herkenhoff and Ohanian [2011] calibrate an island model that allows for consumers to skip mortgage payments and request write-downs to examine the role of mortgage modifications on mobility. Concurrent research by Athreya et al. [2011], [Benjamin and Mateos-Planas, 2011], and Herkenhoff and Ohanian [2012] focuses on distinguishing between default and bankruptcy, where Herkenhoff and Ohanian [2012] is the first to look at labor market implications. Athreya et al. [2011] extend the life cycle framework of Hatchondo et al. [2012] to include a binary default option in addition to the usual binary bankruptcy option. In their model delinquency occurs at low levels of income among younger agents prior to bankruptcy, whereas bankruptcy occurs once income begins to recover (see Arellano [2008]). Focusing on renegotiation, [Benjamin and Mateos-Planas, 2011] reinterpret the variables in the sovereign-debt model of Benjamin and Wright [2009] to generate predictions in a consumer credit environment. Similar to

\footnotetext{
${ }^{10}$ See Musto [2004] for facts about bankruptcy. The benefit of the Equifax data is that it is a $5 \%$ random sample of American individuals with social security numbers. People were drawn based on the last two digits of their social security number, including not only those with credit reports, but also those with no recorded credit
} 
Benjamin and Wright [2009], they study the role of renegotiation in an endowment economy, focusing on the benefit that various types of default provide to households to smooth out income shocks. Lastly, in a purely positive article, Herkenhoff and Ohanian [2012] use the PSID Mortgage Distress Supplement to document a large share of unemployed persons who skip mortgage payments in order to smooth consumption. They show that the ability to default generates similar incentives effects as unemployment insurance extensions: initially, when foreclosure is unlikely, delinquent mortgagors economize on search effort, and as foreclosure becomes more imminent, delinquent mortgagors have a much higher propensity to find a job. They use this new data to calibrate a monthly model that features a frictional labor market and a rich set of mortgage payment choices (default, foreclosure, sale) in order to determine the affect on aggregate variables. They find that the disincentives to search generated by protracted default episodes generate roughly $\frac{1}{2} \%$ of additional unemployment, but they deliberately omit normative conclusions.

In terms of continuous default, Dubey et al. [1990] were to first to allow agents to pick an endogenous fraction of debt to repay. Their model is in a 2-period general equilibrium setting, and agents face a utility penalty of default that is potentially state-contingent. It is important to note that their borrowing and lending market is in general equilibrium; an intermediary pools loans and agents purchase shares of that pool. Araujo and Monteiro [1996] extended this model into an infinite horizon setting, and Seccia and Mateos-Planas [2011] build a 2-period model similar to Dubey et al. [1990] in order to analytically characterize risk sharing.

Regarding the interaction between frictional labor markets and bankruptcy, this topic has been explored empirically and in partial equilibrium. In an influential article, Athreya and Simpson [2006] built a partial equilibrium model along the lines of Ljungqvist and Sargent [1998] to understand how bankruptcy is used as a form of unemployment insurance. In their model there are no wage dynamics but workers choose their search intensity and are subject to human capital shocks the longer they remain unemployed. The mechanism in their model is that by filing bankruptcy (and being subsequently excluded from markets), agents are better able to self-insure and thus economize on search effort; by waiting too long as an unemployed agent, more people suffer human capital losses. They find significant increases in the unemployment rate when bankruptcy is relatively 'easy' and they also show that it is welfare improving to eliminate bankruptcy due to the unambiguous drop in the cost of credit and shorter unemployment durations/fewer realized human capital losses. Chen [2012a] provides a similar analysis in a similar partial equilibrium framework, looking at how the elimination of debts following chapter 7 bankruptcy as opposed to chapter 13 bankruptcy increases labor supply. In her calibrated model, she finds that labor supply increases by $3.5 \%$ following a bankruptcy episode, but she abstains from making welfare conclusions. There are also related papers that incorporate frictionless labor markets in general equilibrium production economies. For instance, Li and Sarte [2006] conduct a welfare analysis of bankruptcy in a production economy with indivisible labor (this paper will be discussed more below). Gordon [2011] also conducts a similar general equilibrium analysis 
of bankruptcy with inelastically supplied and exogenously given efficiency units of labor, allowing for business cycles among other features.

On the social insurance aspect of the paper, many authors have recently tried to quantify the role of various formal welfare programs and unemployment insurance on the 2007-2009 recovery. ${ }^{11}$ The exception to the literature is Mulligan [2011] who also considers the way consumer use mortgage modifications and other "informal" ways of providing self-insurance. Mulligan finds that after correcting for rule changes regarding eligibility, increases in payments to non-employed persons can explain the majority of the observed gap between the marginal rate of substitution between consumption and leisure and the marginal product of labor. The other exception is Sullivan [2008] who studies private borrowing in response to job loss. He finds that during unemployment spells households that have some initial wealth borrow on average 10 cents for each dollar of earnings lost. On unemployment insurance, Rothstein [2011] finds that unemployment extensions increased unemployment by at most $\frac{1}{2} \%$, and, using past data, Chetty [2008] finds that a 10\% increase in unemployment benefit generosity protracts unemployment durations by $48 \%$.

While literature that my paper intersects is expansive (see below), I contribute along the data front similar to Musto [2004], along the theoretic front by building a low-state general equilibrium model that incorporates the wage setting mechanisms of Burdett and Mortensen [1998] and Menzio and Shi [2009, 2011], individually priced debt along the lines of Eaton and Gersovitz [1981], endogenous credit scores as in Chatterjee et al. [2008b], and aggregate risk, and along the policy front by drawing normative conclusions about the current regalia of pro-debtor default policies.

\section{Data}

The data used in this paper come from several sources, the Equifax consumer credit panel, the Panel Study of Income Dynamics, and the Survey of Consumer Finances.

The Equifax Consumer Credit Panel statistics are derived from standardized Primary and Consumer Identification (CID) .1\% random samples, containing roughly 2 million observations from 1999-Q3 until 2012-Q2. ${ }^{12}$ Each of these samples was used separately to verify the results in this paper. For more details on the Equifax Consumer Credit Panel, see Lee and van der Klaauw [2010].

I also show data from the Panel Study of Income Dynamics (PSID), 2009 Mortgage Distress Supplement. This dataset provides the most complete picture of household characteristics at time of default. The data is limited to mortgagors, but provides a unique glimpse

\footnotetext{
${ }^{11}$ See Hubbard et al. [1995] for more on the way welfare distorts private incentives for precautionary savings.

${ }^{12}$ The primary file includes only those who last two digits of their social security numbers were taken in the initial 5\% random sample. The CID includes information on the other members of the households.
} 
into the households' employment status at default. For more on this PSID supplement see Herkenhoff and Ohanian [2012].

The Survey of Consumer Finances 2007-2009 Panel is another unique glimpse into default behavior. I use this data to generate several more pictures related to default and employment, however the timing of the questions in the SCF makes it harder to look at high frequency events. The data do keep track of late and timely payers, bankruptcies, and foreclosures as well as several measure of employment and durations of unemployment. 


\subsection{Stylized Facts}

Fact 1: The incidence of default, defined to be the number of people who have at least one account $90+$ days late and no bankruptcy within a year over the working age population, is roughly $6 \times$ the incidence of bankruptcy on an annual flow basis. The curves in Figure 1 plot the average fraction of new bankruptcies and new default episodes as a fraction of the working age population. ${ }^{13}$ Apart from the sheer magnitude of default relative to bankruptcy, another important aspect of this picture is the clear cyclicality of default. This points to a link between unemployment and default, and I will explore this in more detail in the sections to follow.

Figure 1:

Incidence of Default
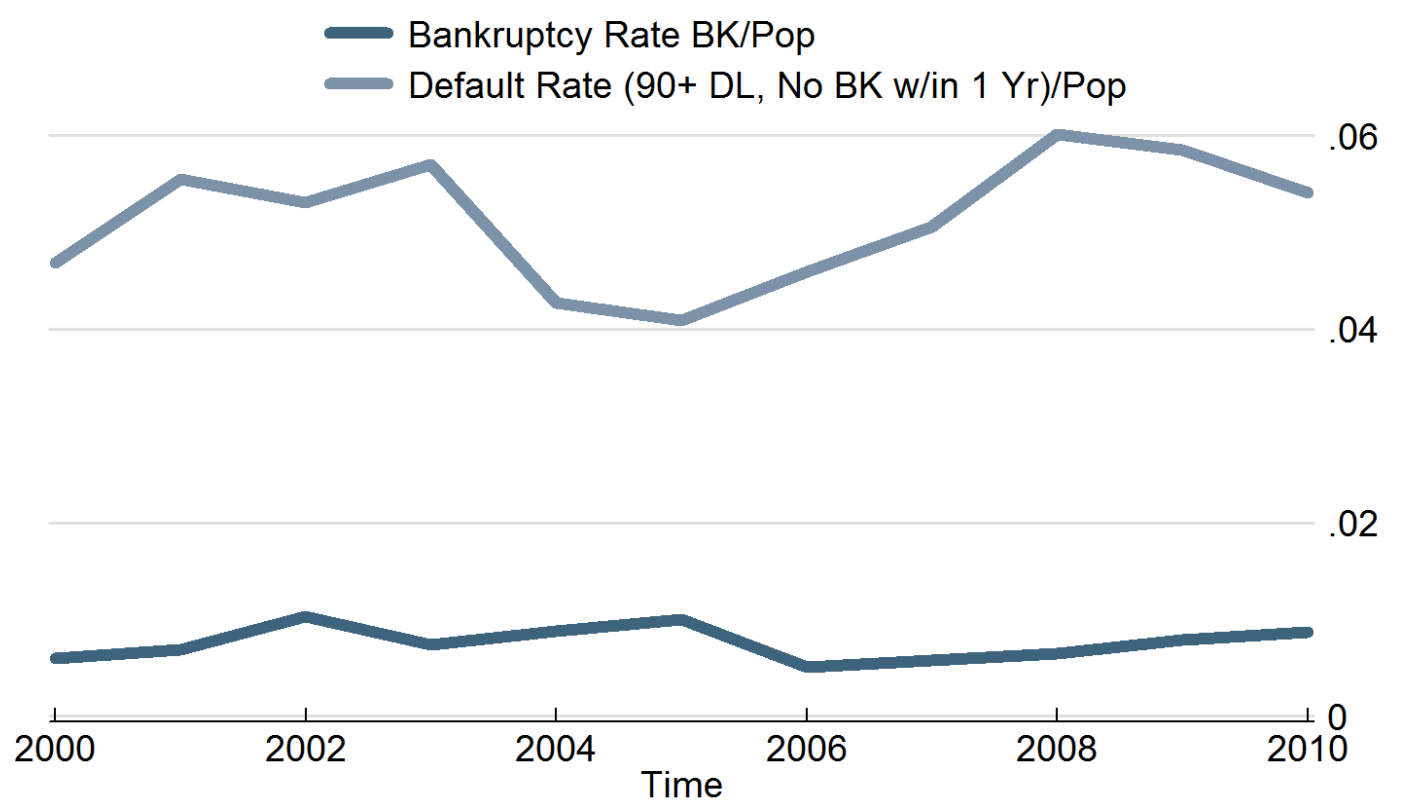

\footnotetext{
${ }^{13}$ Bankruptcies are counted as the first time a bankruptcy flag enters the Equifax records on an individual record, defaults are counted as the first time a consumer has one or more debts $90+$ days late and there is no bankruptcy in the following year.
} 
Fact 2: Job loss causes default, more than negative equity and other traditional triggers. To disentangle the effects of job loss and negative equity, I exploit the survey timing and information on job loss in the 2009 PSID Mortgage Distress Supplement. Table 1 includes two models, each of which estimates the current default status, as of the interview date, as a function of past job loss, controlling for other characteristics such as debt, combined loan to value (the sum of remaining mortgage payments -first, second, and HELOCsover self-reported home value), term characteristics, demographic characteristics, divorce, hospital bills, and various housing bust controls.

A much more detailed analysis and description of the data can be found in an accompanying paper Herkenhoff [2011]. Column (1) in Table 1 is a linear probability regression of an indicator that default, defined to be $60+$ days late in this section only, occurred within 6 months of the survey date on an indicator of recent job loss, defined to be any separation within 6 months of the survey date. These results indicate that after including controls, job losers are $6.4 \%$ more likely than non-job losers to default. Column (2) of table 1 reports the marginal probabilities for the corresponding logit model. The results in Column (2) indicate that recent job losers are $7.5 \%$ more likely than non-job losers to default on average for the people in my sample. ${ }^{14}$ This is a comparable effect in magnitude to severe negative equity which increases the risk of default by $11.2 \%$ and $4.8 \%$ depending on the specification (severe negative equity means combined loan to value greater than $120 \%$, i.e. the mortgages exceed the value of the home by 20\%). Column (3) is the marginal effect at the mean, but most variables have insignificant marignal effects except job loss. This column is included for robustness and illustrates the relative fragility of the negative equity results. Divorce is not a good predictor of default, and burdensome hospital bills, which is part of the classic expense shock cited in the bankruptcy of Livshits et al. [2007], is not a good predictor of default either. As I will show below in a separate dataset for both mortgagors and non-mortgagors, default becomes a more important mechanism as the unemployment spell advances. For more on the PSID and the default behavior of the unemployed, see Herkenhoff and Ohanian [2012].

\footnotetext{
${ }^{14}$ The marginal effect for a discrete binary regressor $X_{k}$ is $P\left(Y=1 \mid X, X_{k}=1\right)-P\left(Y=1 \mid X, X_{k}=0\right)$ where all other regressors are fixed at $X$. The average marginal effect is given by calculating this across every observed $X$ in the sample and then averaging the resulting marginal effects. The marginal effect at the mean is the above calculation setting $X=\bar{X}$ to the sample average. Since many of the variables are indicators, averaging is counterfactual. This is included for completeness. All errors are calculated using the delta method. Survey weights are used, but the results also obtain without the survey weights.
} 
Table 1:

Dependent Variable is Recent Default Indicator

\begin{tabular}{|c|c|c|c|}
\hline & $\begin{array}{l}\text { (1) } \\
\text { Linear Probabil- } \\
\text { ity Model }\end{array}$ & $\begin{array}{l}(2) \\
\text { Logit, Average } \\
\text { Marginal Effect }\end{array}$ & $\begin{array}{l}(3) \\
\text { Logit, Marginal } \\
\text { Effect at Mean }\end{array}$ \\
\hline Job Loss Indicator & $\begin{array}{l}0.0819^{* *} \\
(0.0416)\end{array}$ & $\begin{array}{l}0.0759^{* * *} \\
(0.0273)\end{array}$ & $\begin{array}{l}0.0328^{*} \\
(0.0173)\end{array}$ \\
\hline Combined Loan to Value Ratio $\in(.8,1]$ & $\begin{array}{l}0.00948 \\
(0.0105)\end{array}$ & $\begin{array}{l}0.0130 \\
(0.0104)\end{array}$ & $\begin{array}{l}0.00323 \\
(0.00287)\end{array}$ \\
\hline Combined Loan to Value Ratio $\in(1,1.2]$ & $\begin{array}{l}0.0167 \\
(0.0247)\end{array}$ & $\begin{array}{l}0.0173 \\
(0.0170)\end{array}$ & $\begin{array}{l}0.00461 \\
(0.00520)\end{array}$ \\
\hline Combined Loan to Value Ratio $\in(1.2, \infty)$ & $\begin{array}{l}0.112^{* * *} \\
(0.0395)\end{array}$ & $\begin{array}{l}0.0482^{* *} \\
(0.0231)\end{array}$ & $\begin{array}{l}0.0167 \\
(0.0115)\end{array}$ \\
\hline Unsecured Debt to Income $\in(.25, .5]$ & $\begin{array}{l}0.00846 \\
(0.0126)\end{array}$ & $\begin{array}{l}0.00927 \\
(0.00975)\end{array}$ & $\begin{array}{l}0.00225 \\
(0.00260)\end{array}$ \\
\hline Unsecured Debt to Income $\in(.5, .75]$ & $\begin{array}{l}0.0412 \\
(0.0362)\end{array}$ & $\begin{array}{l}0.0357 \\
(0.0288)\end{array}$ & $\begin{array}{l}0.0113 \\
(0.0118)\end{array}$ \\
\hline Unsecured Debt to Income $\in(.75, \infty)$ & $\begin{array}{l}0.0404^{*} \\
(0.0211)\end{array}$ & $\begin{array}{l}0.0318^{*} \\
(0.0172)\end{array}$ & $\begin{array}{l}0.00957 \\
(0.00712)\end{array}$ \\
\hline Hospital Bills to Income $\in(.1, \infty)$ & $\begin{array}{l}0.00546 \\
(0.0236)\end{array}$ & $\begin{array}{l}0.0133 \\
(0.0175)\end{array}$ & $\begin{array}{l}0.00339 \\
(0.00511)\end{array}$ \\
\hline Divorce Indicator & $\begin{array}{l}0.0175 \\
(0.0292)\end{array}$ & $\begin{array}{l}0.00375 \\
(0.0197)\end{array}$ & $\begin{array}{l}0.000868 \\
(0.00471)\end{array}$ \\
\hline $\begin{array}{l}\text { Demographic Controls } \\
\text { Mortgage Characteristics } \\
\text { State Controls } \\
\text { Observations } \\
\text { R-squared }\end{array}$ & $\begin{array}{l}\text { Yes } \\
\text { Yes } \\
\text { Yes } \\
2,818 \\
0.181\end{array}$ & $\begin{array}{l}\text { Yes } \\
\text { Yes } \\
\text { Yes } \\
2,818\end{array}$ & $\begin{array}{l}\text { Yes } \\
\text { Yes } \\
\text { Yes } \\
2,818\end{array}$ \\
\hline \multicolumn{4}{|c|}{$\begin{array}{l}\text { Standard errors in parentheses } \\
* * * \mathrm{p}<0.01,{ }^{* *} \mathrm{p}<0.05,{ }^{*} \mathrm{p}<0.1\end{array}$} \\
\hline
\end{tabular}


Fact 3: The longer the unemployment spell, the more likely the person is to use default as a consumption smoothing mechanism. The data used for this stylized fact come from the Survey of Consumer Finances. The sub-sample I look at includes heads of household, grouped by their self-declared delinquency status over the last 12 months and time spent unemployed over the last 12 months. Panel (a) of Figure 2 shows that default becomes more likely as unemployment spells become longer. Of the employed persons who were late over the last 12 months, $16.59 \%$ had a wife that was unemployed at some point during that period.

Figure 2:

(a)

Fraction of Debtholders 60+ Days Late

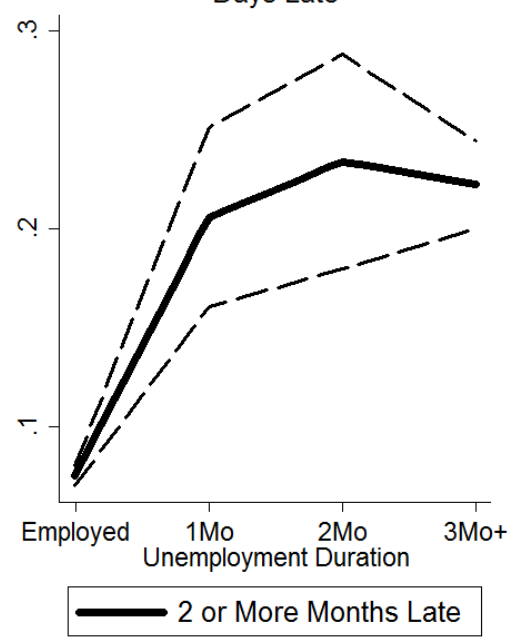

(b)

Employment Per Capita by Mortgage Delinquency Status

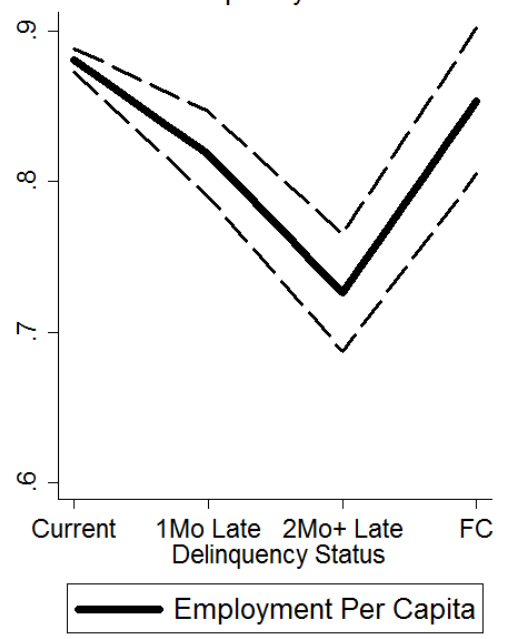

(c)

Non-Mortgagor Employment Per Capita by Delinquency Status

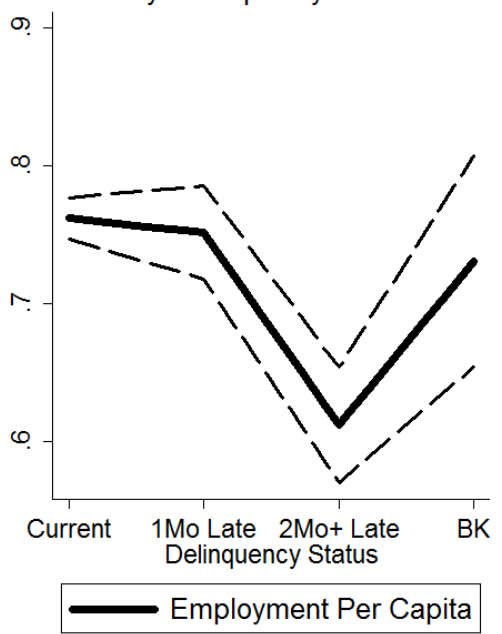

Notes: Dashed lines are 95\% confidence interval for the mean, Sample from 2009 SCF and includes Heads only, Weighted using SCF provided survey weights, Results hold without the weights in same magnitude

Fact 4: Behavioral incentives of default are similar to unemployment insurance. Panel (b) of Figure 2, derived from the 2009 Survey of Consumer finances, illustrates employment incentives are altered by mortgage delinquency. The x-axis is the number of missed payments over the last 12 months, and the y-axis is the contemporaneous per-capita employment rate. The key aspect of the graph is the fact that the employment rate is higher for heads of households that underwent a recent foreclosure (this ' $U$ ' shaped pattern also holds in the PSID, see Herkenhoff and Ohanian [2012]). ${ }^{15} 16$ At initial job loss, they begin to skip

\footnotetext{
${ }^{15}$ One important question is whether people stay in the $60+$ days late bin for a shorter duration than the foreclosure bin, generating a mechanical increase in employment. This is not the case, particularly during this time period. Over this period time spent in each bin is comparable and the transition matrix in Herkenhoff and Ohanian [2012] illustrates this point.

${ }^{16}$ Due to the panel nature of the SCF, and ability to identify people using public foreclosure records, foreclosure dates were lumped into a two year interval, 2007-2009. The relevant question is "Have you (or
} 
payments to maintain living standards, but once foreclosure is initiated, the ability to use default to smooth consumption comes to an end and they are forced to find employment. Panel (c) of Figure 2 illustrates the same graph for non-mortgagors. The behavior of nonmortgagors also supports the theory of default as a consumption smoothing mechanism, but the reason underlying this behavior is different. Bankruptcy is means tested, which distorts incentives to find a job before filing. ${ }^{17}$

Fact 5: Default occurs at a business cycle frequency. Depending on the sample period, Gordon [2011] documents a correlation of HP filtered log bankruptcy filings and real GDP between -.02 and -.45. I conduct a similar exercise for data between 1999-2012 except I detrend linearly so as to not understate the business cycle movements during the 20072009 recession. Over my sample period I find a correlation between the contemporaneous fraction of new defaults per capita and real output of -.9. Likewise, for the fraction of new bankruptcies per capita, this number is -.48 over the same sample period. The detrended series for defaults and real GDP are shown in Figure 3.

Figure 3:

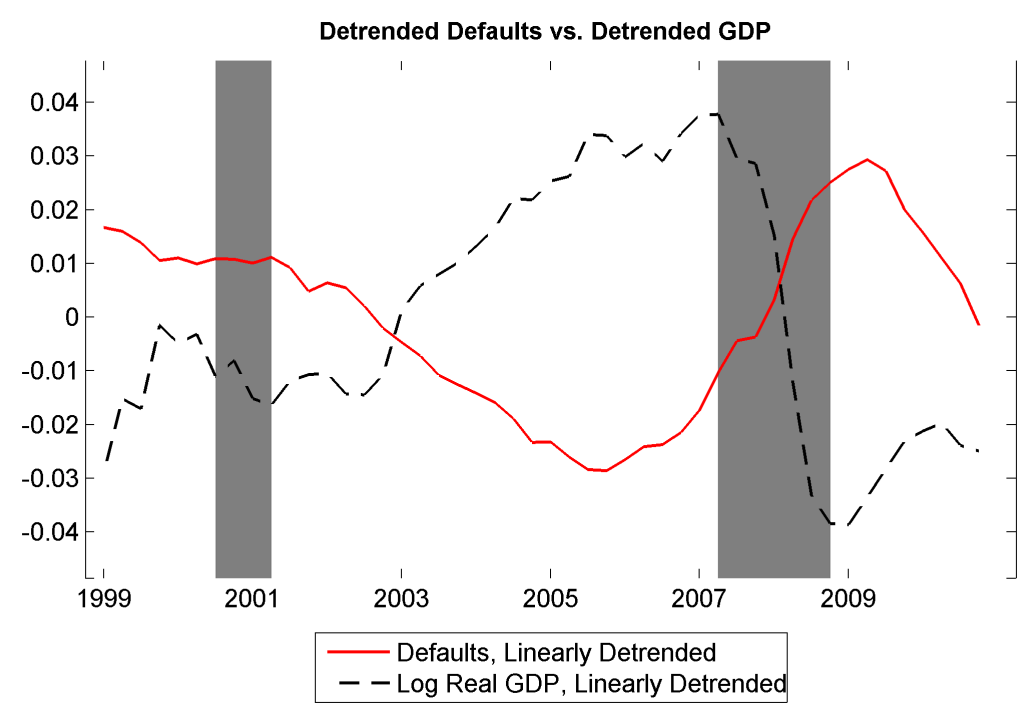

Fact 6: The typical default is characterized by,

i. A declining credit approval rate prior to and during the default episode.

\section{ii. A median credit card utilization rate of $92 \%$}

your [husband/wife/partner]) ever had a foreclosure proceeding brought against a property you have owned?"

${ }^{17}$ This will not be analyzed in this model. See Athreya and Simpson [2006] or Chen [2012b] for more on the interaction between labor markets and bankruptcy. 


\section{iii. A sharp 100 point drop in credit score iv. Continuous default (Alternative Measures in Appendix C)}

Figure 4 is an event study around default episodes and illustrates several measures of average credit conditions prior to and during default. ${ }^{18}$ Panel (a) of Figure 4 shows the credit approval rating of defaulters which mildly drops preceding the default episode and sharply drops thereafter. ${ }^{19}$ Panel (b) is the average number of accounts opened within the last 6 months which shows a similar pattern. ${ }^{20}$ Panel (c) shows the credit card utilization rate for defaulters rises markedly before the default to $82 \%$ on average ( $92 \%$ for the median, see Table 2) and drops in the following quarters. Figure 6 is a histogram of the utilization rate in the cross-section, and it illustrates the stark difference in credit card utilization between nondefaulters and defaulters; non-defaulters have a median utilization rate of $62 \%$ and mean utilization of $54 \% .{ }^{21}$ Panel (d) of Figure 4 illustrates that consumers default only on a fraction of debts, rather than defaulting on everything. The average fraction of accounts in default is $52 \%{ }^{22}$ Figure 5 Panel (a) shows that roughly $1 / 3$ of defaulting accounts are either sold or commissioned to a 3rd party collection agency. If commissioned to collect, Legrady [2005] explains that these agencies charge a fee equal to a percentage of the balance that ranges from less than $10 \%$ for young accounts to $50 \%$ for older accounts. On the other hand, Furletti [2003] explains that severely derogatory accounts, specifically not in bankruptcy, are sold to collection agencies for 5 cents per 1 dollar. Panel (b) illustrates that the real total amount past due climbs throughout the default episode and reaches over $4000 \$$ (measured in 2005 dollars). Panel (c) of Figure 5 demonstrates the punishment for default, a sharp 100 points drop in credit score that bottoms at the period of default. As evidenced in Figure 8 Panel (c), by the time bankruptcy is recorded, credit scores have already dropped and actually rebound in the period of bankruptcy. Figure 5 Panel (d) shows the number

\footnotetext{
${ }^{18}$ Across all individual-quarter observations, I define a new default to be a transition from 60 days late to $90+$ days late with no bankruptcy in the following year. I set that particular observation to be $t=0$ and then I look at the next 4 observations and preceding 4 observations to complete the window around default. I then average the values across individuals at each date. I only use non-missing observations. Table 2 provides summary measures of the distribution of agents across various measures just to be sure that the results are not driven by an averaging process. For instance, the fraction of accounts in default could be an erroneous average of 1's and zero's, but Table 2 and Figure 10 show that there is a non trivial distribution across agents.

${ }^{19}$ Defined to be the number of new accounts opened in the last 6 months over the number of consumer inquiries initiated in the last 6 months. Those with zero initiated inquiries were treated as missing observations for only this portion of the panel.

${ }^{20}$ Possible types of accounts include Auto Bank, Auto Finance, Home Equity Installment, Home Equity Revolving, Mortgage Accounts, Bankcards, Consumer Finance, Retail, Student, and other. On average 1/5 of the types of accounts held by a consumer is secured and a consumers holds 2.5 different types of accounts.

${ }^{21}$ A credit utilization value above 1 indicates the person has exceeded their credit limit and is accruing penalties.

${ }^{22}$ Due to the relatively strict definition of default as $90+$ days late without bankruptcy, several accounts are still $60+$ days late prior to my official determination that a default has occurred (Quarter 0 in the event study). Table 2 and Figure 10 shows that this is not a vestige of averaging.
} 
of accounts in default, which supports the view that consumers select 1 to 2 debts to stop paying. Figures 7 and 8 are similar pictures for the sample of people who file for bankruptcy. They exhibit similar patterns except the magnitudes are larger. For instance, roughly double the number of accounts are involved in the episode for roughly double the amount of total past due balances.

Table 2: Summary Statistics (Source: Equifax)

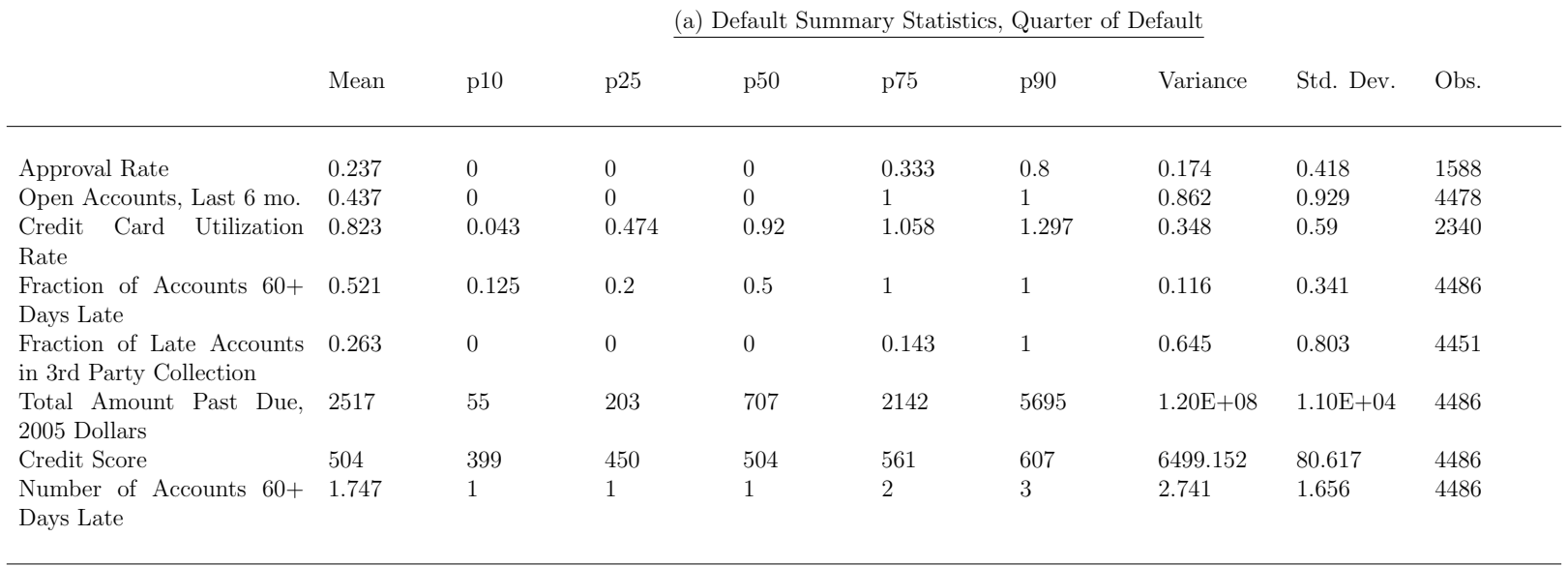

\begin{tabular}{|c|c|c|c|c|c|c|c|c|c|}
\hline & Mean & $\mathrm{p} 10$ & p25 & $\mathrm{p} 50$ & p75 & p90 & Variance & Std. Dev. & Obs. \\
\hline Approval Rate & 0.176 & 0 & 0 & 0 & 0.25 & 0.5 & 0.123 & 0.351 & 399 \\
\hline Open Accounts, Last 6 mo. & 0.375 & 0 & 0 & 0 & 0 & 1 & 0.646 & 0.804 & 890 \\
\hline $\begin{array}{l}\text { Credit Card Utilization } \\
\text { Rate }\end{array}$ & 0.733 & 0 & 0.373 & 0.905 & 1.024 & 1.113 & 0.208 & 0.456 & 316 \\
\hline $\begin{array}{l}\text { Fraction of Accounts } 60+ \\
\text { Days Late }\end{array}$ & 0.623 & 0.033 & 0.389 & 0.667 & 1 & 1 & 0.108 & 0.329 & 890 \\
\hline $\begin{array}{l}\text { Fraction of Late Accounts } \\
\text { in 3rd Party Collection }\end{array}$ & 0.226 & 0 & 0 & 0 & 0.091 & 0.5 & 0.728 & 0.853 & 826 \\
\hline $\begin{array}{l}\text { Total Amount Past Due, } \\
2005 \text { Dollars }\end{array}$ & 4630.113 & 0 & 80.285 & 1319.824 & 4135.106 & $1.30 \mathrm{E}+04$ & $1.20 \mathrm{E}+08$ & $1.10 \mathrm{E}+04$ & 889 \\
\hline Credit Score & 536.004 & 424 & 478 & 544.5 & 594 & 635 & 6597.827 & 81.227 & 890 \\
\hline $\begin{array}{l}\text { Number of Accounts } 60+ \\
\text { Days Late }\end{array}$ & 3.811 & 1 & 1 & 3 & 5 & 8 & 9.809 & 3.132 & 890 \\
\hline
\end{tabular}


Figure 4:

(a) Credit Approval Rate

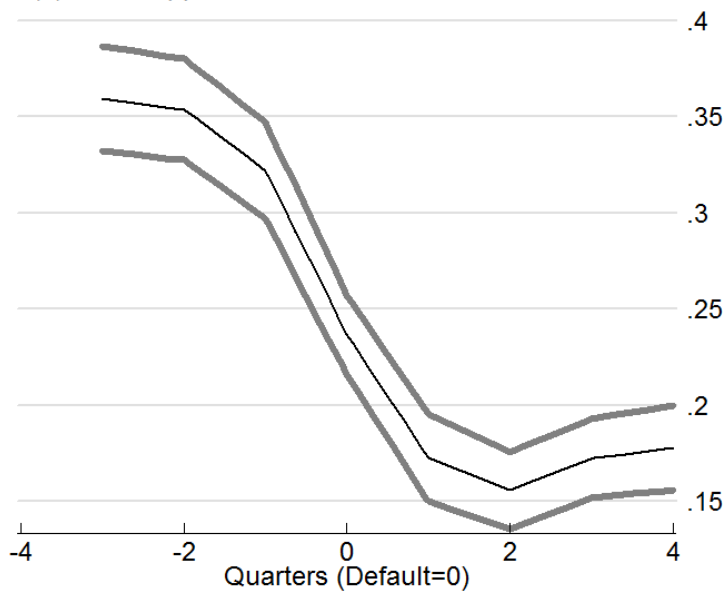

(c) Credit Card Utilization Rate

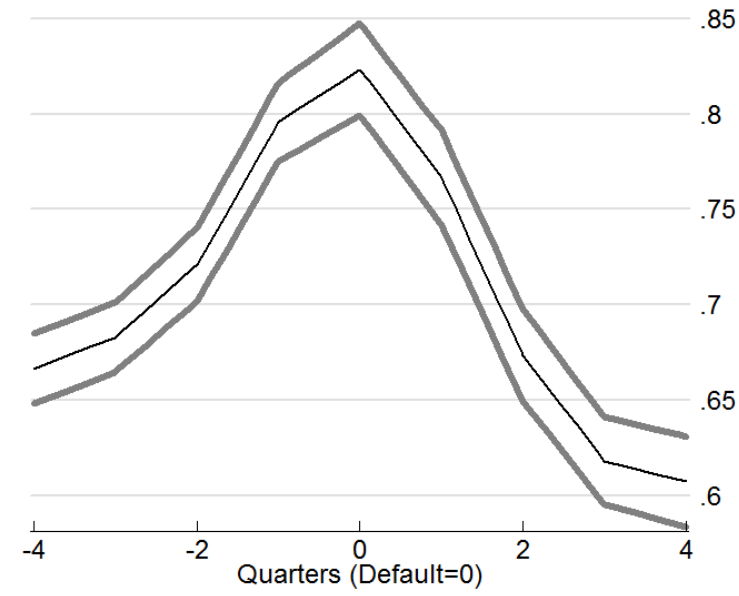

(b) Number of Newly Opened Accts, Last 6 Months

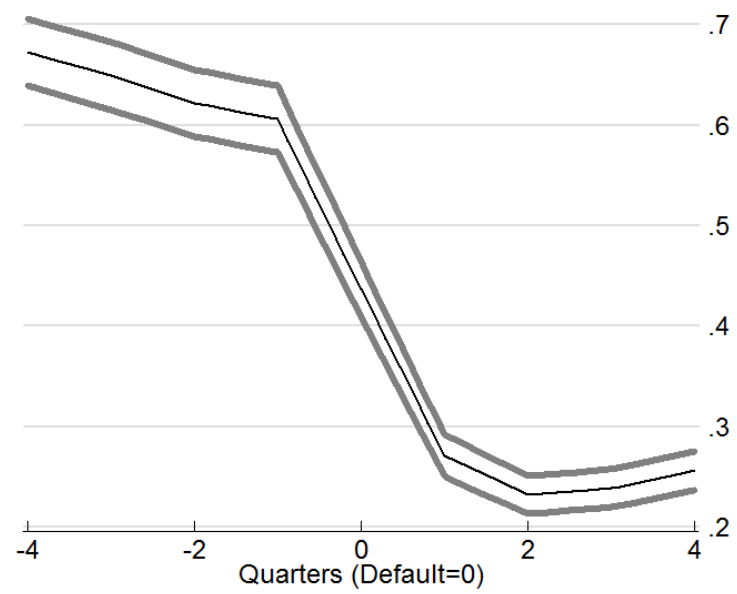

(d) Fraction of Accounts 60+ Days Late

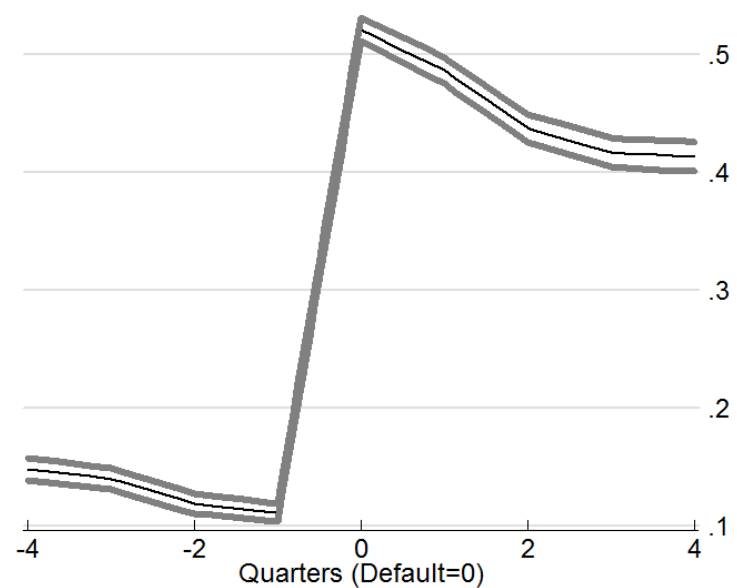

Source: Equifax

Default Definition: 90+ Days Late, No Bankruptcy within 1 Year

Notes: Center Line is Average Across Defaulters, Outer Lines are $C$

Approval rate for those that initiated inquiries, New Accounts in Last $6 \mathrm{mo}$.

divided by Total Consumer Initiated Inquiries Last 6 Months

Total Open Credit Balance divided by Total High Credit, recently updated accounts 
Figure 5:

(a) Fraction of Accounts in 3rd Party Collection

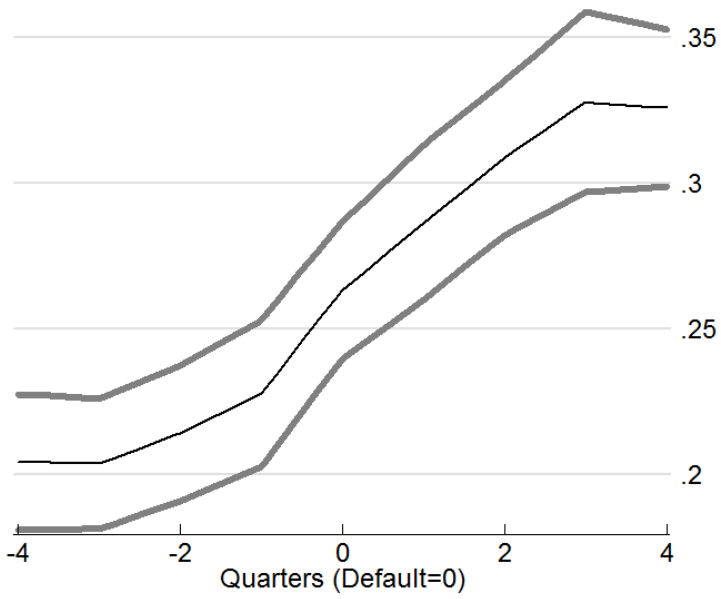

(c) Credit Score

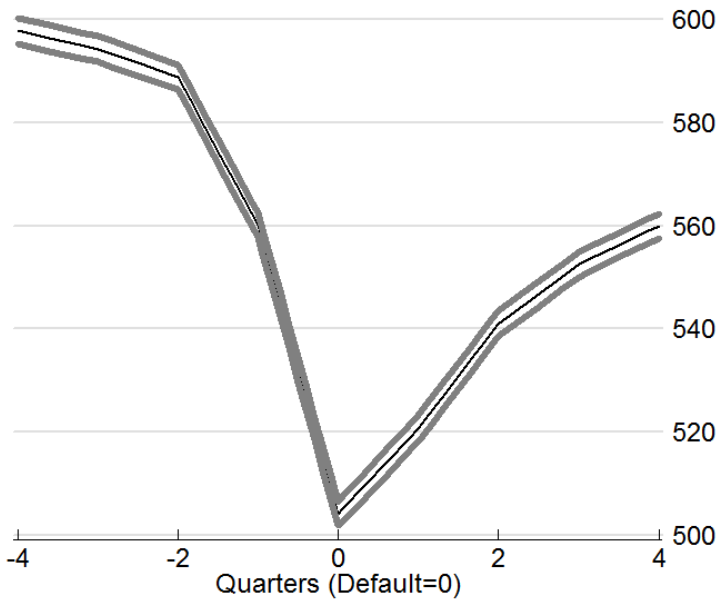

(b) Total Amount Past Due, 2005 Dollars

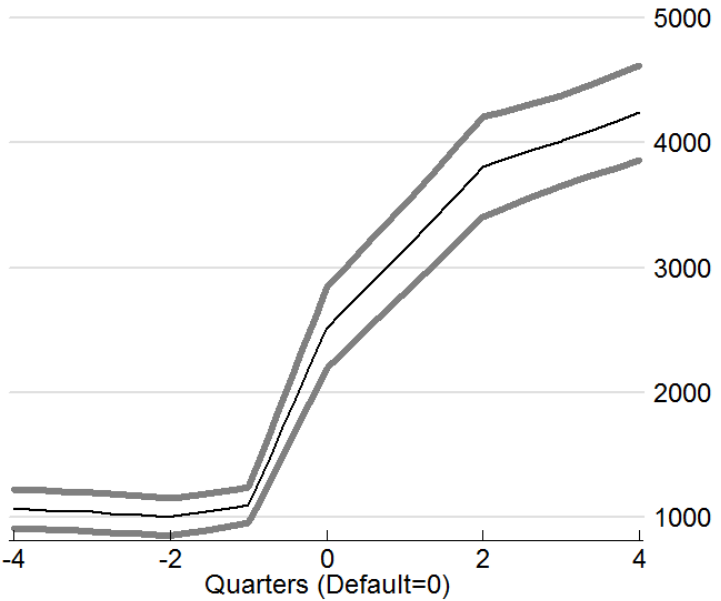

(d) Number of Tradelines 60+ Days Late

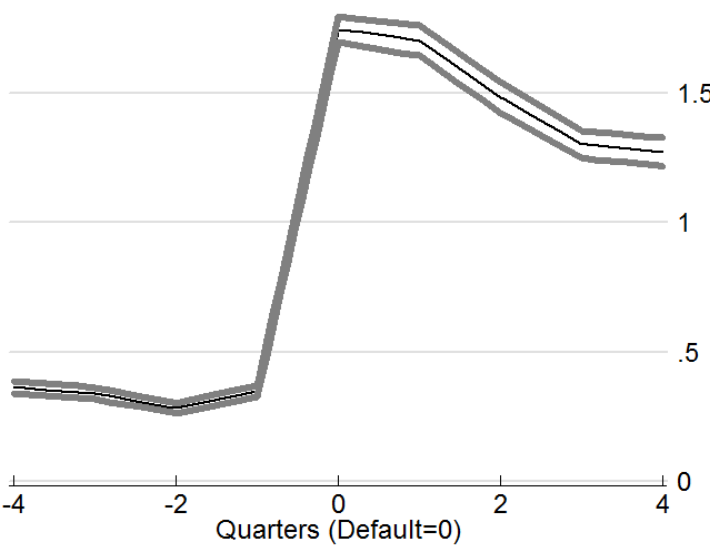

Source: Equifax

Default Definition: 90+ Days Late, No Bankruptcy within 1 Year

Notes: Center Line is Average Across Defaulters, Outer Lines are $C$

Accounts in collection over last 12 months, recently updated accounts.

Total past due defalted by $\mathrm{CPI}$, recently updated accounts. 
Figure 6:

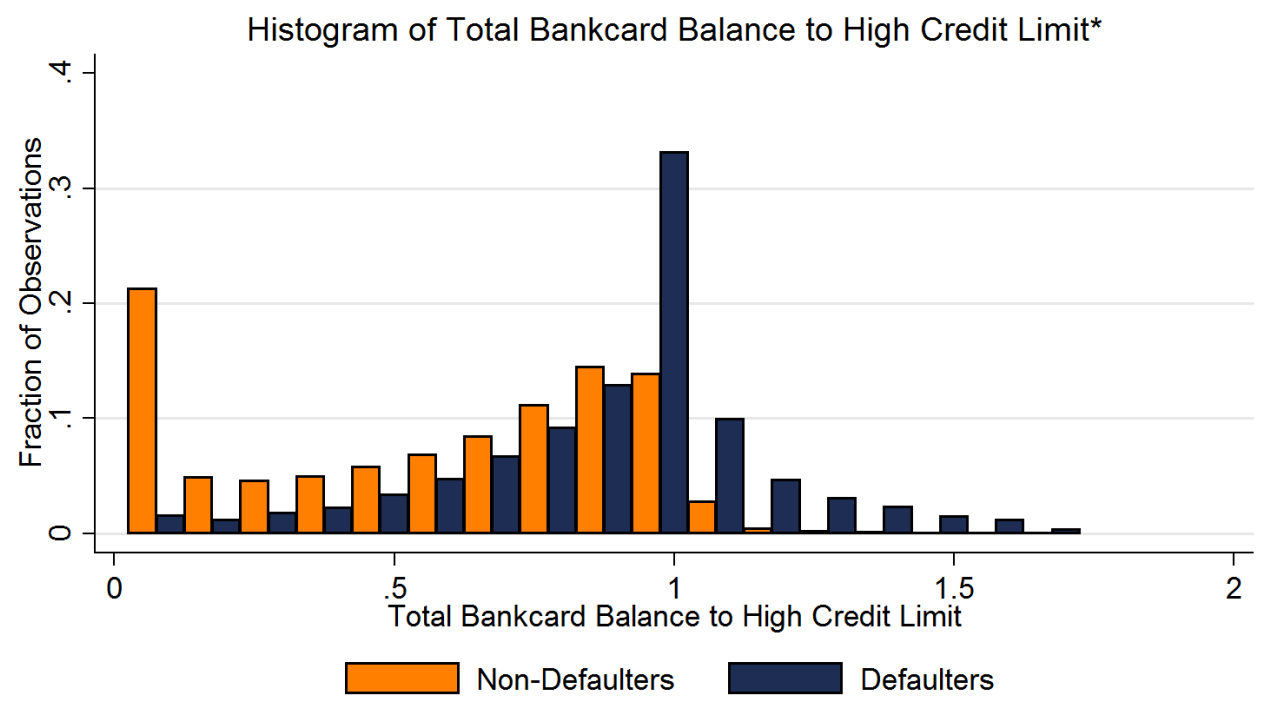

Non-Defaulters: All Cards Less Than 90+ Days Late

*Formula: Sum Total Balance over all Debts/Sum Total High Credit Limit over all Debts

Truncated 1\% Right Tail 
Figure 7:

(a) Credit Approval Rate

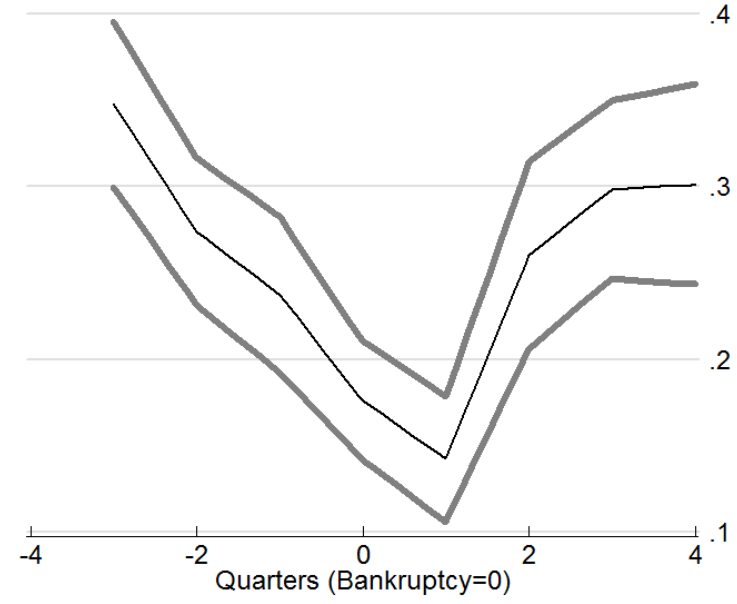

(c) Credit Card Utilization Rate

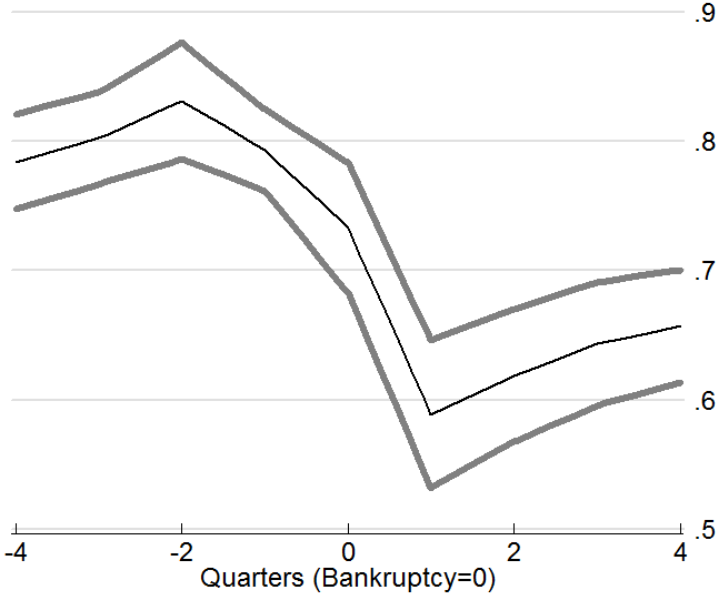

(b) Number of Newly Opened Accts, Last 6 Months

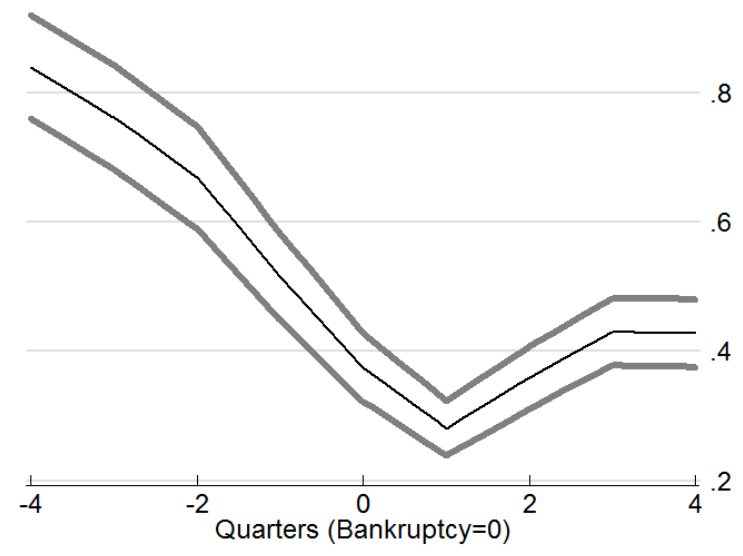

(d) Fraction of Accounts 60+ Days Late

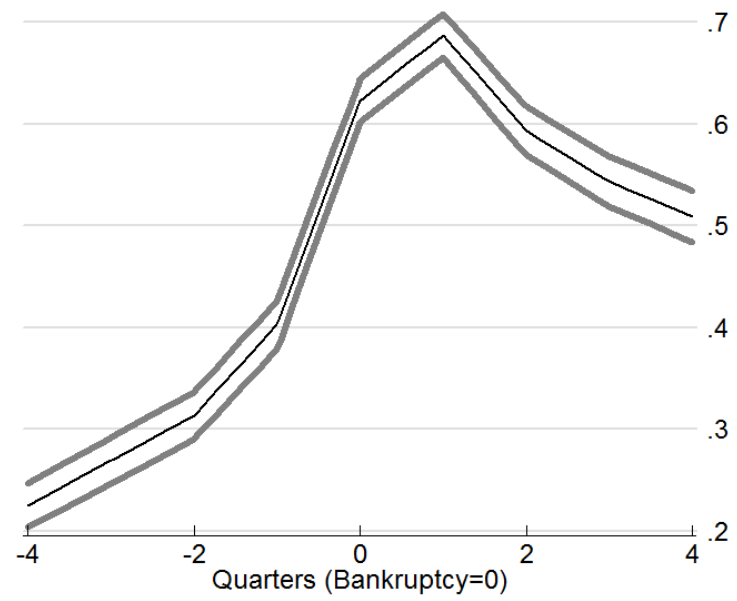

Source: Equifax

Notes: Center Line is Average Across Bankrupts, Outer Lines are C

Approval rate for those that initiated inquiries, New Accounts in Last $6 \mathrm{mo}$.

divided by Total Consumer Initiated Inquiries Last 6 Months

Total Open Credit Balance divided by total High Credit, recently updated accounts 
Figure 8:

(a) Fraction of Accounts in 3rd Party Collection

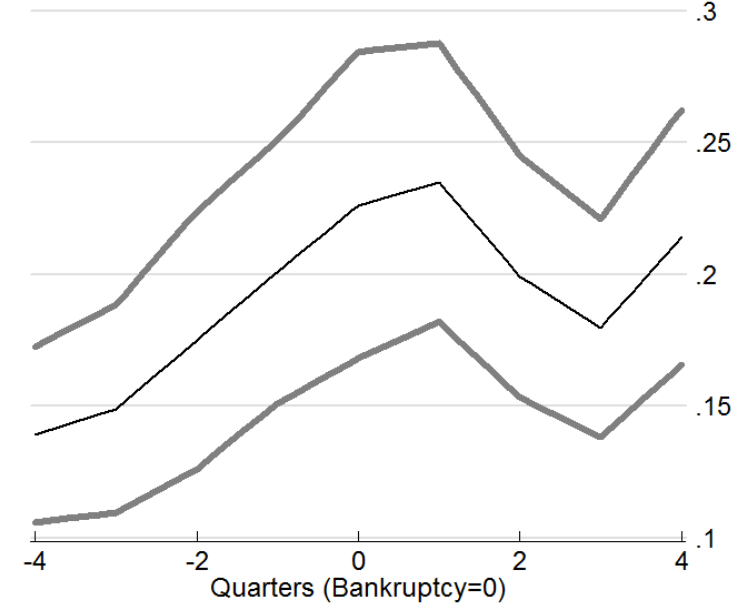

(c) Credit Score

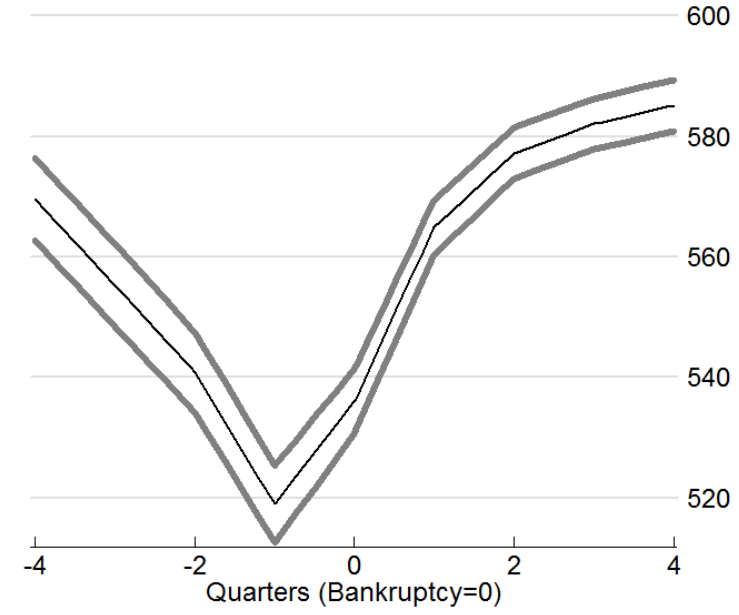

(b) Total Amount Past Due, 2005 Dollars

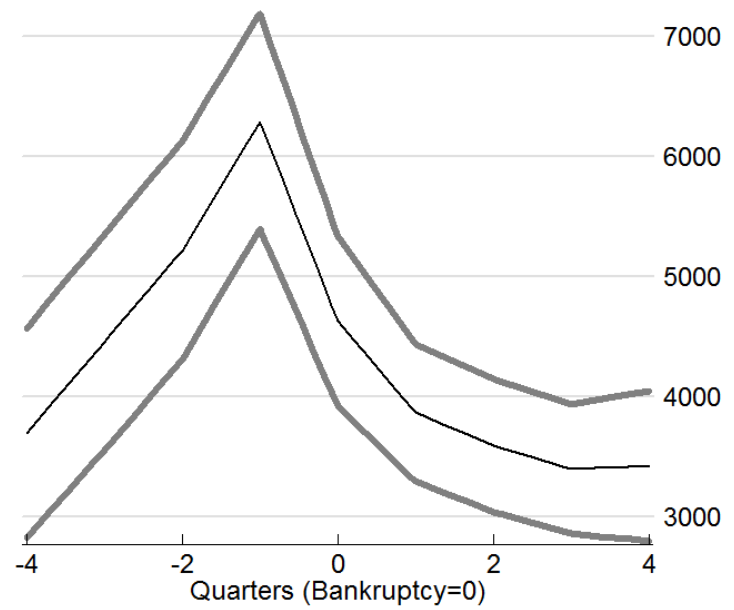

(d) Number of Tradelines 60+ Days Late

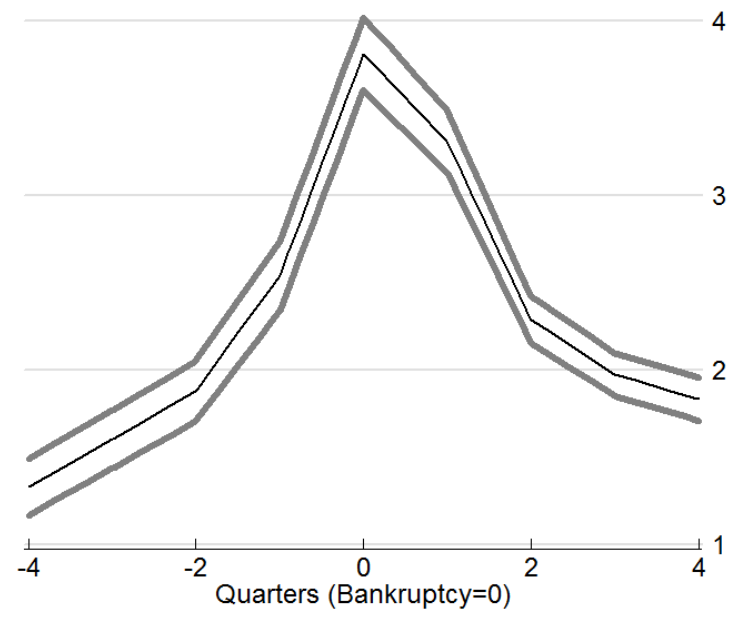

Source: Equifax

Notes: Center Line is Average Across Bankrupts, Outer Lines are Cl Accounts in collection over last 12 months, recently updated accounts. Total past due defalted by $\mathrm{CPI}$, recently updated accounts. 
Fact 7: Defaulting raises effective disposable income significantly. Figure 9 is a histogram of the Back End Debt to Income ratios (see below for explanation) for delinquent mortgagors in the PSID, and Table 3 summarizes both Front End and Back End Debt to Income for current mortgagors as well as delinquent mortgagors. In both measures of debt to income, the numerator is the sum of all annual mortgage payments (First, Second, and HELOC). Front end debt to income is calculated as all annual mortgage payments divided by annual after tax income. Taxes are calculated using the NBER Taxsim program which takes into account the number of children, marital status, mortgage deductions, etc. Back end debt to income is calculated as all annual mortgage payments divided by after-tax incomes less subsistence expenditures. The subsistence expenditures include food expenses, clothing expenses, medical expenses, child care expenses, and transport expenses. Based on this measure median back end debt to income is $23 \%$ for payers versus $47 \%$ for defaulters. Table 3 describes the other moments of the distribution in detail. While mortgagors typically have more debt than other households (including those who outright own), the message is clear, skipping debt payments may supplement disposable income as much as $47 \% .{ }^{23}$

Figure 9:

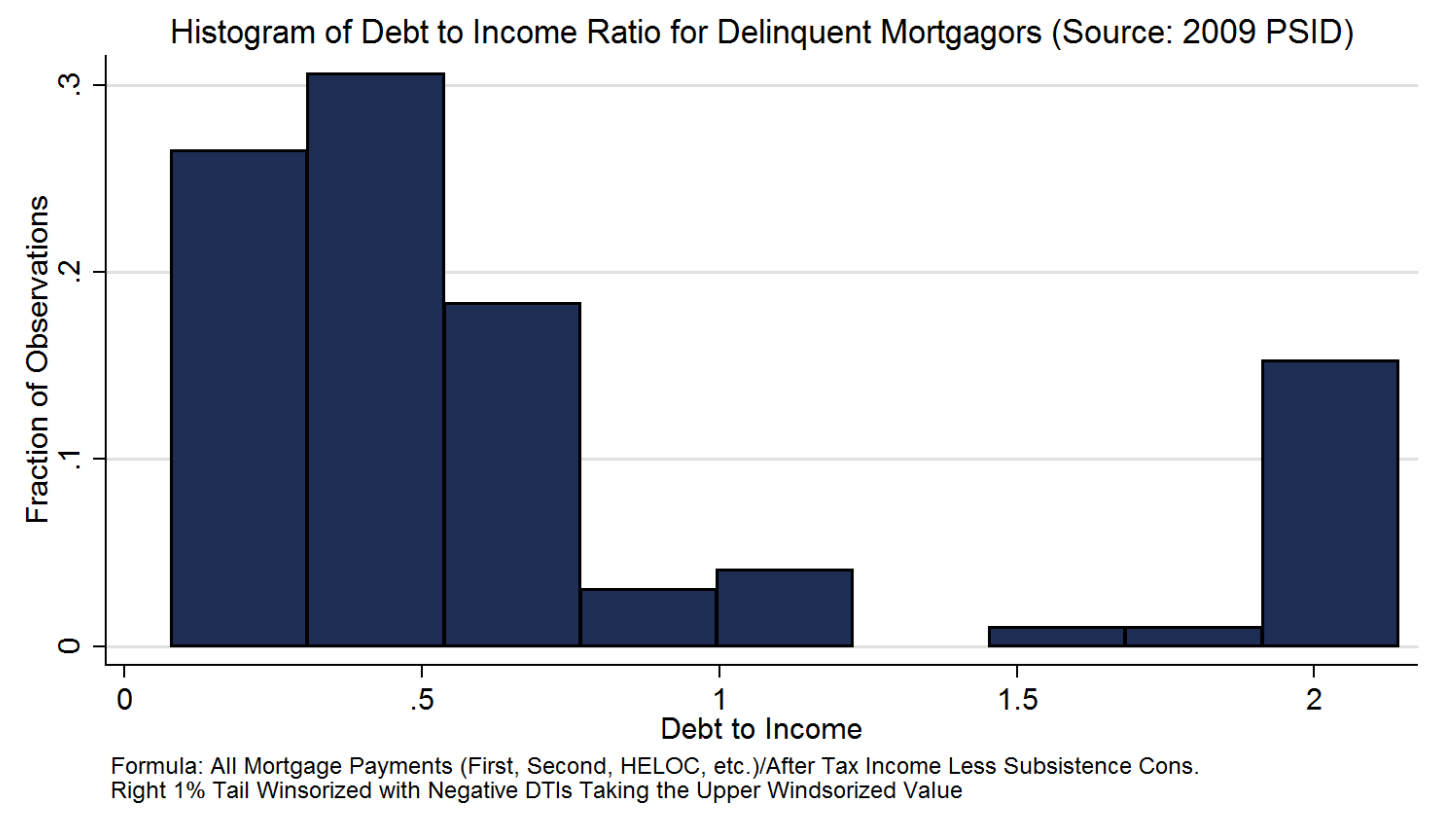

Fact 8: Default is not a binary $0 / 1$ choice. By modeling default as a continuous choice, it is possible to solve default models using perturbation methods. The most surprising stylized fact is that people default on a fraction of their accounts. ${ }^{24}$ For

\footnotetext{
${ }^{23}$ Given the 2-year timing of the PSID, it is difficult to back out income in the months prior to default.

${ }^{24}$ The appendix shows that these facts hold true even when you look at the fraction of delinquent accounts,
} 
Table 3:

Front End DTI (Mortgage Payments/After Tax Income)

\begin{tabular}{|c|c|c|c|c|c|c|c|c|c|}
\hline & Mean & p10 & $\mathrm{p} 25$ & p50 & p75 & p90 & Variance & Std. Dev. & Obs. \\
\hline Current & 0.228 & 0.088 & 0.13 & 0.187 & 0.268 & 0.378 & 0.032 & 0.18 & 2414 \\
\hline Defaulter & 0.423 & 0.182 & 0.261 & 0.345 & 0.456 & 0.855 & 0.086 & 0.294 & 98 \\
\hline
\end{tabular}

$\underline{\text { Back End DTI (Mortgage Payments/After Tax Income Less Subsistence Consumption) }}$

Mean p10 p25 p50 p75 p90 Variance Std. Dev. Obs.

\begin{tabular}{llllllllll}
\hline & & & & & & & & & \\
Current & 0.379 & 0.111 & 0.157 & 0.237 & 0.371 & 0.684 & 0.202 & 0.449 & 2414 \\
Defaulter & 0.732 & 0.241 & 0.326 & 0.479 & 0.73 & 2 & 0.402 & 0.634 & 98 \\
& & & & & & & & & \\
\hline
\end{tabular}

instance, a person with 4 tradelines needing to maintain effective income will only default on two tradelines. Figure 10 is a histogram of the fraction of accounts per borrower that are $60+$ days late at the time of default- which I have defined to be $90+$ days late without any tradelines in bankruptcy for at least 1 year of the default. ${ }^{25}$ Notably, only $28 \%$ of borrowers default on their debts in entirety; binary default is not the modal choice for consumption smoothing. Figure 4 panel (d) shows that the fraction of accounts in default remains a nontrivial fraction for any size window of analysis around default, with a portion of accounts slowly coming out of default 5 quarters later. As of Q1-2011, the average borrower had 5.19 open accounts and 3.36 were recently updated within the last quarter. Having that many different accounts allows consumers to selectively default. ${ }^{26}$

restricting the sample to recently updated accounts, and also if you look at the fraction of the total balance defaulted upon.

${ }^{25}$ The fraction of accounts in default is a simple sum of indicators. Let $N_{A}$ be the number of accounts, the fraction of accounts in default is

$$
\frac{1}{N_{A}} \sum_{i \in \text { All Accounts }} I(\text { Account } \mathrm{i}>90+\text { Days Late and no BK within } 1 \text { year })
$$

${ }^{26}$ Selective default, and a characterization of the types of default, is work in progress, Athreya and Sanchez $[2012]$ 
Figure 10:

Fraction of Accounts 60+ Days Late, at Time of Default

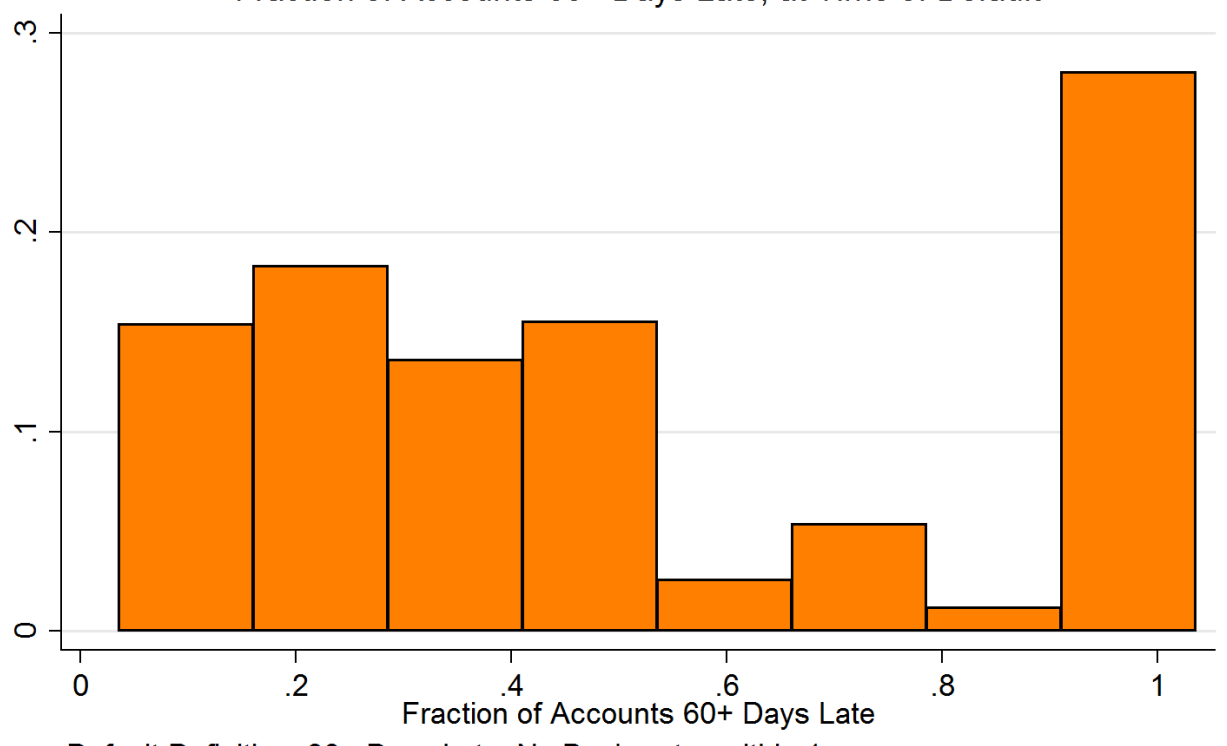

Default Definition: 90+ Days Late, No Bankruptcy within 1 year 


\subsection{Summary of Stylized Facts}

After defining default as 90+ Days late and no bankruptcy within 1 year, I establish several new facts. In summary, the takeaways are as follows,

Fact 1: Default is $5 \times$ to $6 \times$ more prevalent than bankruptcy on an annual flow basis.

Fact 2: Job loss is a better predictor of default than negative equity or hospital bills.

Fact 3: Roughly $20 \%$ of all unemployed debtholders default in the SCF, and $20 \%$ of all unemployed mortgagors default in the PSID; moreover, the likelihood of default is increasing in the duration of the unemployment spell.

Fact 4: Default generates distortionary labor market incentive effects. The incentive effects are similar to unemployment insurance, exhibiting a spike out of unemployment at expiration.

Fact 5: Default is contemporaneously procyclical which is supportive evidence of default being used by unemployed borrowers at high frequencies.

Fact 6: People default because they are credit constrained and credit scores respond to default much more than bankruptcy. (A) The punishment for defaulting is a lower credit score which translates into being $14 \%$ more likely to be denied consumer initiated credit (likely an understatement for reasons discussed in the text). (B) The median defaulter is credit constrained with a $10 \%$ drop in the credit approval rate prior to the initial default and a median credit card utilization rate of $92 \%$.

Fact 7: Default raises effective disposable income of the median mortgage defaulter by $47 \%$.

Fact 8: Default is a continuous choice, and less than $1 / 3$ will do a traditional binary default on every account. ${ }^{27}$

\footnotetext{
${ }^{27}$ Consumers have on average 5 tradelines, spanning at least 2 types of debt within the set of Auto Bank, Auto Finance, Bankcards, Consumer Finance, Home Equity Installments, Home Equity Revolving Lines of Credit, Mortgage, Retail, or Other types of debt.
} 


\section{Overview of the Model}

The endowment economy version of the model features heterogeneous households and incomplete markets. In order to maximize the present discounted value of consumption, households borrow from a competitive lending sector. The mechanism that differentiates this model from past models is that households have the ability to repay a certain fraction of the debts they owe as in Dubey et al. [1990], and the punishment for defaulting is an endogenously lower credit score following Chatterjee et al. [2008b] and Chatterjee et al. [2008a]. Lower credit scores result in higher effective interest rates for any given income level and thus less self-insurance going forward.

After analyzing the endowment economy version of the model, I look at the way labor markets and consumer credit markets interact by nesting the continuous default choice into a 'block recursive' model of the labor market (see Menzio and Shi [2009, 2010] or Section 6.1 for an explanation of block recursivity). The main mechanism in the model will be a reservation wage decision, i.e. agents will choose which wage to look for and the wage they choose determines the probability they find a job. Households that are out of work have access to a home production technology and a credit market in order to smooth consumption. For many households that are unable to service debt while unemployed and face prohibitively high borrowing costs, the best option to maintain consumption is to simply default. The extra insurance provided by default allows unemployed agents to post higher wages, but the drop in the endogenous credit score makes future borrowing activity even more costly.

\subsection{Consumer's Problem}

Consider a single good economy with a continuum of infinitely lived heterogeneous agents that differ with respect to their stochastic endowment $y_{t} \in Y \subseteq \mathbb{R}_{++}$, their discrete type $i_{t} \in I \equiv\{H, L\}$, their net assets $b_{t} \in B \subseteq \mathbb{R}$, and their credit score $f_{t} \in F \subseteq[0,1]$. The type of an agent is private information and determines default behavior through the default penalty function and the discount factor, to be explained in more detail below.

The only good in this economy is the consumption good, taken to be the numeraire, and agents seek to maximize their discounted flow utility over consumption which is increasing, concave, and twice continuously differentiable in the consumption good. In order to do so, agents have access to a competitive borrowing and lending market where they can borrow $\left(b_{t+1}<0\right)$ or save $\left(b_{t+1}>0\right)$ in consumption-good-denominated contracts at a competitive rate $q\left(y_{t}, b_{t+1}, f_{t+1}\right)$, also to be explained in more detail below.

All borrowing contracts are assumed to be unsecured and non-enforceable. However, as opposed to the usual defaultable debt model based on Eaton and Gersovitz [1981], agents are free to default on a non-trivial fraction $r_{t} \in R \equiv[\underline{r}, \bar{r}] \subseteq[0,1]$ of the debt more similar to Dubey et al. [1990]. There are two penalties to default, (i) a direct utility penalty that 
depends on the type $i_{t}$ of the agent $x_{i_{t}}\left(r_{t}\right):[\underline{r}, \bar{r}] \rightarrow \mathbb{R}_{-}$, and (ii) a reduced credit score. The penalty function $x_{i_{t}}\left(r_{t}\right)$ is assumed to be everywhere below zero, strictly increasing, concave, continuous, and twice differentiable in $r_{t}$. The default penalty is more severe for the high type which means $x_{H}\left(r_{t}\right)<x_{L}\left(r_{t}\right) \leq 0, \quad \forall r_{t} \in R \backslash\{\bar{r}\}$ and $x_{H}(\bar{r})-x_{L}(\bar{r})=0$. The debt payments that are skipped are discharged. While this might seem like a particularly strong assumption, Furletti [2003] explains that severely derogatory accounts, not in bankruptcy, are sold to collection agencies for 5 cents per 1 dollar. ${ }^{28}$ Out of completeness, Appendix E includes the cure rates which are transitions in the matrix from delinquent to current. Alternatively, one could interpret the fraction that is repaid as the overall recovery rate.

As mentioned above, the type of an agent is private information where I allow for heterogeneity across types in the default penalty and the discount factor $0<\beta_{i}<1$ for $i \in\{H, L\}$, $\beta_{L} \leq \beta_{H}$. As a result, there is room for a meaningful credit score, which, in this model, is taken to be the probability that the agent is of the high type, given the observed repayment behavior, the prior debt, and the prior credit score. For the time being, assume the credit score is updated according to $f_{t+1}=g\left(r_{t}, b_{t}, f_{t}\right) \equiv \operatorname{Pr}\left(i_{t+1}=H \mid f_{t}, r_{t}, b_{t}\right)$. In order for the credit score to convey meaningful information in an infinite horizon setting, the type process is assumed to be Markov with transition matrix $\Pi_{2 \times 2}$ where each element $\pi_{i j}$ indicates the probability of switching from type $i$ to type $j$.

Agents take the credit updating process and price of loans as given and make contemporaneous choices over net assets and repayment behavior to maximize the following objective,

$$
E_{0}\left[u\left(c_{0}\right)+x_{i_{0}}\left(r_{0}\right)+\sum_{t=1}^{\infty}\left(\prod_{\tau=1}^{t} \beta_{i_{\tau}}\right)\left(u\left(c_{t}\right)+x_{i_{t}}\left(r_{t}\right)\right)\right]
$$

Since I am going to be solving for recursive equilibria in the sections to follow, I will drop the time subscript and use primes to indicate tomorrow's variables. With this notation in hand, the dynamic programming problem of the agent of type $i$ with endowment $y$, assets or borrowing $b$, and prior credit score $f$, is to pick a repayment fraction $r$ and next period's assets $b^{\prime}$ to maximize the Bellman equation given below, taking the bond price and credit scoring as given:

$$
V_{i}(y, b, f)=\max _{r, b^{\prime}} u(c)+x_{i}(r)+\beta_{i} \mathbb{E}\left[\pi_{i i} V_{i}\left(y^{\prime}, b^{\prime}, f^{\prime}\right)+\pi_{i j} V_{j}\left(y^{\prime}, b^{\prime}, f^{\prime}\right)\right]
$$

Such that

$$
c+q\left(y, b^{\prime}, f^{\prime}\right) b^{\prime} \leq y+r b
$$

\footnotetext{
${ }^{28}$ Furletti writes, "Although Chapter 7 bankruptcies often result in a complete loss for card issuers, firms that specialize in finding errors and fraud in bankruptcy petitions will sometimes purchase Chapter 7 chargeoffs for $\$ 0.01$ per $\$ 100$ of debt. In contrast, non-bankruptcy credit card chargeoffs can fetch as much as $\$ 5$ per $\$ 100$ of debt." The only caveat is that this is technically a reflection of PV(revenue)-PV(cost).
} 


$$
\begin{gathered}
f^{\prime}=g(r, b, f) \equiv \operatorname{Pr}\left(i^{\prime}=H \mid f, r, b\right) \\
y^{\prime} \sim G\left(y^{\prime} \mid y\right)
\end{gathered}
$$

Denote the corresponding policy functions associated with $(1)$ as $\left\{r^{i}(y, b, f)\right\}_{i=H, L}$ for the repayment choice, and $\left\{b^{i}(y, b, f)\right\}_{i=H, L}$ for the borrowing and lending decision rules.

\subsection{Lender's Problem}

\section{Lender Assumptions:}

L.1 From the perspective of the intermediary, households are anonymous, except for their credit score.

L.2 Lenders know the agent's income $y$, the requested loan size $b^{\prime}$, the updated credit score $f^{\prime}$, and agent's equilibrium repayment policies.

In this model, there is a mass of intermediaries that are free to enter the borrowing and lending market where they can frictionlessly accept deposits and make loans to households. Each of these intermediaries has access to a savings technology that yields the risk free rate $r_{f}$. As a result, in the case of lending, intermediaries only lend to agents whose expected repayment rate is at least the risk free return. The payoff of lending an amount $b^{\prime}$ to an agent with income $y$ and updated credit score $f^{\prime}$, is the product of the belief that when repayment is due tomorrow the agent is of the high type $\left(f^{\prime}\right)$ or low type $\left(1-f^{\prime}\right)$ and the corresponding fraction that will be repaid conditional on the agent actually realizing type $i, r^{i}\left(y^{\prime}, b^{\prime}, f^{\prime}\right)$. The main assumption in this model, anonymity, requires that the intermediaries use a 3rd party credit report. Thus, $f^{\prime}$ is given and the price of a debt contract $b^{\prime}<0$ is determined as follows,

$$
\left(1+r_{f}\right) \leq \frac{\mathbb{E}\left[\left(1-f^{\prime}\right) \cdot r^{L}\left(y^{\prime}, b^{\prime}, f^{\prime}\right) b^{\prime}+\left(f^{\prime}\right) \cdot r^{H}\left(y^{\prime}, b^{\prime}, f^{\prime}\right) b^{\prime}\right]}{q\left(y, b^{\prime}, f^{\prime}\right) b^{\prime}} \text { for } \quad b^{\prime}<0, b^{\prime} \in B
$$

Likewise, intermediaries are willing to take deposits that yield no greater than $1+r_{f}$. However, given the free entry assumption, intermediary profits are competed away. Accordingly, equation (2) holds with equality and the borrowing and lending schedule is given by,

$$
q\left(y, b^{\prime}, f^{\prime}\right)= \begin{cases}\frac{1}{1+r_{f}} & \text { if } b^{\prime} \geq 0 \\ \frac{\mathbb{E}\left[\left(1-f^{\prime}\right) \cdot r^{L}\left(y^{\prime}, b^{\prime}, f^{\prime}\right)+\left(f^{\prime}\right) \cdot r^{H}\left(y^{\prime}, b^{\prime}, f^{\prime}\right)\right]}{1+r_{f}} & \text { if } b^{\prime}<0\end{cases}
$$




\subsection{Credit Rating Agency}

\section{Credit Rating Agency Assumptions:}

C.1 Credit Rating Agencies know the agent's beginning assets $b$, beginning credit score $f$, current repayment choice $r^{o b s}$, and the equilibrium household repayment policy function.

As the problem is written, from the perspective of the intermediary, agents are anonymous except for their prior credit score $f$. As such, there is a separate credit agency that updates the probability the agent is the high type, $f^{\prime}=g(r, b, f) \equiv \operatorname{Pr}\left(i^{\prime}=H \mid f, r, b\right)$, and provides this information costlessly to intermediaries. One key feature to note is that the updated score does not depend on the income of the agent, an assumption that is consistent with legal restrictions and corroborated by the fact that the Equifax dataset does not include any measure of income. ${ }^{29}$ The new credit score $f^{\prime}$ is derived from the contemporaneous repayment behavior of the agents, last period's credit score $f$, and the initial asset position $b$, and the household's repayment decision rule. I assume that the credit rating agency knows the repayment policy of the household, conditional on observables, but they do not know the asset policy. ${ }^{30}$ The credit rating agency efficiently updates beliefs by using Bayes' law wherever possible and off-equilibrium beliefs will be made explicit in the examples below. ${ }^{31}$ Thus the credit score updating rule is,

$$
\hat{f}=\frac{f \cdot \operatorname{Pr}\left(r^{H}(\hat{y}, b, f)=r^{o b s} \mid i=H, b, f, r^{o b s}\right)}{f \cdot \operatorname{Pr}\left(r^{H}(\hat{y}, b, f)=r^{o b s} \mid i=H, b, f, r^{o b s}\right)+(1-f) \cdot \operatorname{Pr}\left(r^{L}(\hat{y}, b, f)=r^{o b s} \mid i=L, b, f, r^{o b s}\right)}
$$

$$
f^{\prime}=\hat{f} \cdot \pi_{H, H}+(1-\hat{f}) \cdot \pi_{L, H}
$$

\footnotetext{
${ }^{29}$ Other Sources: http://www.ehow.com/about_7372283_credit-bureau-income-compare-debt_ .html http://www . experian.com/ask-experian/20090901-income-information-isnt-part-of-a-credit-report . html

${ }^{30}$ Tomorrow's borrowing choice (b') is not known by the credit rating agency at the time of the intraperiod update

${ }^{31}$ Exploiting the fact that the type is markov, the probability tomorrow's type is high is given by,

$$
\operatorname{Pr}\left(i^{\prime}=H \mid f, r, b\right)=\operatorname{Pr}(i=H \mid f, r, b) \times \pi_{H H}+(1-\operatorname{Pr}(i=H \mid f, r, b)) \times \pi_{L H}
$$
}

Now solve for the conditional probability the type is high today,

$$
\begin{aligned}
\operatorname{Pr}(i=H \mid f, r, b) & =\operatorname{Pr}(i=H \cap f \cap r \cap b) / \operatorname{Pr}(f \cap r \cap b) \\
& =[\operatorname{Pr}(f \cap r \cap b \mid i=H) * \operatorname{Pr}(i=H)] / \operatorname{Pr}(f \cap r \cap b) \\
& =[\operatorname{Pr}(f \cap r \cap b \mid i=H) * \operatorname{Pr}(i=H)] /[\operatorname{Pr}(f \cap r \cap b \mid i=h) * \operatorname{Pr}(i=H) \\
& +\operatorname{Pr}(f \cap r \cap b \mid i=L) * \operatorname{Pr}(i=L)]
\end{aligned}
$$

Line 1 uses Bayes' law. Line 2 uses Bayes' law again to see $\operatorname{Pr}(f \cap r \cap b \mid i=H)=\operatorname{Pr}(i=H \cap f \cap r \cap b) / \operatorname{Pr}(i=$ $H)$ and then multiplying both sides by $\operatorname{Pr}(i=H)$ and substituting. Finally, Line 3 uses the law of total probability. 
Note, for the definition of equilibrium and the proofs that follow, $f^{\prime}=g(r, b, f)$ will be used for convenience.

\subsection{Timing}

The timing is implicit in the value function formulation. First, the endowment $y$ is realized and the type $i$ evolves. Second, the agent then makes a repayment decision, understanding that the repayment choice will affect the ability to borrow through credit scores, today. In other words, credit scores are updated intra-temporally. Third, the agent picks net assets going forward which are priced based on the new credit score. Fourth, the agent then advances to the next time period.

\subsection{Equilibrium}

Definition A Bayesian Recursive Equilibrium for this economy is a set of repayment decision rules $\left\{r^{i}(y, b, f)\right\}_{i=H, L}$, borrowing and lending decision rules $\left\{b^{i}(y, b, f)\right\}_{i=H, L}$, a bond price schedule $q(y, b, f)$, and a credit score updating rule $g(r, b, f)$ such that:

i. Given $q(y, b, f)$ and $g(r, b, f)$, the repayment decision rules $\left\{r^{i}(y, b, f)\right\}_{i=H, L}$ and borrowing and lending decision rules $\left\{b^{i}(y, b, f)\right\}_{i=H, L}$ solve the agent Dynamic Programming Problem (1) for both types. ${ }^{32}$

ii. The bond price schedule is consistent with $\left\{r^{i}(y, b, f)\right\}_{i=H, L}$ and yields zero profit in equilibrium (i.e. equation (2) holds with equality for all lending transactions.)

iii. The updating rule for the credit rating agency is Bayesian whenever it applies and is consistent with $\left\{r^{i}(y, b, f)\right\}_{i=H, L}$, taking the form given by equations (3) and (4).

Definition I define Pooling Bayesian Recursive Equilibria to be to be Bayesian Recursive Equilibria in which both types have the same policy function across all points in the state space.

Definition I define Perfectly Separating Bayesian Recursive Equilibria to be to be Bayesian Recursive Equilibria in which low type $(i=L)$ agents always default on some non-zero fraction of borrowings, and high type agents $(i=H)$ always repay borrowings in full.

\footnotetext{
${ }^{32}$ This is the same as sequential rationality
} 


\subsection{Existence and Characterization of Equilibria}

There are no restrictions on the choice sets by type which means they may pick the same policy $r^{H}(y, b, f)=r^{L}(y, b, f)$, making the observed repayment choices non-informative of the type.

Proposition 4.1. Let $\beta_{L}=0$ and $0<\beta_{H}<1$, and let the penalty functions be given by $x_{L}(r)=0, \forall r \in R$ and

$$
x_{H}(r)= \begin{cases}\underline{x}, & \text { if } r<\bar{r} \text { Note }: \underline{x}<0 \text { given by A.3 } \\ 0, & \text { if } r=\bar{r}\end{cases}
$$

Under the additional assumptions A.1(i-iii), A.2, and A.3, a Perfectly Separating Bayesian Recursive Equilibrium exists where beliefs are given by,

$$
\hat{g}(r, f, b) \equiv \begin{cases}\pi_{L H}, & \text { if } b<0 \& r<\bar{r} \\ \pi_{H H}, & \text { if } b<0 \& r=\bar{r} \\ f \pi_{H H}+(1-f) \pi_{L H}, & \text { Otherwise }\end{cases}
$$

and bond prices are given by $\hat{q}\left(y, b^{\prime}, f^{\prime}\right) \equiv \frac{f^{\prime} \bar{r}+\left(1-f^{\prime}\right) \underline{r}}{\left(1+r_{f}\right)}$.

Proof. See appendix B, this is special case of Proposition 6.2.

Lemma 4.2. Let $r \in R \equiv[\underline{r}, \bar{r}]$, and assume the utility function is twice continuously differentiable, $u^{\prime \prime}<0, u^{\prime}>0, \lim _{c \rightarrow 0} u^{\prime}(c)=+\infty, \lim _{c \rightarrow+\infty} u^{\prime}(c)=0$, and assume that the penalty function is also twice continuously differentiable $x_{i}^{\prime \prime}<0, x_{i}^{\prime}>0, \lim _{r \rightarrow \underline{r}} x^{\prime}(r)=-\infty$, $\lim _{r \rightarrow \bar{r}} x^{\prime}(r)=0$ and $x_{i, 1}(r) \neq x_{j, 1}(r) \forall r \in R$, no Pooling Bayesian Recursive Equilibrium with borrowing exists (Note: This obtains regardless of off-equilibrium path beliefs).

Proof. See Appendix B, this is a special case of Lemma 6.3.

Proposition 4.3. Assume for $i \in\{H, L\}$,

$$
x_{i}(r)= \begin{cases}-\infty, & \text { if } r<\bar{r} \\ 0, & \text { if } r=\bar{r}\end{cases}
$$

Under the additional assumptions A.1(i-iii) and A.2, a Pooling Bayesian Recursive Equilibrium with borrowing exists where $q^{*}=1 /\left(1+r_{f}\right)$.

Proof. See Appendix B, this is a special case of Proposition 6.4. 


\section{Adding a General Equilibrium Labor Market}

Suppose now that $y \in Y \subset \mathbb{R}$ is aggregate labor productivity and it fluctuates randomly over time. Furthermore, there is heterogeneity in debt $b \in B \subset \mathbb{R}$, credit scores $f \in F \subseteq[0,1]$, unemployment benefits $z \in Z \subset \mathbb{R}_{++}$, wages $w \in \mathcal{W} \subset \mathbb{R}_{++}$, and employment status $e \in\{W, U\}$ ( $\mathrm{W}=$ Employed, $\mathrm{U}=$ unemployed). The distribution of agents across states, $\mu(b, f, z, w, e): \mathbb{R} \times[0,1] \times \mathbb{R}_{++} \times \mathbb{R}_{++} \times\{W, U\} \rightarrow[0,1]$, fluctuates over time with the aggregate state. Let $\Omega=(\mu, y)$ summarize the aggregate shock $y$, and the distribution of agents $\mu$ across states. Let $\Phi\left(\Omega, y^{\prime}\right)=\mu^{\prime}$ describe the law of motion for the aggregate distribution and $y^{\prime} \sim F\left(y^{\prime} \mid y\right)$ is the law of motion for aggregate productivity. ${ }^{33}$

There is free entry of firms, and the vacancy posting cost $\kappa(y): Y \rightarrow \mathbb{R}_{++}$potentially varies with aggregate productivity. ${ }^{34}$ As in Burdett and Mortensen [1998] firms direct their search by posting vacancies in certain submarkets that are indexed by $w \in \mathbb{R}_{++}$. The posted wage $w$ is fixed once an employee is found. The submarket tightness is given by $\theta(w ; \Omega)=\frac{v(w ; \Omega)}{u(w ; \Omega)}$ where $v(w ; \Omega)$ is the number of vacancies posted in the $w$ submarket and $u(w ; \Omega)$ is the number of unemployed people in that submarket. ${ }^{35}$ The constant returns to scale of the matching function will guarantee that the ratio of unemployment and vacancies is all that matters for determining job finding rates. Let the vacancy filling rate be given by $p_{V}(\theta(w ; \Omega))=\frac{M(w ; \Omega)}{v(w ; \Omega)}$ and let the job finding rate be given by $p_{U}(\theta(w ; \Omega))=\frac{M(w ; \Omega)}{u(w ; \Omega)}$. The value to a firm of posting a vacancy in submarket $w$ is given below: ${ }^{36}$

$$
V(w ; \Omega)=-\kappa(y)+p_{V}(\theta(w ; \Omega)) J(w ; \Omega)
$$

With free entry it must be the case that profits are competed away. Thus $V(w ; \Omega)=0$ for any submarket that is visited with positive probability. Thus, the free entry condition is given below:

$$
\kappa(y)=p_{V}(\theta(w ; \Omega)) J(w ; \Omega) \text { if } \theta(w ; \Omega)>0
$$

Given a sufficiently well behaved function $p_{V}(\cdot)$, it is possible to invert this equation to solve for the market tightness $\theta(w ; \Omega)$ :

$$
\theta(w ; \Omega)=p_{V}^{-1}\left(\frac{\kappa}{J(w ; \Omega)}\right) \text { if } \theta(w ; \Omega)>0
$$

The value of an ongoing match is similar to Menzio and Shi [2009, 2011], where I use several key simplifying assumptions similar to Karahan and Rhee [2011], except in the model below, there is a state contingent job destruction rate $\delta(y, z)$ preventing firms from operating

\footnotetext{
${ }^{33}$ This is the same notation as in Krusell and Smith [1998].

${ }^{34}$ See Hagedorn and Manovskii [2008] for more on cyclical vacancy costs.

${ }^{35} \mathrm{Off}$ equilibrium markets will have a tightness of 0

${ }^{36}$ Notice the timing- the firm is not subject to risk at posting
} 
in negative surplus matches and a state contingent vacancy cost $\kappa(y) .{ }^{37}$ Notice that the expectation $\mathbb{E}_{\Omega^{\prime}}$ is over the aggregates which includes the distribution of people across states (I will omit the subscript from now on):

$$
J(w ; \Omega)=y-w+\beta \mathbb{E}_{\Omega^{\prime}}\left[\left(1-\delta\left(y^{\prime}, w\right)\right) J\left(w ; \Omega^{\prime}\right)\right]
$$

Where the aggregate law of motion for $\Omega^{\prime}$ is,

$$
\begin{aligned}
\Omega^{\prime} & =\left(\mu^{\prime}, y^{\prime}\right) \\
\mu^{\prime} & =\Phi\left(\Omega, y^{\prime}\right) \\
y^{\prime} & \sim F\left(y^{\prime} \mid y\right)
\end{aligned}
$$

And I will assume that zero profit matches are destroyed with probability $1:^{38}$

$$
\delta(y, w)= \begin{cases}\bar{\delta} & \text { if } y>w \\ 1 & \text { if } y<w\end{cases}
$$

Unemployed agents have a value function denoted $U$. While out of a job, they have access to an idiosyncratic home production technology that produces $z \in \mathbb{R}_{++}$units of the single consumption good per period, regardless of time spent searching for a job. The initial home production technology level is set to match a $\gamma \%$ replacement rate $z=\gamma w$, but it declines stochastically thereafter. The labor market is frictional and characterized by directed search, meaning that instead of random search and matching, households choose to look for jobs that pay $\tilde{w} \in \mathcal{W} \subset \mathbb{R}_{++}$where $\tilde{w}$ is a choice variable.

Once the agent has chosen a submarket in which to search, the agent is matched with a job according to $p_{U}(\theta(w ; \Omega))=M(w ; \Omega) / u(w ; \Omega)$, derived from a wage specific constant returns to scale matching function $M(w ; \Omega)$ and the aggregate number of unemployed persons searching for a job at that wage, $u(w ; \Omega)$. I will discuss additional restrictions placed on $p_{U}(\cdot)$ in the sections to follow.

In order to make tomorrow's type the only relevant information for creditors, I must be explicit about the timing of the realization of the type: the type is realized before the wages are posted. ${ }^{39}$ In the problem below, the expectation operator incorporates uncertainty over the Markov type $\left(i^{\prime}\right)$, the aggregate state $\left(\Omega^{\prime}\right)$, and the unemployment benefits $\left(z^{\prime}\right)$ which may potentially expire. As explained in the firm problem, the law of motion for the aggregate distribution is given by $\Phi$, i.e. $\mu^{\prime}=\Phi\left(\Omega, y^{\prime}\right)$. With this notation in hand, an unemployed

\footnotetext{
${ }^{37}$ This will correct for the irregular Beveridge curve common in directed search models without on-thejob-search. See Menzio and Shi [2011] and Appendix A for more.

${ }^{38}$ There is efficiency loss here since future surplus might be positive even though today's profits are zero. I can no longer solve the social planners problem, but this assumption allows me to ignore the household's surplus (which depends on several states) in calculating the equilibrium market tightness.

${ }^{39}$ If creditors lent to an agent and the wage posting policy that the creditors had to forecast depended on today's type, then in addition to $f^{\prime}$, the creditors would need to know $f$ (the prior).
} 
household of type $i$, unemployment benefits $z$, assets $b$, credit score $f$, with aggregate labor productivity and the distribution across types $\Omega=(y, \mu)$, faces the following problem:

$$
\begin{aligned}
U_{i}(z, b, f ; \Omega) & =\max _{r, b^{\prime}} u(c)+x_{i}(r) \\
& +\beta_{i} \mathbb{E}_{\Omega^{\prime}, i^{\prime}, z^{\prime}}\left[\max _{\tilde{w}}\left\{p_{U}\left(\theta\left(\tilde{w} ; \Omega^{\prime}\right)\right) W_{i^{\prime}}\left(\tilde{w}, b^{\prime}, f^{\prime} ; \Omega^{\prime}\right)+\left(1-p_{U}\left(\theta\left(\tilde{w} ; \Omega^{\prime}\right)\right)\right) U_{i^{\prime}}\left(z^{\prime}, b^{\prime}, f^{\prime} ; \Omega^{\prime}\right)\right\}\right]
\end{aligned}
$$

Subject to the budget constraint (8), law of motion for credit scores (9), law of motion for the aggregate state (10), and laws of motion for productivity and benefits (11),

$$
\begin{gathered}
c+q_{U}\left(z, b^{\prime}, f^{\prime} ; \Omega\right) b^{\prime} \leq z+r b \\
f^{\prime}=g(r, b, f ; \Omega) \equiv \operatorname{Pr}\left(i^{\prime}=H \mid f, r, b, \Omega\right) \\
\Omega^{\prime}=\left(\Phi\left(\Omega, y^{\prime}\right), y^{\prime}\right) \\
y^{\prime} \sim F\left(y^{\prime} \mid y\right) \text { and } z^{\prime} \sim G\left(z^{\prime} \mid z\right) .
\end{gathered}
$$

Wages in an existing match are constant, and all matches produce a common stochastic amount $y$ per period, i.e. $y$ is aggregate labor productivity. The only way wages change is if the match is destroyed, which occurs with probability $\delta(y, w)$ (discussed above). Therefore an employed household of type $i$, wages $w$, assets $b$, credit score $f$, with aggregate labor productivity and the distribution across types $\Omega=(y, \mu)$, faces the following decision:

$$
\begin{aligned}
W_{i}(w, b, f ; \Omega) & =\max _{r, b^{\prime}} u(c)+x_{i}(r) \\
& +\beta_{i} \mathbb{E}_{\Omega^{\prime}, i^{\prime}}\left[\left(1-\delta\left(y^{\prime}, w\right)\right) W_{i^{\prime}}\left(w, b^{\prime}, f^{\prime} ; \Omega^{\prime}\right)+\delta\left(y^{\prime}, w\right) U_{i^{\prime}}\left(\gamma w, b^{\prime}, f^{\prime} ; \Omega^{\prime}\right)\right]
\end{aligned}
$$

Such that (9)-(11) hold and,

$$
c+q_{W}\left(w, b^{\prime}, f^{\prime} ; \Omega\right) b^{\prime} \leq w+r b
$$




\section{$5.1 \quad$ Timing}

As before, the timing is implicit in the value function formulation. First, the aggregate state $\Omega$ is realized and the type $i$ evolves. Second, the unemployed search for jobs at specific wages knowing both their type and the aggregate state. Within the period employment outcomes are realized: (i) based on the new aggregate state and the current wage, employed people are separated, and (ii) the unemployed learn if they were matched. Fourth, the agents then make a repayment decision, understanding that the repayment choice will affect the ability to borrow through credit scores, today. In other words, credit scores are updated intratemporally. Fifth, the agent picks net assets going forward which are priced based on the new credit score. Sixth, the agent then advances to the next time period.

\subsection{Lender's Problem}

From the perspective of the Lender, I will maintain the assumption of household anonymity except through the credit score. The only change to the Lender's problem is to incorporate employment status. Denote the repayment choice for unemployed agents as $r_{U}^{i}(z, b, f ; \Omega)$ and for employed agents as $r_{W}^{i}(w, b, f ; \Omega)$. Furthermore, let $\tilde{w}^{i}(z, b, f ; \Omega)$ be the optimal wage policy of a type $i$ unemployed agent that has benefits $z$, chose to go into next period with assets $b$ and had an updated credit score of $f$. I introduce the tilde notation for expected repayment for an unemployed person.

$$
\begin{aligned}
\tilde{r}^{i}(z, b, f ; \Omega)= & p_{U}\left(\theta\left(\tilde{w}^{i}(z, b, f ; \Omega) ; \Omega\right)\right) r_{W}^{i}(\tilde{w}, b, f ; \Omega) \\
& +\left(1-p_{U}\left(\theta\left(\tilde{w}^{i}(z, b, f ; \Omega) ; \Omega\right)\right)\right) r_{U}^{i}(z, b, f ; \Omega) \quad \forall i \in\{H, L\}
\end{aligned}
$$

The first component is the repayment if the agent finds a job and the second component is the repayment if the agent remains unemployed. Using this expression, the bond price for unemployed agents is given as follows:

$$
\left(1+r_{f}\right) \leq \frac{\mathbb{E}\left[\left(1-f^{\prime}\right) \cdot \tilde{r}^{L}\left(z^{\prime}, b^{\prime}, f^{\prime} ; \Omega^{\prime}\right) b^{\prime}+f^{\prime} \cdot \tilde{r}^{H}\left(z^{\prime}, b^{\prime}, f^{\prime} ; \Omega^{\prime}\right) b^{\prime}\right]}{q_{U}\left(z, b^{\prime}, f^{\prime} ; \Omega\right) b^{\prime}} \text { for } b^{\prime}<0, b^{\prime} \in B
$$

With free entry, this yields the following loan schedule for unemployed agents:

$$
q_{U}\left(z, b^{\prime}, f^{\prime} ; \Omega\right)= \begin{cases}\mathbb{E}\left[\left(1-f^{\prime}\right) \cdot \tilde{r}^{L}\left(z^{\prime}, b^{\prime}, f^{\prime} ; \Omega^{\prime}\right)+f^{\prime} \cdot \tilde{r}^{H}\left(z^{\prime}, b^{\prime}, f^{\prime} ; \Omega^{\prime}\right)\right] /\left(1+r_{f}\right) & \text { if } \quad b^{\prime}<0 \\ 1 /\left(1+r_{f}\right) & \text { if } \quad b^{\prime} \geq 0\end{cases}
$$

I will also introduce the hat notation for expected repayment, conditional on employment status as follows:

$$
\hat{r}_{e}(w, b, f ; \Omega)=(1-f) \cdot r_{e}^{L}(w, b, f ; \Omega)+f \cdot r_{e}^{H}(w, b, f ; \Omega), \quad e \in\{W, U\}
$$


With this notation in hand, the bond price for employed agents is given as follows:

$$
\left(1+r_{f}\right) \leq \frac{\mathbb{E}\left[\left(1-\delta\left(y^{\prime}, w\right)\right) \hat{r}_{W}\left(w, b^{\prime}, f^{\prime} ; \Omega^{\prime}\right) b^{\prime}+\delta\left(y^{\prime}, w\right) \hat{r}_{U}\left(\gamma w, b^{\prime}, f^{\prime} ; \Omega^{\prime}\right) b^{\prime}\right]}{q_{W}\left(w, b^{\prime}, f^{\prime} ; \Omega\right) b^{\prime}} \text { for } b^{\prime}<0, b^{\prime} \in B
$$

With free entry, this yields the following loan schedule for employed agents:

$q_{W}\left(w, b^{\prime}, f^{\prime} ; \Omega\right)= \begin{cases}\mathbb{E}\left[\left(1-\delta\left(y^{\prime}, w\right)\right) \hat{r}_{W}\left(w, b^{\prime}, f^{\prime} ; \Omega^{\prime}\right) b^{\prime}+\delta\left(y^{\prime}, w\right) \hat{r}_{U}\left(\gamma w, b^{\prime}, f^{\prime} ; \Omega^{\prime}\right) b^{\prime}\right] /\left(1+r_{f}\right) & \text { if } \quad b^{\prime}<0 \\ 1 /\left(1+r_{f}\right) & \text { if } \quad b^{\prime} \geq 0\end{cases}$

\subsection{Credit Agency}

As before, the maintained assumption is that credit rating agencies provide the ratings costlessly to intermediaries. As in the previous endowment model, credit rating agencies do not observe the income or employment status of an agent. ${ }^{40}$ They have the past credit score (their prior), past debt holdings, and current repayment behavior (as in the real world), and they know the equilibrium repayment policy function of households. ${ }^{41}$

Thus credit rating agencies take repayment behavior as given and compare possible employment/income $(e, \hat{w})$ pairs that would generate the observed repayment behavior. The distribution across employment and income pairs that the credit rating agency uses to build this probability must be consistent with $\mu$, the aggregate distribution across all types. They then compare the likelihood of those employment/income pairs in order to predict the type (recall, they provide the lenders with information about tomorrow's predicted type $i^{\prime}=H$ ). In the case of Bayesian updating, the new credit scores are given by, ${ }^{42}$

$\hat{f}=\frac{f \cdot \operatorname{Pr}\left(r_{e}^{H}(\hat{w}, b, f ; \Omega)=r^{o b s} \mid i=H, b, f, r^{o b s}, \Omega\right)}{f \cdot \operatorname{Pr}\left(r_{e}^{H}(\hat{w}, b, f ; \Omega)=r^{o b s} \mid i=H, b, f, r^{o b s}, \Omega\right)+(1-f) \cdot \operatorname{Pr}\left(r_{e}^{L}(\hat{w}, b, f ; \Omega)=r^{o b s} \mid i=L, b, f, r^{o b s}, \Omega\right)}$

\footnotetext{
${ }^{40}$ This is consistent with actual credit scoring: http://www.myfico.com/crediteducation/ whatsinyourscore.aspx

${ }^{41}$ As before, they do not know the bond policy function

${ }^{42}$ Here the notation

$$
\operatorname{Pr}\left(r_{e}^{H}(\hat{w}, b, f ; \Omega)=r^{o b s} \mid i=H, b, f, r^{o b s}, \Omega\right)
$$
}

is short hand for

$$
\sum_{e \in\{W, U\}} \operatorname{Pr}(\text { Employment }=e) \cdot \operatorname{Pr}\left(\hat{w}=r_{e}^{H(-1)}\left(r^{o b s}, b, f ; \Omega\right) \mid e, i=H, b, f, r^{o b s}, \Omega\right)
$$

where $r_{e}^{H(-1)}$ is the inverse of the repayment function with respect to the wage argument and the probabilities are calculated according to the aggregate distribution $\mu$, e.g. $\operatorname{Pr}($ Employment $=e)=$ $\int_{b} \int_{f} \int_{z} \int_{w} \mu(b, f, z, w, e) d b d f d z d w$. 


$$
f^{\prime}=\hat{f} \cdot \pi_{H, H}+(1-\hat{f}) \cdot \pi_{L, H}
$$

In general, I will be looking at Bayesian Equilibria and thus I must specify off-equilibrium path beliefs when $\mu$ is degenerate for both the low and high types and Bayes' rule does not apply. I will make those beliefs explicit in the examples below. For convenience in the equilibrium definitions below, I will denote $f^{\prime}=g(r, b, f ; \Omega)$.

\subsection{Equilibrium}

Definition A Bayesian Recursive Equilibrium of this model is a wage policy function for the household $\left\{\tilde{w}^{i}(z, b, f ; \Omega)\right\}_{i=H, L}$, a set of repayment decision rules $\left\{r_{e}^{i}\left(w_{e}, b, f ; \Omega\right)\right\}_{i=H, L ~}^{e=W, U}$ (where $w_{U}$ is unemployment benefits and $w_{W}$ is the wage), borrowing and lending decision rules $\left\{b_{e}^{i}\left(w_{e}, b, f ; \Omega\right)\right\}_{i=H, L} e=W, U$, a bond price schedule $\left\{q_{e}\left(w_{e}, b, f ; \Omega\right)\right\}_{e=W, U}$, a credit score updating rule $g(r, b, f ; \Omega)$, a market tightness function $\theta(w ; \psi)$, and a law of motion for the aggregates $\mu^{\prime}=\Phi\left(\mu, y, y^{\prime}\right)=\Phi\left(\Omega, y^{\prime}\right)$ such that:

- Taking as given the aggregate law of motion, the updating rule, the market tightness, and the bond price, the households' policy functions solve the Dynamic Programming Problems (7) and (12) for both types and employment statuses.

- The bond price schedule $\left\{q_{e}\left(w_{e}, b, f ; \Omega\right)\right\}_{e=W, U}$ is consistent with repayment decisions $\left\{r_{e}^{i}\left(w_{e}, b, f ; \Omega\right)\right\}_{i=H, L} e=W, U$ and wage policies $\left\{\tilde{w}^{i}(z, b, f ; \Omega)\right\}_{i=H, L}$ and yields zero profit in equilibrium (i.e. equations (14) and (16) hold with equality for all lending transactions).

- The updating rule for the credit rating agency is Bayesian wherever applicable and is consistent with repayment decisions $\left\{r_{e}^{i}\left(w_{e}, b, f ; \Omega\right)\right\}_{i=H, L} e=W, U$, taking the form given by equations (17) and (18).

- The market tightness function $\theta(w ; \psi)$ satisfies the free entry condition (5) for each submarket and is thus consistent with the firm's dynamic programming problem.

- The policy functions for the household and the associated distribution over households is consistent with the aggregate law of motion $\mu^{\prime}=\Phi\left(\Omega, y^{\prime}\right)$.

Definition A Bayesian Block Recursive Equilibrium of this model is the same as above, except the household's problem and firm's problem only depends on the aggregate shock $y$, 
not on the distribution of households $\mu(b, f, z, w, e)$ across assets $b$, credit scores $f$, unemployment benefits $z$, wages $w$, or employment status $e \in\{W, U\} .{ }^{43}$

Definition A Perfectly Separating Bayesian Block Recursive Equilibrium is an equilibrium in which low type $(i=L)$ agents always default on some non-zero fraction of borrowings, and high type agents $(i=H)$ always repay borrowings in full. Additionally, the household's problem and firm's problem only depends on the aggregate shock $y$, not on the distribution of households across states.

Definition A Pooling Bayesian Block Recursive Equilibrium is an equilibrium in which the low type and high type agents have the same repayment policy across all possible states. Additionally, the household's problem and firm's problem only depends on the aggregate shock $y$, not on the distribution of households across states.

\section{Existence and Characterization of Block Recursive Equilibria}

I will first lay out the intuition underlying Block Recursivity and then move into formal proofs.

\subsection{Intuition}

In order to have block recursivity in the model presented above, it must meet several criteria:

(1) The labor market is characterized by directed search

(2) There is free entry of firms

(3) The matching function is constant returns to scale

(4) Debt is priced individually

(5) The parameters are restricted to generate perfect separation of borrowing types

\footnotetext{
${ }^{43}$ The name 'block recursive' comes from the fact that you solve for the equilibrium without using the first several lines(the first 'block') without using the last line (the last 'block') that describes the distribution. The distribution does fluctuate over time and it is obtained independently by simulation after solving the household and firms problems as well as obtaining prices.
} 
What is the intuition behind these conditions? Imagine a world in which there are firms that maximize their profit conditional on having a worker of a certain type, I, II, or III. Firms may pay a cost to reach into a stack of resumes submitted by workers of various types. In a random search world, the distribution of workers' resumes within the stack matters since the firm does not know which type of worker they will draw. To form expectations, they must forecast their odds of drawing each various type of worker. Now contrast this with a directed search world. In the directed search world, the workers' resumes are split up into different stacks, with the type I resume stack only containing type I worker resumes, and the type II stack only containing type II worker resumes. Therefore, under assumption (1), when a firm draws from a resume stack, the distribution across types does not matter. However, this is not enough to eliminate the role of the distribution of workers since the size of each resume stack still matters when a firm makes its decision; this is where assumption (2) enters.

To understand assumption (2), assume that the number of resumes in each resume stack changes over time and there is a room full of firms who each want to obtain a worker. Suppose that firms are allowed to line up at the stack they want to draw from and that prior to this decision there is a coin flip: if the coin is heads there are $X_{1}$ type I resumes and if the coin is tails there are $X_{1}^{\prime}\left(\neq X_{1}\right)$ type I resumes. ${ }^{44}$ Assumption (2), free entry, will guarantee that the expected profit resulting from the draw of resumes is constant across the various resume stacks, and hence no aspect of the distribution other than through the coin flip (which is the aggregate state) will matter in determining firm behavior.

Assumption (3), states that only the ratio of firms to resumes matters, not the number of firms or the number of resumes. In the context of a standard matching model, the last assumption guarantees that the probability of obtaining a new hire only depends on the ratio of unemployment to vacancies, not unemployment alone and not vacancies alone.

The last two assumptions (4)-(5) are needed to ensure the distribution of households across states does not enter directly into the households' problem. Recall that the updating rule in the endowment economy was trivial since the ergodic distribution of incomes was known ex-ante from the Markov process for income. Now, with an aggregate shock, the distribution of households across income is fluctuating and therefore the updating rule potentially depends on this distribution. ${ }^{45}$ In order to make the updating rule independent of the distribution of agents, I must assume that the block recursive equilibrium is Perfectly Separating.

As defined above, a Perfectly Separating Bayesian Block Recursive Equilibrium is an equilibrium in which low type agents always default on some non-zero fraction of borrowings,

\footnotetext{
${ }^{44}$ For simplicity, assume the number of resumes of the other types are constant

${ }^{45}$ In a model with heterogeneity over employment status and wages, the creditors try to guess what employment status and wage combinations could generate the observed repayment behavior for each type and then compare the likelihood of those combinations being obtained. In general, this would depend on the distribution of agents across wage and employment pairs and the updating function would be given by (17) and (18).
} 
and high type agents always repay borrowings in full. Therefore if the agent borrows and subsequently defaults, the credit rating agency knows with probability 1 that the agent is the low type today. Since the type is Markovian over time, the forecast for tomorrow's type is non-degenerate. ${ }^{46}$ Thus the updating formula for the type of a borrower that skips any fraction of the debt payment reduces to the following: ${ }^{47}$

$$
f^{\prime}=\pi_{L, H} \quad \forall r^{o b s}<\bar{r}, \quad \forall b<0
$$

In the case of saving, the update for today's type remains the same $\hat{f}=f$, but since the types are switching according to a Markov process and the repayment decisions is made tomorrow, the forecast for tomorrow's type is given the following: ${ }^{48}$

$$
f^{\prime}=f \cdot \pi_{H, H}+(1-f) \cdot \pi_{L, H} \quad \forall b>0
$$

Finally, since bonds are priced individually (4) and the price take the credit scoring as given, the bond price will not depend on the distribution if the equilibrium is Perfectly Separating.

\subsection{Proofs}

To formalize this intuition, I prove several features of the model where the assumptions used in the proofs are detailed in Appendix B:

\footnotetext{
${ }^{46}$ So long as $\pi_{L H}>0$

47 The update for the probability that today's type is high is zero since the high type will never skip repayment and the low type always skips (i.e. $\left.\operatorname{Pr}\left(r_{e}^{H}(\hat{w}, b, f ; \Omega)=r^{o b s} \mid i=H, b<0, f, r^{o b s}<\bar{r}, \Omega\right)=0\right)$ :

$$
\hat{f}=\frac{0}{0+(1-f) \cdot \operatorname{Pr}\left(r_{e}^{L}(\hat{w}, b, f ; \Omega)=r^{o b s} \mid i=L, b, f, r^{o b s}, \Omega\right)} \quad \forall r^{o b s}<\bar{r}, \quad \forall b<0
$$

Now combine this with the law of motion for tomorrow's type to obtain (21)

$$
f^{\prime}=\hat{f} \cdot \pi_{H, H}+(1-\hat{f}) \cdot \pi_{L, H}
$$

${ }^{48}$ For simplicity, let $\bar{r}=1$. The update for today's type is a trivial since it is optimal at every point in the state space to 'receive' the full amount (i.e. $\operatorname{Pr}\left(r_{e}^{L}(\hat{w}, b, f ; \Omega)=1 \mid i=L, b>0, f, r^{o b s}=1, \Omega\right)=1$ and $\operatorname{Pr}\left(r_{e}^{H}(\hat{w}, b, f ; \Omega)=1 \mid i=H, b>0, f, r^{o b s}=1, \Omega\right)=1$ - i.e. given the positive assets, any income and employment combination would pick $r=1$ and therefore no information is contained in this choice):

$$
\begin{aligned}
\hat{f} & =\frac{f \cdot 1}{f \cdot 1+(1-f) \cdot 1} \quad, \quad \forall b<0, r^{o b s}=\bar{r} \\
& =f
\end{aligned}
$$

Now combine this with the law of motion for tomorrow's type to obtain (25)

$$
f^{\prime}=\hat{f} \cdot \pi_{H, H}+(1-\hat{f}) \cdot \pi_{L, H}
$$


1. Lemma 6.1 establishes that the firm problem and implied market tightness are independent of the distribution across types.

2. Proposition 6.2 then shows existence of a perfectly separating block recursive equilibrium. ${ }^{49}$

3. Lemma 6.3 rules out pooling equilibria under general assumptions

4. Proposition 6.4 then uses one of the arguments made in Lemma 6.3, surprisingly, to establish the existence of a pooling equilibrium.

Lemma 6.1. By construction, the model satisfies assumptions (1)-(3) of Section 6.1. Under the additional requirements that $q_{V}: \mathbb{R} \rightarrow[0,1]$ is invertible and both $\mathcal{W} \subseteq \mathbb{R}_{++}$(the wage domain) and $Y \subseteq \mathbb{R}$ (the aggregate shock domain) are bounded above and below, there is a unique solution to the firm's problem that does not depend on the aggregate distribution and the implied market tightness is independent of the distribution of agents across states.

Proof. See Appendix B.

Proposition 6.2. By construction, the model satisfies assumptions (1)-(4) of Section 6.1. Let $\beta_{L}=0$ and $0<\beta_{H}<1$, and let the penalty functions be given by $x_{L}(r)=0, \forall r \in R$ and

$$
x_{H}(r)= \begin{cases}\underline{x}, & \text { if } r<\bar{r} \text { Note: } \underline{x}<0 \text { given by A.3 } \\ 0, & \text { if } r=\bar{r}\end{cases}
$$

Under the additional assumptions A.1-A.4 (see Appendix B), a Perfectly Separating Bayesian Block Recursive Equilibrium exists where beliefs are given by,

$$
\hat{g}(r, f, b) \equiv \begin{cases}\pi_{L H}, & \text { if } b<0 \& r<\bar{r} \\ \pi_{H H}, & \text { if } b<0 \& r=\bar{r} \\ f \pi_{H H}+(1-f) \pi_{L H}, & \text { Otherwise }\end{cases}
$$

and bond prices are given by $\hat{q}\left(w, b^{\prime}, f^{\prime}\right) \equiv \frac{f^{\prime} \bar{r}+\left(1-f^{\prime}\right) \underline{r}}{\left(1+r_{f}\right)}$.

Proof. See Appendix B.

Lemma 6.3. Let $r \in R \equiv[\underline{r}, \bar{r}]$, and assume the utility function is twice continuously differentiable, $u^{\prime \prime}<0, u^{\prime}>0, \lim _{c \rightarrow 0} u^{\prime}(c)=+\infty$, $\lim _{c \rightarrow+\infty} u^{\prime}(c)=0$, and assume that the penalty function is also twice continuously differentiable $x_{i}^{\prime \prime}<0, x_{i}^{\prime}>0, \lim _{r \rightarrow \underline{r}} x^{\prime}(r)=-\infty$, $\lim _{r \rightarrow \bar{r}} x^{\prime}(r)=0$ and $x_{i, 1}(r) \neq x_{j, 1}(r) \forall r \in R$, no Pooling Bayesian Recursive Equilibrium with borrowing exists (Note: This obtains regardless of off-equilibrium path beliefs).

\footnotetext{
${ }^{49}$ This is not a unique equilibrium of the model.
} 
Proof. See Appendix B.

Proposition 6.4. Assume for $i \in\{H, L\}$,

$$
x_{i}(r)= \begin{cases}-\infty, & \text { if } r<\bar{r} \\ 0, & \text { if } r=\bar{r}\end{cases}
$$

Under additional assumptions A.1, A.2, and A.4 (see Appendix B), a Pooling Bayesian Block Recursive Equilibrium with borrowing exists where $q^{*}=1 /\left(1+r_{f}\right)$.

Proof. See Appendix B.

\section{Reservation Wage Mechanism}

Even under the strong assumptions of Proposition 6.2, reservation wages fall as self-insurance increases. To see this, further assume there is no aggregate risk, only idiosyncratic employment risk. In this case, it is possible to solve for the value of a firm $\left(\delta\left(y^{\prime}, w\right)=\bar{\delta}\right.$ since there is no aggregate risk):

$$
J(w)=\frac{y-w}{1-\beta(1-\bar{\delta})}
$$

Let $M(u, v)=u^{\alpha} v^{1-\alpha}$. Then $p_{V}=M / v=\theta^{-\alpha}$ and the equilibrium market tightness can be solved for by hand from the free-entry condition:

$$
\begin{aligned}
k & =\theta^{-\alpha} J(w) \\
\Longrightarrow \theta(w) & =\left(\frac{1}{\kappa} \frac{y-w}{1-\beta(1-\bar{\delta})}\right)^{1 / \alpha}
\end{aligned}
$$

Using the Cobb- Douglas matching function, $p_{U}=M / u=\theta^{1-\alpha}$. Thus

$$
\frac{\frac{\partial p_{U}(w)}{\partial w}}{p_{U}(w)}=-\frac{(1-\alpha)}{\alpha} \frac{1}{y-w}
$$

Recall the timing assumption that type is realized before wages are posted. Consider a low type agent that has debt, $b<0$, is perfectly myopic $\beta_{L}=0$. The crux of the analysis is to compare this agent in a world in which default is allowed next period or default is outlawed next period.

Define self-insurance as the resources available other than wages, $s i=r b-q b^{\prime}$. Since the low-type household is perfectly myopic, I use the flow utility of consumption and the continuation value. The household's wage posting first order condition is given by the following: 


$$
\max _{\tilde{w}} p_{U}(\theta(\tilde{w})) u(\tilde{w}+s i)+\left(1-p_{U}(\theta(\tilde{w}))\right) u(z+s i)
$$

Taking first order conditions with respect to the wage:

$$
\underbrace{\frac{\partial p_{U}(\theta(\tilde{w}))}{\partial \tilde{w}}(u(z+s i)-u(\tilde{w}+s i))}_{\text {Potential Loss, Post \& Dont Find }}=\underbrace{p_{U}(\theta(\tilde{w})) \frac{\partial u(\tilde{w}+s i)}{\partial \tilde{w}}}_{\text {Potential Gain }}
$$

With logarithmic utility, and under the assumptions above, this condition reduces to the following:

$$
\underbrace{-\frac{(1-\alpha)}{\alpha} \frac{1}{y-\tilde{w}}}_{L H S}=\underbrace{-\frac{1}{(\tilde{w}+s i) \ln \left(\frac{\tilde{w}+s i}{z+s i}\right)}}_{R H S}
$$

This formula implies a wage that is a function of social insurance $(s i)$. The implicit wage $\tilde{w}(s i)$ can be compared across different self-insurance regimes. The left hand side decreases in the wage and is constant across social insurance regimes. The right hand side, so long as $z<w$, increases in the wage and shifts downward when social insurance increases, i.e. si $\uparrow$. With default in a perfectly separating equilibrium such as Proposition 6.2, agents repay nothing and borrow as much as possible. Net self insurance is therefore the amount borrowed, $s i=\frac{\pi_{L H}}{1+r_{f}} \underline{b}>0$. Without default, if the agent has borrowed previously (lets say they borrowed $\underline{b}$ for simplicity), agents repay $\underline{b}$ and borrow $\frac{1}{1+r_{f}} \underline{b}$ leaving net self insurance to be negative, $s i=\left(\frac{1}{1+r_{f}}-1\right) \underline{b}<0$. Figure 11 shows this mechanism in action, plotting both the right hand side and left hand side of equation (26); the figure depicts the increase in the reservation wage. 
Figure 11:

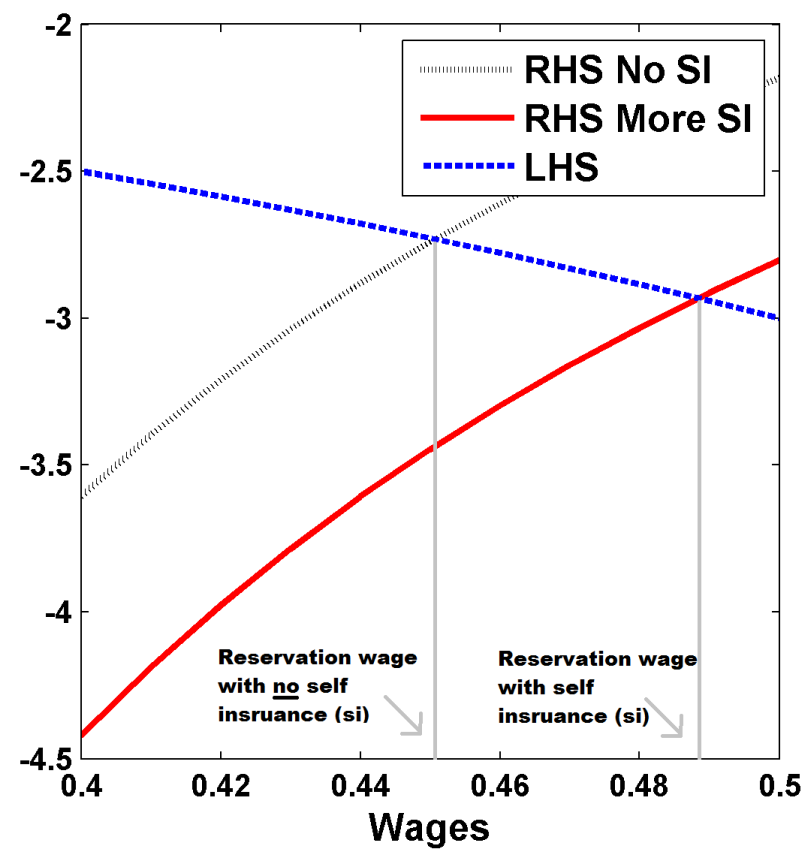




\section{Calibration}

I set the period to be one quarter. The discount factor for the high type $\beta_{H}=.99$ corresponding to a risk free annual rate of $4 \%$. I set the discount factor of the low type to $\beta_{L}=.8$ which corresponds to a quarterly interest rate of $25 \%$. The discount factors control the debt to income levels of defaulters which, as I will show below, are remarkably close in the model to those of the data. The aggregate productivity fluctuates over time according to an AR(1) process, discretized using Tauchen's method.

$$
\begin{gathered}
\ln \left(y^{\prime}\right)=\rho \ln (y)+\epsilon \\
\epsilon \sim N\left(0, \sigma_{e}^{2}\right)
\end{gathered}
$$

I take the standard business cycle parameters from Hansen [1985], $\rho=.95, \sigma_{e}^{2}=.007$. Likewise I use the matching function popularized by Haan et al. [1997]:

$$
M(u, v)=\frac{u \cdot v}{\left(u^{l}+v^{l}\right)^{1 / l}} \in[0,1)
$$

I follow Schaal [2011] and set the matching function parameter to $l=1.6$.

As in the real world, I set the benefit replacement rate to $50 \% \gamma=50 \%$, and I calibrate the chance of losing benefits to match the 26 week average duration of benefits. I set the lowest possible benefit received at $\underline{z}=.2$. For job destruction, I use a $4.5 \%$ quarterly firing rate which is consistent with the JOLTS firing rate of $1.5 \%$ per month (recall there is no on the job search in this model so all separations are firings). Using the numbers in Shimer [2005] and Haan et al. [1997]. I set firm entry costs to target $\theta=.85$ (see Hagedorn and Manovskii [2008]). The quarterly job filing rate is $1-(1-.71)^{3}=.9756$ and the quarterly job finding rate is $1-(1-.45)^{3}=.833$ which implies $\theta=p_{U} / p_{V}=.833 / .9756=.85$.

Preferences are given below:

$$
\frac{c^{1-\sigma}-1}{1-\sigma}-\left(\kappa_{L} I(i=L)+\kappa_{H}(i=H)\right) \times \frac{\bar{r}-r}{\epsilon+r-\underline{r}}
$$

I follow the literature and set the risk aversion paramter to 2, $\sigma=2$, (see Arellano [2008]).

I choose the penalty parameters $\kappa_{H}$ and $\kappa_{L}$ in order to do two things: (i) to match distribution fraction defaulted upon, and (ii) admit a block recursive equilibrium (Proposition 6.2 limits the values that admit Block Recursive Equilibria). I will show sensitivity analysis below across various $\kappa_{H}$ and $\kappa_{L}$ that admist Block Recursive Equilibria. ${ }^{50} \pi_{H, H}=.75$ partially determines the rebound speed of the credit score, and $\pi_{L, L}$ determines the initial drop of the credit score. I therefore use the following type transition matrix,

$$
\Pi=\left[\begin{array}{ccc} 
& L^{\prime} & H^{\prime} \\
L & .5 & .5 \\
H & .25 & .75
\end{array}\right]
$$

\footnotetext{
${ }^{50}$ Araujo and Funchal [2006] calibrate this penalty based on exemption levels of bankruptcy across states.
} 
Table 4: Implied Income Process, Annual Log Income Process

\begin{tabular}{lll} 
& \multicolumn{2}{c}{ Data } \\
& Auto Correlation & Innovation Std. Dev. \\
\hline Storesletten et al. (2004) & 0.95 & 0.12 \\
\hline
\end{tabular}

\begin{tabular}{llc} 
& \multicolumn{2}{c}{ Baseline } \\
& Auto Correlation & Innovation Std. Dev. \\
\hline Default Model & 0.994 & 0.132 \\
No Default Model & 0.994 & 0.127 \\
\hline
\end{tabular}

\begin{tabular}{lll} 
& \multicolumn{2}{c}{ Cyclical Vacancy Costs } \\
& Auto Correlation & Innovation Std. Dev. \\
\hline Default Model & 0.994 & 0.132 \\
No Default Model & 0.995 & 0.127 \\
\hline
\end{tabular}

\subsection{Model Fit}

Definition I define the Default economy as one in which punishments are relaxed, i.e. $\kappa_{L}=.013$ and $\kappa_{H}=100$.

Definition I define the No Default economy as one in which punishments are prohibitively large, i.e. $\kappa_{L}=100$ and $\kappa_{H}=100$.

In the tables below, I present results for simulations of the model with default $\kappa_{L}=.013$ and without default $\kappa_{L}=100$, holing $\kappa_{H}=100$ fixed in both instances. The model economy is simulated for $\mathrm{N}=50,000$ agents over 300 periods, 20 times. In each simulation the first 100 observations are burned in order to eliminate dependence on the initial distribution.

In terms of the calibration, Table 4 shows that the implied income process is very stable as compared to the one estimated by Storesletten et al. [2004], even though there are occasional large swings in income corresponding to job loss and benefit expiration: ${ }^{51}$

The interesting fact to note about Table 4 is that even though there is more self-insurance among the low-types that default, their corresponding wage posting behavior induces larger swings in income than what would otherwise occur if default were outlawed. In a model with bankruptcy and partial equilibrium search, Athreya and Simpson [2006] also find the standard deviation of consumption increases significantly when bankruptcy is introduced, even though bankruptcy is typically viewed as some type of insurance mechanism. Athreya and Simpson write, "It is remarkable that even though households borrow much less when

\footnotetext{
${ }^{51}$ Standard errors omitted, in every case the standard error is less than $1 \mathrm{e}-4$
} 
Table 5:

Table 6: Aggregate Outcomes

\begin{tabular}{|c|c|c|c|c|c|}
\hline & \multicolumn{2}{|c|}{ Baseline } & \multicolumn{2}{|c|}{ Cyclical Vacancy Posting Cost } & \multirow[t]{2}{*}{ Data } \\
\hline & Default & No Default & Default & No Default & \\
\hline Avg. Unemployment & $5.91 \%$ & $5.71 \%$ & $5.89 \%$ & $5.67 \%$ & $5.76 \%$ \\
\hline \multicolumn{6}{|l|}{ Rate } \\
\hline Annualized Default & $9.77 \%$ & $0 \%$ & $9.73 \%$ & $0 \%$ & $6.3 \%$ \\
\hline Rate & & & & & \\
\hline $\begin{array}{l}\text { Average Fraction Re- } \\
\text { paid During Default }\end{array}$ & $17.18 \%$ & NA & $17.32 \%$ & NA & $49 \%$ (Credit Card) $38 \%$ (Student Loan) \\
\hline
\end{tabular}

bankruptcy is eliminated, they actually experience less variation in consumption $\left(\sigma_{c}\right)$ compared to the benchmark. This is evident in Table 3: $\sigma_{c}$ falls from 0.172 to 0.141. Part of this derives from the reduction in the incentives to gamble so that search effort rises. The other part emerges from an appreciable shift away from large debt holdings ('borrow' falls)."

Table 5 summarizes how the model does in terms of matching the unemployment rate, the default rate, and the fraction of debt defaulted upon. The model does quite well at matching the unemployment rate in general. Across the two default regimes, there is a .2\% difference in unemployment rates. The default rate of the model is over $9 \%$ which similar to mortgage default rates but slightly higher than default rates across all debt (6\% in the data). The fraction repaid is quite low, but this is discussed more below.

Figure 12 shows the debt to income ratios of defaulters. The model does exceptionally well at matching the debt to income ratios of the defaulters in the PSID Mortgage Distress supplement. This particular aspect of the model is controlled by the discount factors $\beta_{i}$.

Figure 13 shows the model's FICO score versus the data. The FICO score in the model is controlled by the transition matrix $\Pi$ which is entirely determined by $\pi_{H H}$ and $\pi_{L L}$ in the parametrization. The initial drop and subsequent persistence are both targets of the calibration, and even under perfect separation, they model does quite well at matching the FICO score dynamics. To make the comparison, I have normalized the FICO score to lie in the range taken by the data, between zero and 1 .

Table 14 shows that the model is quite close to matching the fraction of debt defaulted upon (although slightly higher than what is in the data), but fails to generate persistence in default due to the assumption that defaults are written-off and punishable only by credit score. The persistence is loosely controlled by the probability of remaining a low type agent, but also has to do with the way defaults are measured in the data versus the model. A 
Figure 12:

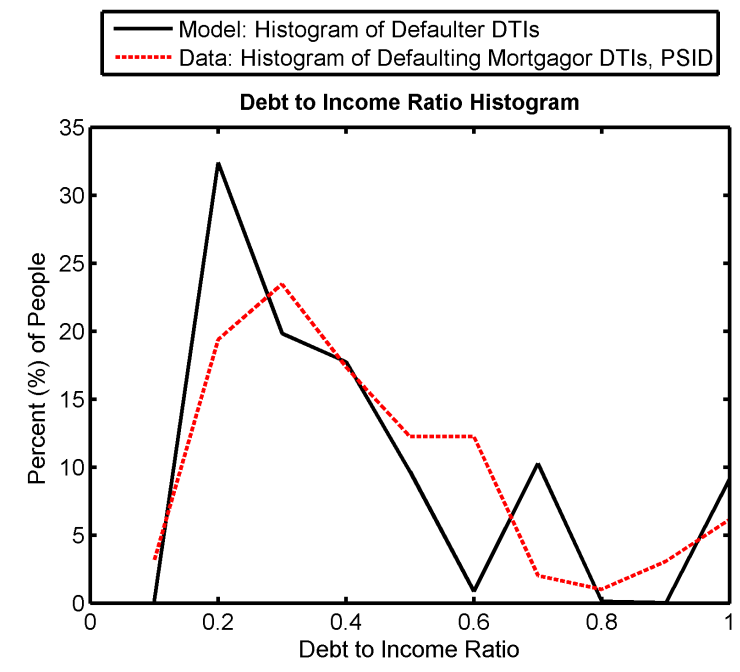

Figure 13:

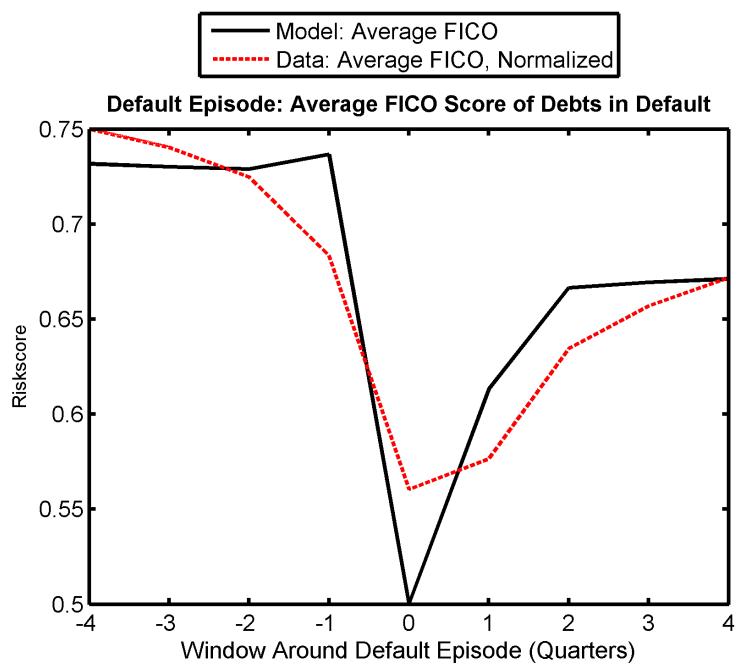

written-off account in the data continues to show up as a default, even if the consumer is acting like the debt is off the books. The model creditors takes the debt off their books in the period of default, thus generating a lack of persistence in measured default of the model.

In terms of the labor market dynamics, Table 7 shows the model does significantly better than the classic Mortensen-Pissarides model in matching the volatility of unemployment and 
Figure 14:

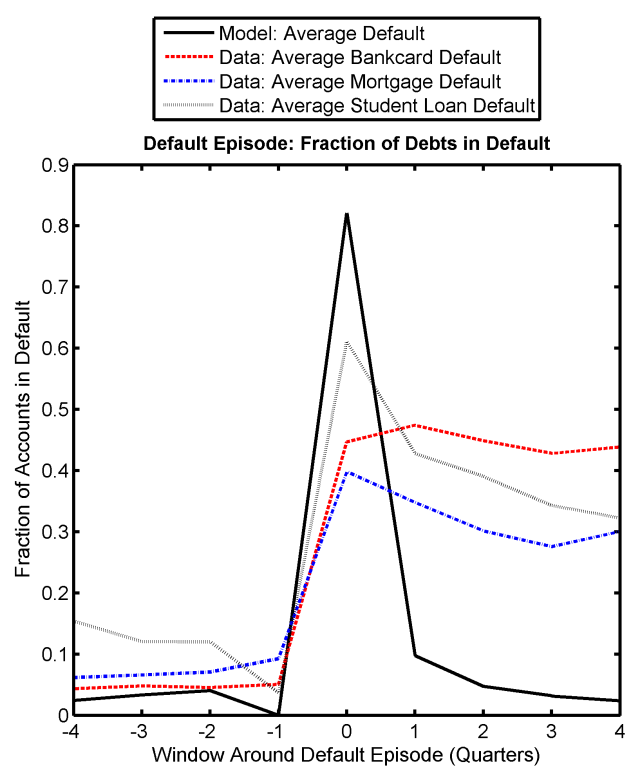

vacancies. ${ }^{52}$ While still far from the data, the rigid wage aspect of the model generates much more volatility of unemployment.

Another interesting facet of the model, as is apparent from the low volatility of the market tightness, is that unemployment and vacancies co-move positively. This is a problem previously encountered by Mortensen and Pissarides [1994], Merz [1995], and explained well in Menzio and Shi [2011]. ${ }^{53}$ In a typical Mortensen Pissarides model with Nash bargaining and worker homogeneity, when productivity goes down, firms post fewer vacancies anticipating lower profits (remember the firm get a constant slice of the pie) and unemployment goes up since the currently unemployed workers have a harder time finding jobs. In the directed search framework with sticky wages, when productivity goes down, workers post lower wages, and thus firms have incentives to lock workers in at those low wages. So unemployment goes up, firms post more vacancies trying to get low wage workers, and thus the Beveridge curve is irregular. However, given the current state of the labor market, this may not be a crux. In fact, this may be a forte of this particular exercise. The model is able to explain why this shift in the Beveridge curve may occur and it is via self-insurance, see Appendix A.

\footnotetext{
${ }^{52}$ Every time series is HP filtered, with a smoothing parameter $\lambda=1600$

${ }^{53}$ One way to get around this problem in a block recursive model is to include directed search. My solution is to allow the vacancy cost to move with the business cycle, reflecting the costs of financing a vacancy via commercial paper (i.e. the spread on commercial paper moves countercyclically, making it harder to post in bad times when spreads are high). See below.
} 
Table 7: Labor Market Performance

\begin{tabular}{|c|c|c|c|c|c|}
\hline & Default & No Default & Default + VC & Shimer-MP & Data \\
\hline Volatility of Unemployment to Productivity & 1.80 & 1.87 & 2.00 & 0.45 & 9.5 \\
\hline Volatility of Vacancies to Productivity & 2.03 & 2.31 & 3.01 & 1.35 & 10.1 \\
\hline Volatility of Tightness $(\mathrm{v} / \mathrm{u})$ to Productivity & 0.97 & 1.42 & 2.91 & 1.75 & 19.1 \\
\hline \multicolumn{6}{|c|}{$\begin{array}{l}\text { Notes: VC indicates the version of the model in which vacancy posting costs fluctuate with the aggregate } \\
\text { state (to be explain below). Data are from Shimer [2005]. All model data are logged and HP filtered with } \\
\text { smoothing parameter } 1600 \text {. Statistics computed as average of } 20 \text { repetitions of } 50,000 \text { individuals over } 200 \\
\text { quarters ( } 50 \text { years) in an environment where default is allowed. }\end{array}$} \\
\hline
\end{tabular}

Table 8: Correlations Among Aggregates, Data

\begin{tabular}{|c|c|c|c|c|c|c|c|}
\hline $\mathrm{x}$ & $u$ & $v$ & $\theta$ & $y$ & $\tilde{w}$ & UE Rate & $\begin{array}{l}\text { Default } \\
\text { Rate }\end{array}$ \\
\hline $\mathrm{SD}(\mathrm{x}) / \mathrm{SD}(\mathrm{y})$ & 9.5 & 10.1 & 19.1 & 1.00 & - & 5.90 & 6.065 \\
\hline Autocorr. & 0.936 & 0.94 & 0.941 & 0.878 & - & 0.908 & 0.9176 \\
\hline \multicolumn{8}{|l|}{$\operatorname{Corr}(\mathrm{x}, \cdot)$} \\
\hline$u$ & 1 & -0.894 & -0.971 & -0.408 & - & -0.949 & 0.5501 \\
\hline$v$ & & 1 & 0.975 & 0.364 & - & 0.897 & -0.692 \\
\hline$\theta$ & & & 1 & 0.396 & - & 0.948 & -0.5971 \\
\hline$y$ & & & & 1 & - & 0.396 & -0.3379 \\
\hline$\tilde{w}$ & & & & & 1 & - & - \\
\hline UE Rate & & & & & & 1 & 0.2286 \\
\hline Default Rate & & & & & & & 1 \\
\hline
\end{tabular}

Notes: All series, logged and HP filtered with smoothing parameter 1600. Data in first 6 columns come from Shimer (2005). Data in the last column come from the BLS. The unemployment rate is from the BLS CPS database. Vacancies (Job Opening) and Hiring rates (UE Rate) are taken from the BLS JOLTS database. Default are taken from the FRBNY Consumer Credit Quarterly Report. Productivity data, output per employee, taken from Brugeman, Hagedorn, Manovskii (2010). Data in last column cover 2001-Q1 to 2010Q2. Data in first four columns are from the entire postwar period. $\tilde{w}$ is the reservation wage, included for completeness. 
Table 9: Correlations Among Aggregates, Baseline Model

\begin{tabular}{|c|c|c|c|c|c|c|c|}
\hline $\mathrm{x}$ & $u$ & $v$ & $\theta$ & $y$ & $\tilde{w}$ & UE Rate & $\begin{array}{l}\text { Default } \\
\text { Rate }\end{array}$ \\
\hline $\mathrm{SD}(\mathrm{x}) / \mathrm{SD}(\mathrm{y})$ & 1.81 & 2.03 & 0.97 & 1.00 & 0.61 & 1.28 & 2.96 \\
\hline Autocorrelation & 0.1692 & 0.154 & 0.24 & 0.6903 & 0.7039 & -0.0403 & 0.0011 \\
\hline \multicolumn{8}{|l|}{$\operatorname{Corr}(\mathrm{x}, \cdot)$} \\
\hline$u$ & 1 & 0.8781 & -0.0138 & 0.0118 & 0.0148 & 0.0136 & 0.462 \\
\hline$v$ & & 1 & 0.4638 & 0.1675 & 0.0967 & 0.174 & 0.394 \\
\hline$\theta$ & & & 1 & 0.3311 & 0.177 & 0.3416 & -0.0296 \\
\hline$y$ & & & & 1 & 0.9872 & 0.0964 & -0.0023 \\
\hline$\tilde{w}$ & & & & & 1 & 0.0428 & 0.0027 \\
\hline UE Rate & & & & & & 1 & 0.0341 \\
\hline Default Rate & & & & & & & 1 \\
\hline \multicolumn{8}{|c|}{$\begin{array}{l}\text { Notes: All model data are logged and HP filtered with smoothing parameter } 1600 \text {. Statistics computed as } \\
\text { average of } 20 \text { repetitions of } 50,000 \text { individuals over } 200 \text { quarters ( } 50 \text { years) in an environment where default } \\
\text { is allowed. Default in the model is any failure to repay, regardless of default size. } \tilde{w} \text { is the model's reservation } \\
\text { wage. }\end{array}$} \\
\hline
\end{tabular}


Table 10: Correlations Among Aggregates, Cyclical Vacancy Posting Cost Model

\begin{tabular}{|c|c|c|c|c|c|c|c|}
\hline $\mathbf{x}$ & $u$ & $v$ & $\theta$ & $y$ & $\tilde{w}$ & UE Rate & $\begin{array}{l}\text { Default } \\
\text { Rate }\end{array}$ \\
\hline $\mathrm{SD}(\mathrm{x}) / \mathrm{SD}(\mathrm{y})$ & 2.01 & 3.02 & 2.92 & 1.00 & 1.11 & 1.70 & 3.16 \\
\hline Autocorrelation & 0.2875 & 0.3171 & 0.6375 & 0.6903 & 0.7014 & 0.256 & 0.1041 \\
\hline \multicolumn{8}{|l|}{$\operatorname{Corr}(\mathrm{x}, \cdot)$} \\
\hline$u$ & 1 & 0.3796 & -0.2914 & -0.3125 & -0.3168 & -0.1789 & 0.5379 \\
\hline$v$ & & 1 & 0.7721 & 0.7419 & 0.7293 & 0.5668 & 0.1738 \\
\hline$\theta$ & & & 1 & 0.9835 & 0.9734 & 0.71 & -0.1902 \\
\hline$y$ & & & & 1 & 0.9987 & 0.6932 & -0.2067 \\
\hline$\tilde{w}$ & & & & & 1 & 0.6843 & -0.2097 \\
\hline UE Rate & & & & & & 1 & -0.0977 \\
\hline Default Rate & & & & & & & 1 \\
\hline \multicolumn{8}{|c|}{$\begin{array}{l}\text { Notes: All model data are logged and HP filtered with smoothing parameter } 1600 \text {. Statistics computed as } \\
\text { average of } 20 \text { repetitions of } 50,000 \text { individuals over } 200 \text { quarters ( } 50 \text { years) in an environment where default } \\
\text { is allowed. Default in the model is any failure to repay, regardless of default size. } \tilde{w} \text { is the model's reservation } \\
\text { wage. }\end{array}$} \\
\hline
\end{tabular}




\section{Main Welfare Comparison}

Many authors have looked at Welfare in models of bankruptcy beginning with Athreya [2002]. In a partial equilibrium endowment economy with loan pooling, he found a substantial welfare gain to eliminating default. The crux of this result was that eliminating default lowered the costs of borrowing for everyone since everyone faced the same interest rate given by the loan pool risk premium. In response, Li and Sarte [2006] looked at the role of bankruptcy in an economy with capital formation and indivisible labor. They find that eliminating bankruptcy reduces welfare. The reason for this result in their model is that when bankruptcy is eliminated, the risk premium falls and more households borrow. By borrowing more, households bid up the rental rate of capital and savings (i.e. the potential capital stock) can only go to households who borrow or firms that rent capital. As a result of the increased rental rate, output goes down, labor used in production falls, and welfare decreases. Athreya and Simpson [2006] use the partial equilibrium framework of Ljungqvist and Sargent [1998] to study to interaction between unemployment insurance and bankruptcy. They find that the ability to file bankruptcy lowers search effort in the lowest deciles of the wealth distribution. However, the welfare gains to these lower deciles is offset by the increased borrowing costs to all others, and thus, once again, it is welfare enhancing to eliminate bankruptcy.

The present analysis features several new characteristics. Firstly, I calibrate to match default, which is a business cycle event and several times larger than bankruptcy in magnitude. Secondly, the labor market is frictional and set in general equilibrium, allowing for feedback effects from the aggregate state. Thirdly, the default decision and default punishments are more reflective of actuality. As a result, my welfare conclusions stand in contrast to the above studies. I find very small net gains from allowing default, but the small net gain hides the large gross changes in welfare resulting from (a) wage posting behavior, (b) the changing cost of credit, and (c) the altered business cycle properties of the economy.

The welfare criteria for eliminating default is a simple derivation from the CES preferences. Let $x_{j t}$ be the state vector for agent $j$ at date $t$. Simulate an N (large) person economy for $T$ periods, dropping the first $\tau$ periods to eliminate initial condition dependence. Define $E V^{N o \text { Def }}=\frac{1}{N} \sum_{j=1}^{N} \sum_{t=\tau}^{T} V\left(x_{j t} ;\left(\mu_{t}, y_{t}\right)\right)$ to be the recovered expected net present value of an agent living in a world with a stringent default penalty. ${ }^{54}$ Likewise let $E V^{D e f}$ be the expected net present value of an agent living in a world with default. The welfare gain to making default punishments stronger is then given by the following expression, where the discount factor is weighted according to the ergodic distribution of types,

$$
\text { Welfre Gain }(+) / \operatorname{Loss}(-)=\left(\frac{E V^{N o D e f}+\frac{1}{(1-\widehat{\beta})(1-\sigma)}}{E V^{D e f}+\frac{1}{(1-\widehat{\beta})(1-\sigma)}}\right)^{\frac{1}{1-\sigma}}-1
$$

\footnotetext{
${ }^{54}$ I use the word recovered, since I must simulate in order to recover the distribution of agents across states as the aggregate state fluctuates. I essentially run a Monte Carlo exercise where I simulate $1 \mathrm{~mm}$ agents for 300 periods to recover this expected value.
} 
Table 11: Welfare

Welfare Change from

Eliminating Default

\begin{tabular}{ll}
\hline Baseline & $-0.12 \%$ \\
Cyclical Vacancy Cost & $-0.10 \%$ \\
\hline
\end{tabular}

$$
\widehat{\beta}=f_{L}(\mu) \beta_{L}+f_{H}(\mu) \beta_{H}
$$

Table 11 details the results of the model. I find that it is mildy welfare improving to eliminate default. To understand this result, consider the two forces in the model:

(a) The cost of credit increases for all other borrowers (see Figure 16 which shows the bond prices in both economies)

(b) The unemployed low-types post higher wages (see Figure 15 which shows the wage policy functions in both economies)

The main mechanism of the model is captured by Figure 15. This image shows that the borrowing low type agents have a considerably higher reservation wage than the borrowing high type agents. The difference in reservation wages then generates a difference in job finding rates through the equilibrium market tightness $\theta(\tilde{w} ; \Omega)$ which is decreasing in $\tilde{w}$.

Both Figures 17 and 18 were generated by simulating the economy, marking default episodes as date 0, and looking at behavior 4 quarters before the default and 4 quarters after the default. I then took averages across people to build the measures (to be consistent, I did the same for the Equifax data). Figure 17 shows that the model generates the same $20 \%$ unemployment rate among defaulters. In the model, job losers borrow. In fact, both types of agents borrow upon benefit expiration. Thus being a low type agent is not a sufficient condition for default- the agent must be both unemployed and low type in order for the agent to borrow and default. Figure 18 also illustrates the phenomenon present in most defaultable debt models, agents tend to default as their conditions improve; this makes sense since when an agent has found a new job, they dont need access to the credit markets (i.e. they dont care about their credit score as much) and thus they default. 
Figure 15:

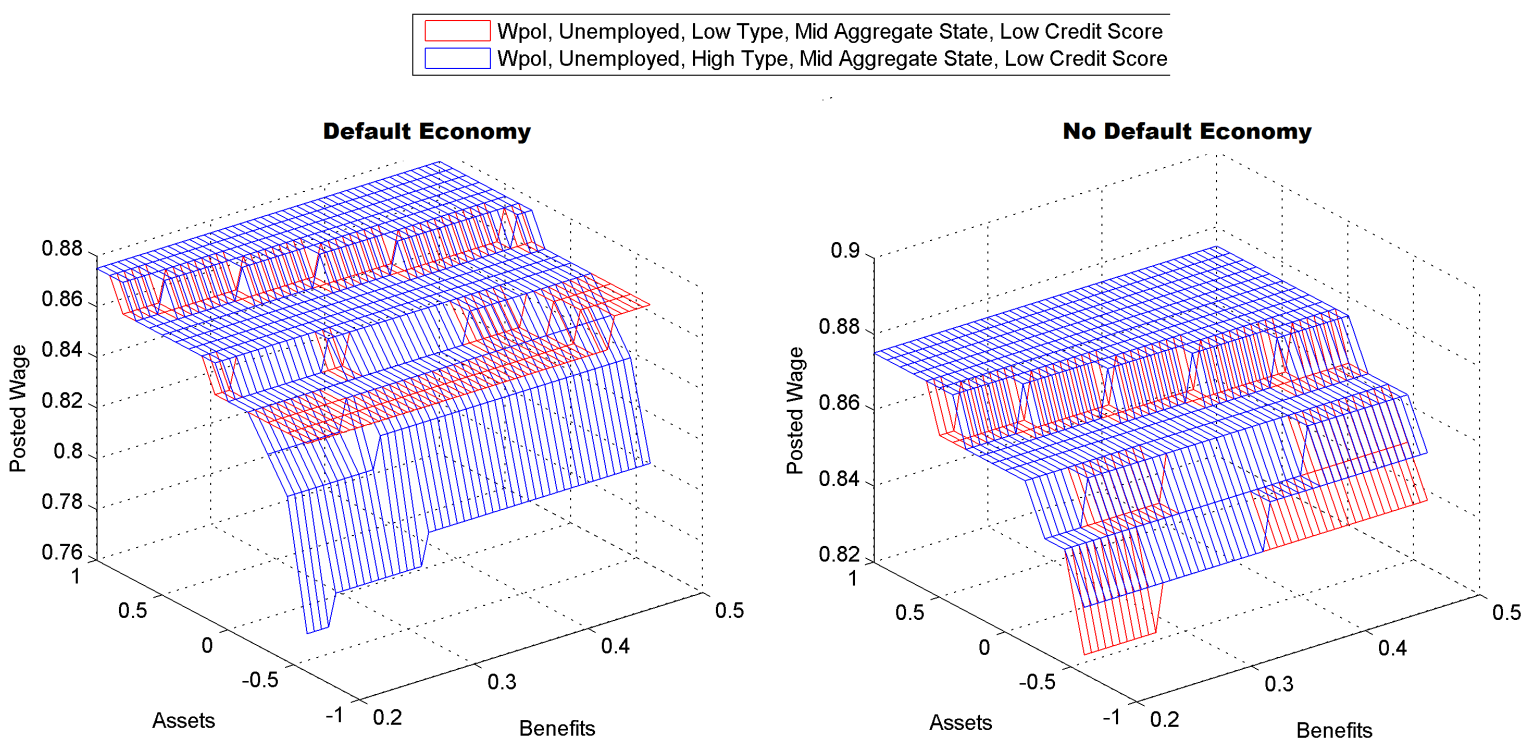

Figure 16:
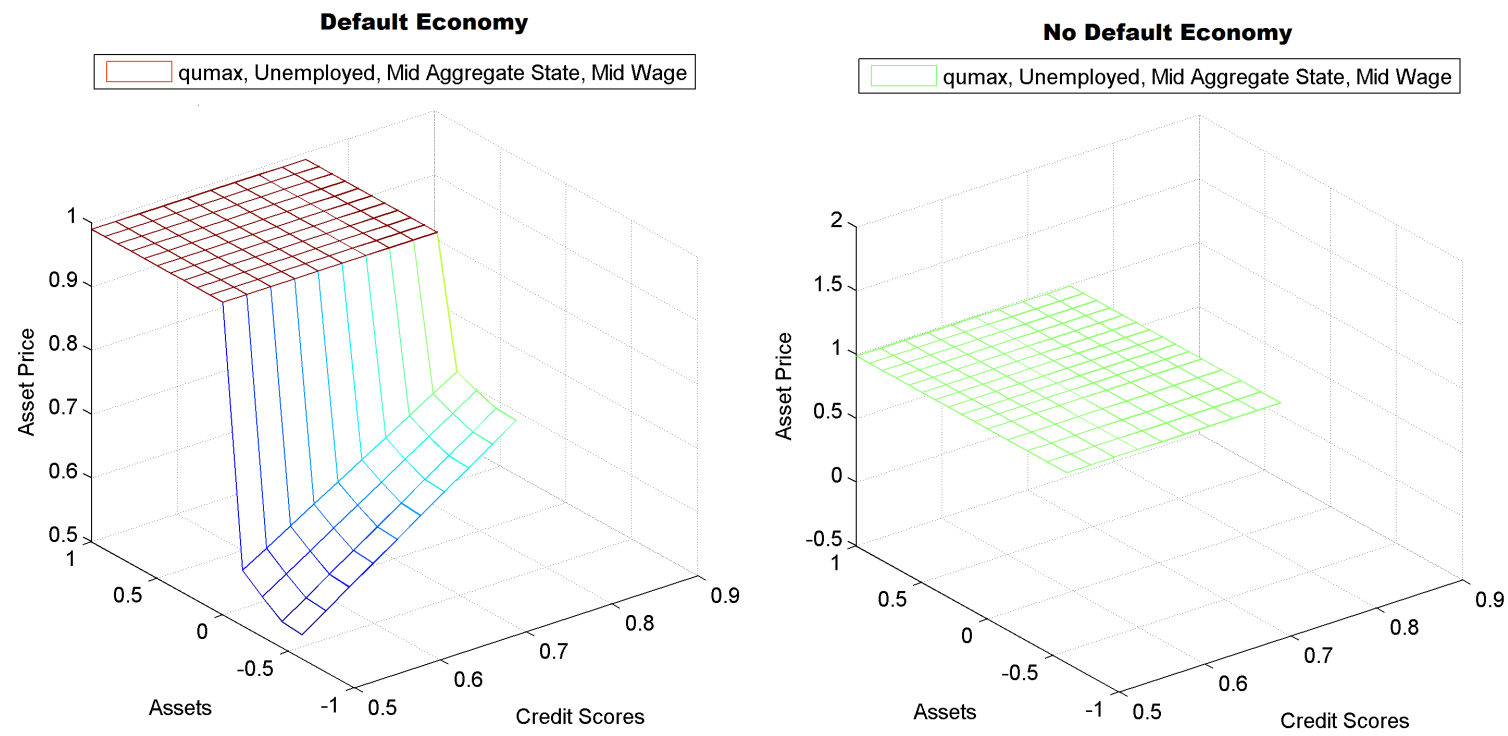
Figure 17:

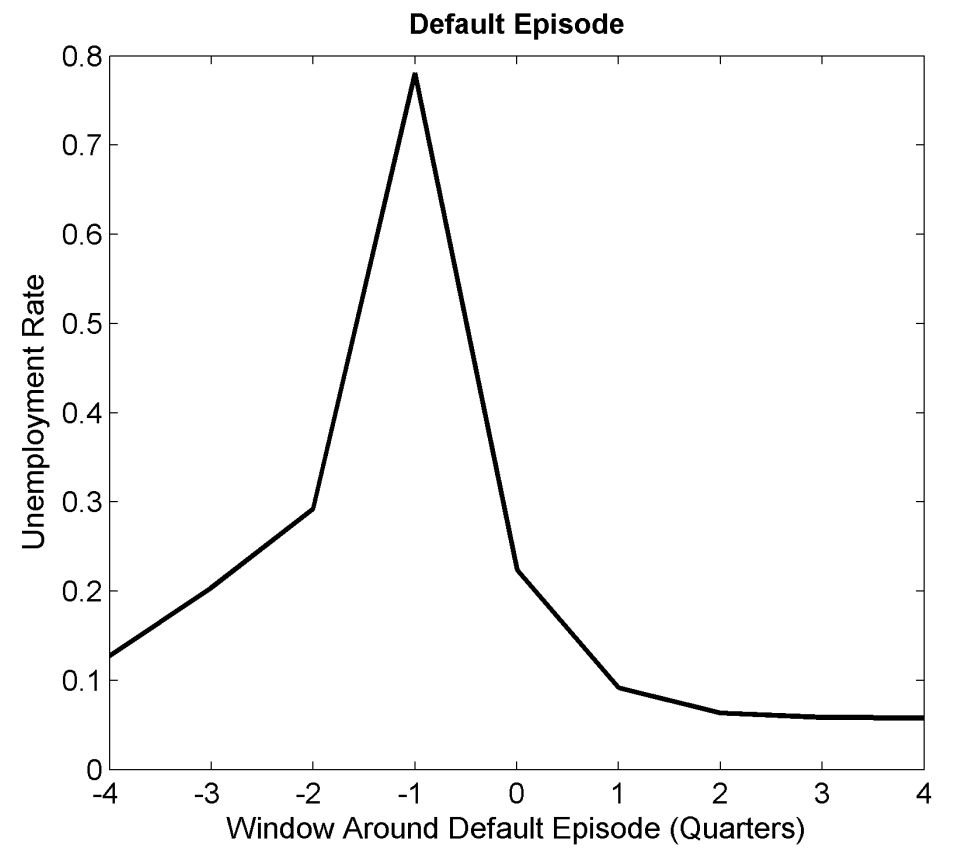

Figure 18:
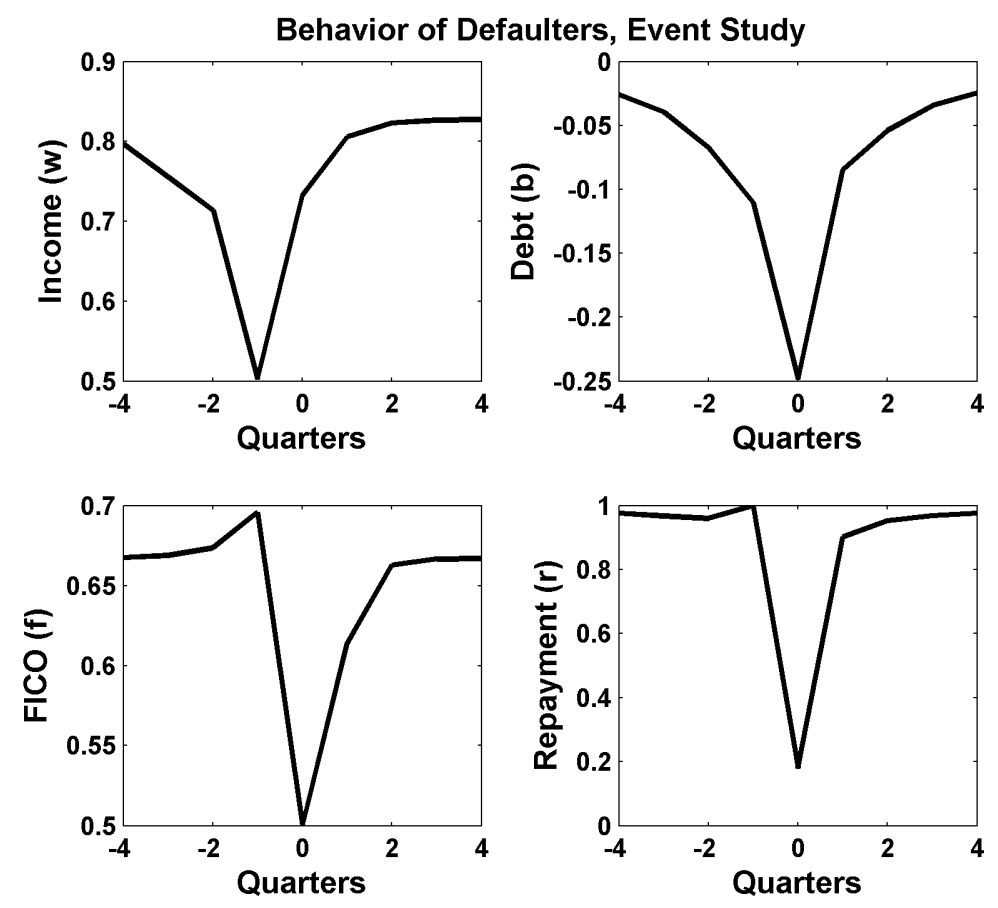


\section{Transition Experiment}

The main experiment is to feed the model the actual time series for job destruction and the actual time series for productivity from the official NBER peak 2007-IV, past the official NBER trough 2009-II, and through the ensuing recovery, separately and simultaneously, to see what bearing default has on the labor market recovery following a severe contraction. To understand the basic mechanisms at play in the default economy, I feed the shocks to the default version model only. In the second part of this section, I do a comparison between two economies, one that introduces unexpected and permanent protection for defaulters versus the other that continues to prohibit default.

\subsection{Transition Mechanisms in Default Economy}

To understand the basic mechanisms at play during a simulated business cycle, I run the following experiment:

1. I engineer labor productivity shocks to match HP-Filtered log output per employee data taken from Brügemann et al. [2010] for 2007-IV to 2010-II (see Figure 19).

- Agents still rationally believe productivity follows AR(1) process.

2. I engineer unexpected job destruction shocks at each date calibrated to match the quarterly JOLTS layoff rate for 2007-IV to 2010-II (see Figure 19).

- Agents expect $\bar{\delta}$ to return to $4.5 \%$ at the end of each period.

3. Follow economy from start of crisis to 4 quarters after

4. Recover aggregate distribution via simulation

\section{Compare labor market dynamics, both crash and recovery}

Figure 20 illustrates the positive comovement between unemployment and default, and the negative co-movement between the reservation wage and the default rate. In the model, agents reduce their reservation wage for two reasons: (a) productivity falls and (b) defaulters post higher reservation wages. The higher reservation wage postings are reflected in a lower average market tightness $(\mathrm{v} / \mathrm{u})$. The Beveridge curves implications of this prediction are explained further below. 
Figure 19: Forcing Variables
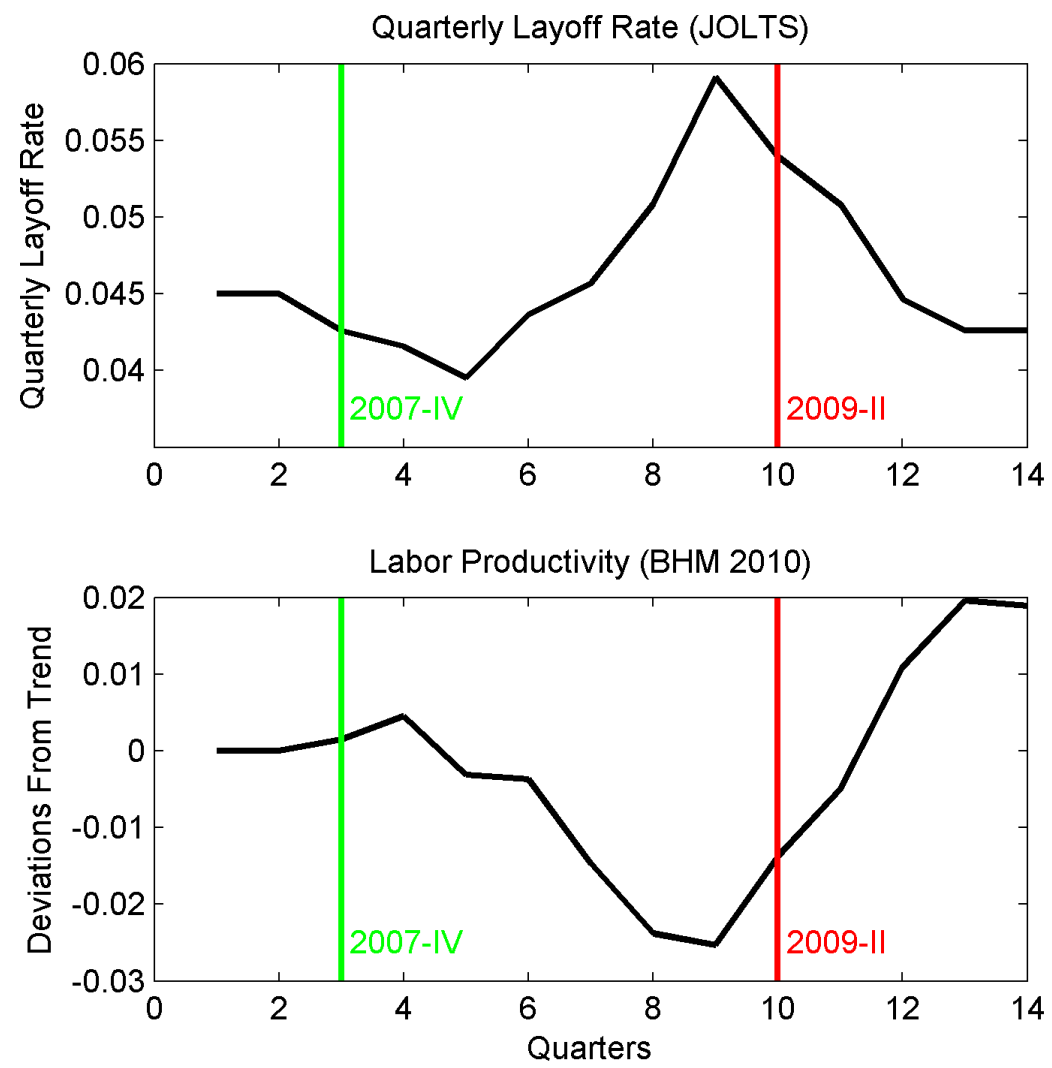
Figure 20: Default Economy, Response to Shocks
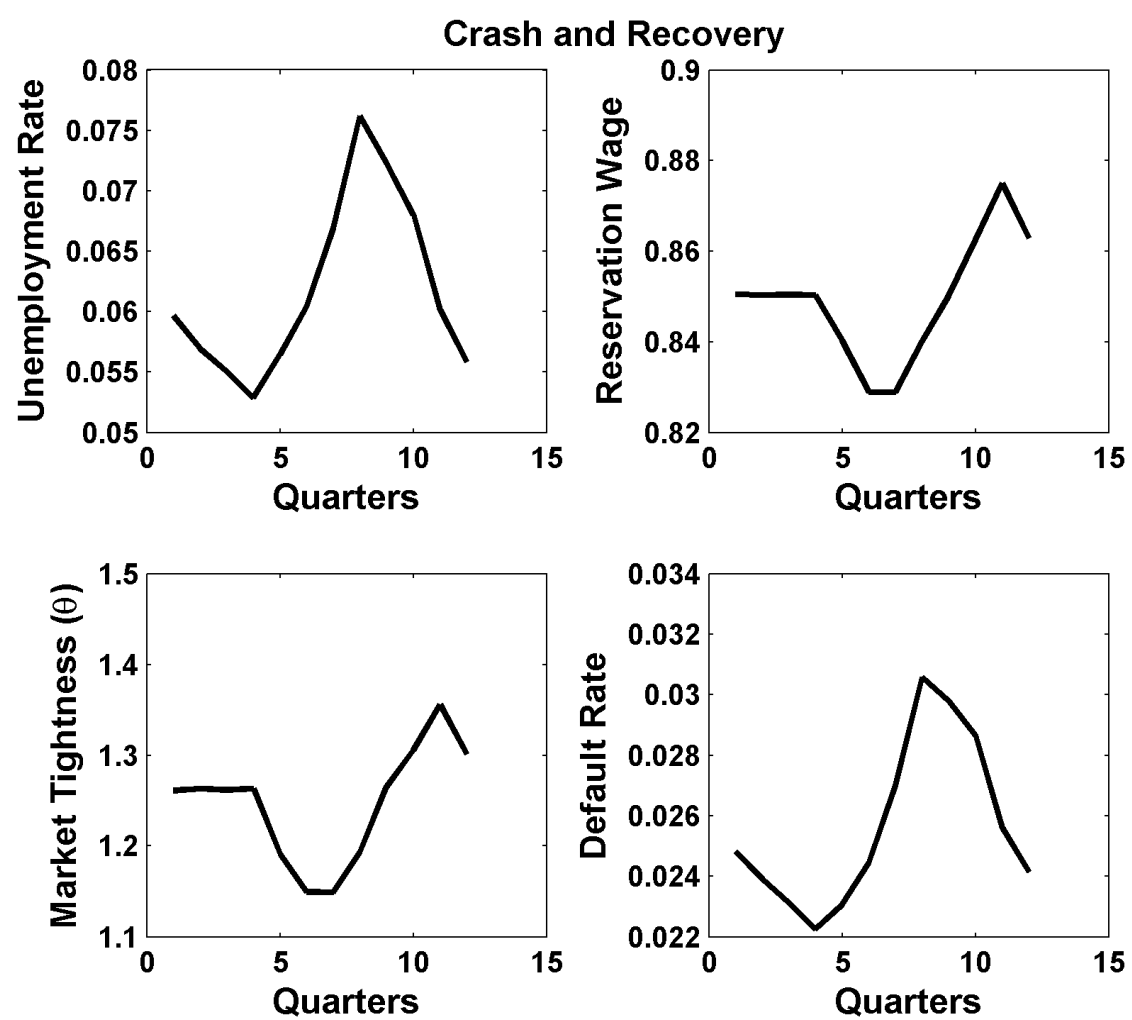


\subsection{Transition Experiment, Policy Change}

I conduct a similar experiment as in Section 10.1, feeding the model the productivity and job destruction shocks, but this time, the two economies are identical until 2007-IV. At this date, one economy allows default, unexpectedly and permanently, and the other economy does not. The timeline for the experiment is below:

1. I engineer labor productivity shocks to match HP-Filtered log output per employee data taken from Brügemann et al. [2010] for 2007-IV to 2010-II (see Figure 19).

- Agents still rationally believe productivity follows $\mathrm{AR}(1)$ process.

2. I engineer unexpected job destruction shocks at each date calibrated to match the quarterly JOLTS layoff rate for 2007-IV to 2010-II (see Figure 19).

- Agents expect $\bar{\delta}$ to return to $4.5 \%$ at the end of each period.

3. Both economies have prohibitively costly default penalties until onset of recession (2007-IV).

4. In 2007-IV one economy unexpectedly allows default, the other does not (Mortgage Servicer Settlement, State Moratoria, CARD Act, HAMP etc.) .

5. The change is permanent and agents know this.

Figure 21 shows the unemployment rate difference across the two economies (the dotted green lines is for both shocks, and the dashed line is for job-destruction shocks only). At impact, the unemployed high-type agents actually post lower wages to obtain a job and receive the benefits of a lower cost of credit. Therefore, initially in the default economy, the unemployment rate drops below that of the default economy and I observe the drop in Figure 21. As the recession takes hold, however, the unemployment rate begins to rise in the default economy since the remaining unemployed low-type agents have higher reservation wages. Figure 23 captures the difference in job finding rates across economies (the solid line is for the economy with default and the dashed line is for the economy without default), Figure 24 captures the changes in the reservation wage, and Figure 22 shows the actual unemployment rates. 
Figure 21:

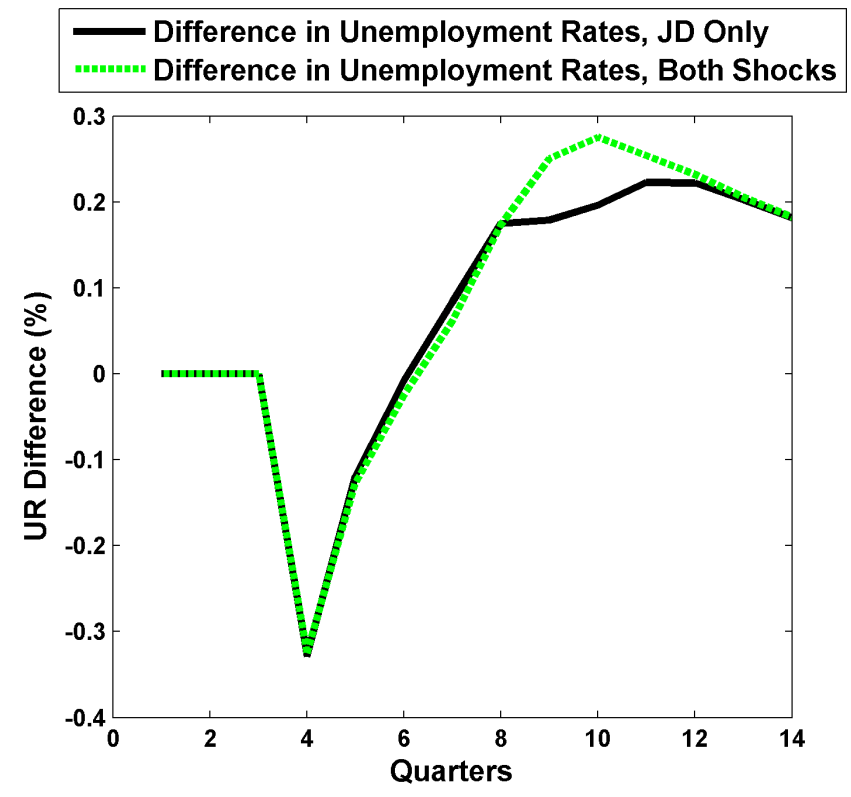

Figure 22:

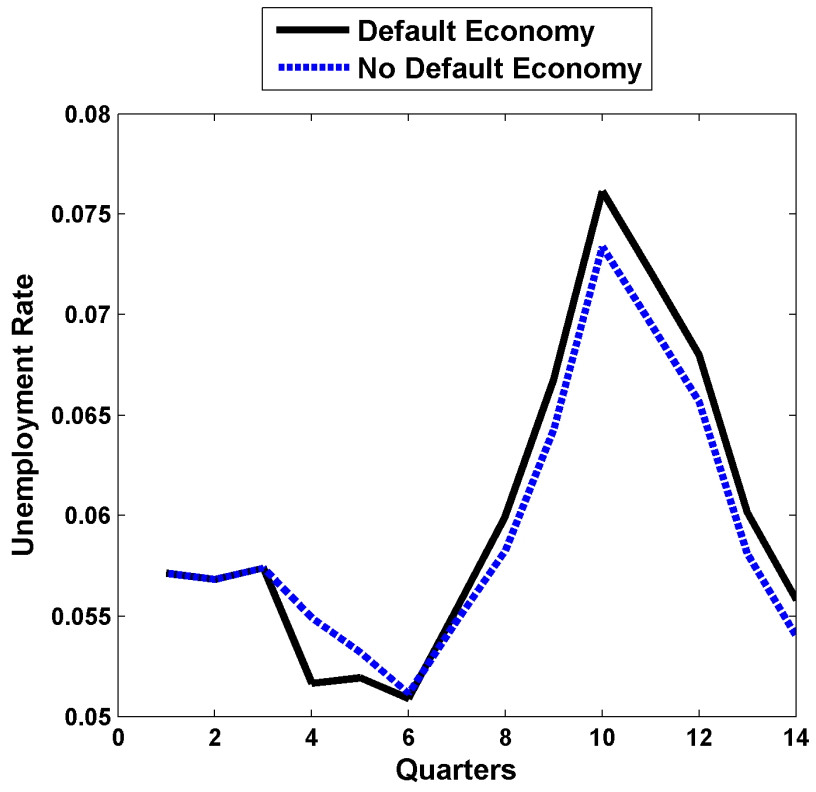


Figure 23:

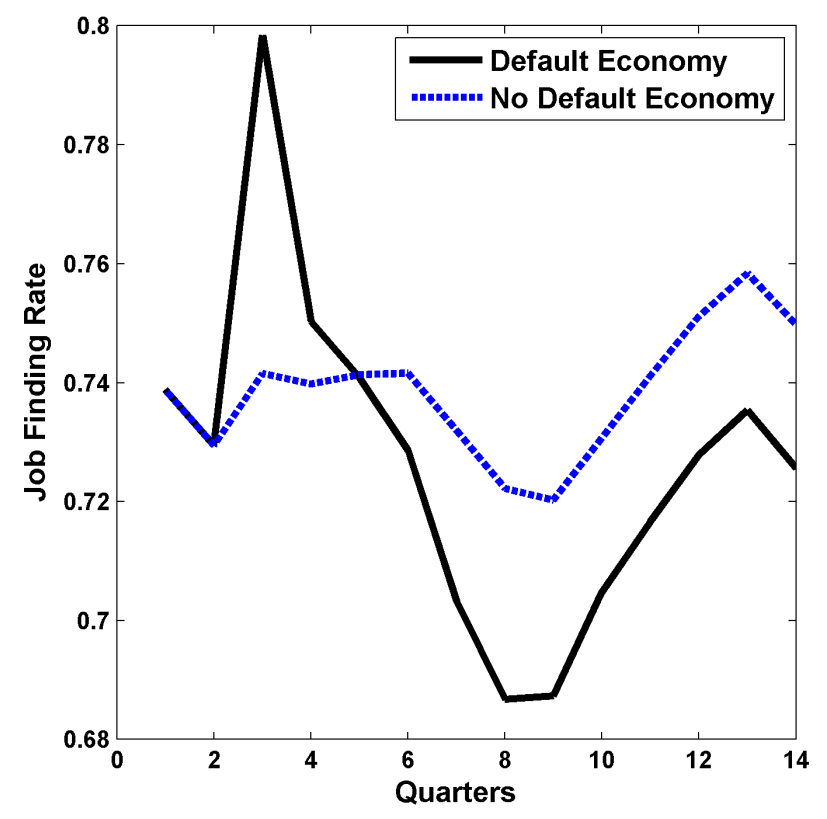

Figure 24:

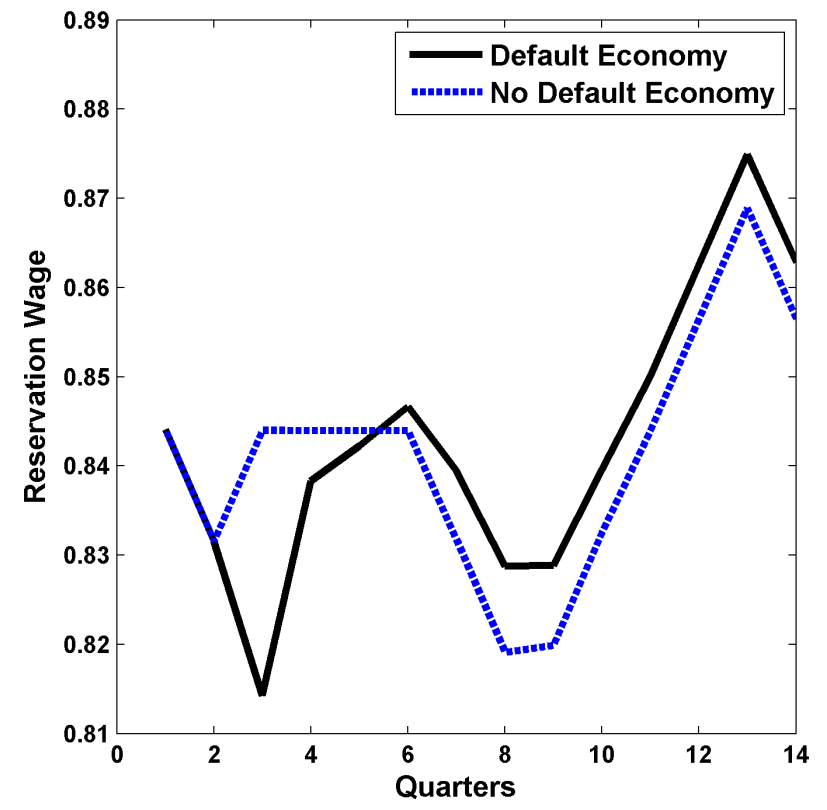




\section{Conclusions}

In this paper I consider how consumers self-insure at high frequencies, outside of the traditional formal institutions of unemployment insurance and bankruptcy. I show several new stylized facts: (i) default, which I define to be $90+$ days late without filing for bankruptcy within a year, dwarfs bankruptcy on a quarterly basis, occurring $5 \times$ to $6 \times$ times more often (ii) job loss is the most important cause of default, more so than negative equity or health shocks (iii) default is a business cycle event, roughly twice as cyclical as bankruptcy (iii) the median defaulter is credit constrained with a utilization rate of $92 \%$ (iv) the default decision boosts disposable income significantly, e.g. $34 \%$ for the median homeowner, and (v) the fraction of accounts on which consumers default is continuous, meaning that they selectively default on a non-trivial number accounts.

I then use these facts to build a highly tractable general equilibrium model with a frictional labor market similar to Burdett and Mortensen [1998] and Menzio and Shi [2009, 2011], individually priced debt along the lines of Eaton and Gersovitz [1981], endogenous credit scores as in Chatterjee et al. [2008b], and aggregate risk, capable of providing an answer to the normative aspect of the main question. After calibrating the model to match the new data, I find that the ability to better insure oneself during unemployment and subsequently look for higher-paying hard-to-find jobs trumps the increase in the cost of credit, and as a result, protecting defaulters improves overall welfare. The transition experiments show that the mechanism produces higher unemployment during recessions and that this difference in persistent.

This new model structure features a continuous default choice, thus eliminating the nonconvexities associated with traditional binary bankruptcy models. Since default is smooth and block recursivity reduces the model down to a representative agent problem, the model can be solved using perturbation methods, and then estimated. This is future work in progress.

\section{References}

A. Araujo and B. Funchal. How much debtors' punishment? Fundação Getulio Vargas, 2006.

A. Araujo and P.K. Monteiro. Infinite horizon incomplete markets with a continuum of states. Mathematical Finance, 6(2):119-132, 1996.

C. Arellano. Default risk and income fluctuations in emerging economies. The American Economic Review, 98(3):690-712, 2008.

Herkenhoff K.H. Ohanian L.E. Athreya, K.B. and J.M. Sanchez. Selective default. In Progress, 2012. 
K. Athreya, J.M. Sanchez, X. Tam, and E. Young. A model of credit card delinquency. 2011.

K.B. Athreya. Welfare implications of the bankruptcy reform act of 1999. Journal of Monetary Economics, 49(8):1567-1595, 2002.

K.B. Athreya and N.B. Simpson. Unsecured debt with public insurance: From bad to worse. Journal of Monetary economics, 53(4):797-825, 2006.

D. Benjamin and X. Mateos-Planas. Formal and informal default in consumer credit. 2011.

D. Benjamin and M.L.J. Wright. Recovery before redemption: A theory of delays in sovereign debt renegotiations. Unpublished Paper, University of California at Los Angeles, 2009.

B. Brügemann, M. Hagedorn, and I. Manovskii. Labor productivity during postwar recessions: Basic data, facts, and figures. 2010.

K. Burdett and D.T. Mortensen. Wage differentials, employer size, and unemployment. International Economic Review, pages 257-273, 1998.

S. Chatterjee. An equilibrium model of the timing of bankruptcy filings. In Credit, defaul and bankruptcy conference, LAEF, UCSB, 2010.

S. Chatterjee, D. Corbae, and J.V. Rios-Rull. A finite-life private-information theory of unsecured consumer debt. Journal of Economic Theory, 142(1):149-177, 2008a.

S. Chatterjee, D. Corbae, and J.V. Rios-Rull. A theory of credit scoring and competitive pricing of default risk. Unpublished working paper, University of Texas at Austin, 2008b.

D. Chen. Impact of personal bankruptcy on labor supply decisions. Technical report, mimeo, 2012a.

D. Chen. The interaction between labor and credit markets: The impact of bankruptcy on labor supply decisions. 2012b.

R. Chetty. Moral hazard vs. liquidity and optimal unemployment insurance. Technical report, National Bureau of Economic Research, 2008.

A. Dawsey and L. Ausubel. Informal bankruptcy. 2002.

P. Dubey, J. Geanakoplos, and M. Shubik. Default and efficiency in a general equilibrium model with incomplete markets. Research paper, (879R):915, 1990.

P. Dubey, J. Geanakoplos, and M. Shubik. Default and punishment in general equilibrium1. econometrica, 73(1):1-37, 2005.

J. Eaton and M. Gersovitz. Debt with potential repudiation: Theoretical and empirical analysis. The Review of Economic Studies, pages 289-309, 1981. 
M. Furletti. Consumer bankruptcy: how unsecured lenders fare. Technical report, Federal Reserve Bank of Philadelphia, 2003.

G. Gordon. Evaluating default policy: The business cycle matters. 2011.

W.J. Haan, G. Ramey, and J. Watson. Job destruction and propagation of shocks. Technical report, National Bureau of Economic Research, 1997.

M. Hagedorn and I. Manovskii. The cyclical behavior of equilibrium unemployment and vacancies revisited. 2008.

G.D. Hansen. Indivisible labor and the business cycle. Journal of monetary Economics, 16 (3):309-327, 1985.

J.C. Hatchondo, L. Martinez, and J.M. Sanchez. Mortgage Defaults. INTERNATIONAL MONETARY FUND, 2012.

K.F. Herkenhoff. What actually causes mortgage defaults, redefaults, and modifications. Ziman Center Working Paper 2012-02WP, 2011.

K.F. Herkenhoff. Estimating a model of continuous default. Manuscript, 2012.

K.F. Herkenhoff and L. Ohanian. Foreclosure delay and us unemployment. Federal Reserve Bank of St. Louis Working Paper Series, 2012.

K.F. Herkenhoff and L.E. Ohanian. Labor market dysfunction during the great recession. Technical report, National Bureau of Economic Research, 2011.

R.G. Hubbard, J. Skinner, and S.P. Zeldes. Precautionary saving and social insurance. Technical report, National Bureau of Economic Research, 1995.

F. Karahan and S. Rhee. Housing and the labor market: The role of migration on aggregate unemployment. University of Pennsylvania, mimeo, 2011.

A. Krueger and A. Mueller. Job search and job finding in a period of mass unemployment: Evidence from high-frequency longitudinal data. Technical report, Princeton University, Department of Economics, Industrial Relations Section., 2011.

P. Krusell and A.A. Smith, Jr. Income and wealth heterogeneity in the macroeconomy. Journal of Political Economy, 106(5):867-896, 1998.

D. Lee and W. van der Klaauw. An introduction to the frbny consumer credit panel. 2010.

P. Legrady. Creditors exercising options for receivables management. Business Credit, 107 (8):62, 2005.

W. Li and P.D. Sarte. Us consumer bankruptcy choice: The importance of general equilibrium effects. Journal of Monetary Economics, 53(3):613-631, 2006. 
I. Livshits, J. MacGee, and M. Tertilt. Consumer bankruptcy: A fresh start. The American Economic Review, 97(1):402-418, 2007.

L. Ljungqvist and T.J. Sargent. The european unemployment dilemma. Journal of Political Economy, 106(3):514-550, 1998.

G. Menzio and S. Shi. Efficient search on the job and the business cycle. Technical report, National Bureau of Economic Research, 2009.

G. Menzio and S. Shi. Block recursive equilibria for stochastic models of search on the job. Journal of Economic Theory, 145(4):1453-1494, 2010.

G. Menzio and S. Shi. Efficient search on the job and the business cycle. Journal of Political Economy, 119(3):468-510, 2011.

M. Merz. Search in the labor market and the real business cycle. Journal of Monetary Economics, 36(2):269-300, 1995.

D.T. Mortensen and C.A. Pissarides. Job creation and job destruction in the theory of unemployment. The review of economic studies, 61(3):397-415, 1994.

C.B. Mulligan. Means-tested subsidies and economic performance since 2007. Technical report, National Bureau of Economic Research, 2011.

D.K. Musto. What happens when information leaves a market? evidence from postbankruptcy consumers*. The Journal of Business, 77(4):725-748, 2004.

J. Rothstein. Unemployment insurance and job search in the great recession. Technical report, National Bureau of Economic Research, 2011.

E. Schaal. Uncertainty, productivity and unemployment in the great depression. In 2011 Meeting Papers, number 1450. Society for Economic Dynamics, 2011.

G. Seccia and X. Mateos-Planas. Consumer default with complete markets: risk-based pricing and finite punishment. 2011.

R. Shimer. The cyclical behavior of equilibrium unemployment and vacancies. American economic review, pages 25-49, 2005.

K. Storesletten, C.I. Telmer, and A. Yaron. Cyclical dynamics in idiosyncratic labor market risk. Journal of Political Economy, 112(3):695-717, 2004.

J.X. Sullivan. Borrowing during unemployment. Journal of Human Resources, 43(2):383$412,2008$.

M. White. Why don't more households file for bankruptcy? Journal of Law Economics and Organization, 14(2):205-231, 1998. 


\section{A Adding in Cyclical Vacancy Posting Costs}

In order to correct for the irregular Beveridge curve, I assume that firms must borrow to finance the costs of recruiting employees. The intraperiod loan is size $\bar{\kappa}$ subject to an interest rate $\tilde{r}(y)$ that fluctuates over time with aggregate productivity, $y$. The interest rate will be further decomposed as follows, $\tilde{r}(y)=\bar{r}\left(1-\sigma_{s}(y)\right)$ where $\bar{r}$ is a base interest rate. I will take this rate as exogenous, and calibrate it to the BofA Merrill Lynch US High Yield Master II Option-Adjusted Spread. This spread reflects borrowing costs for risky small businesses, is highly countercycical $\left(\operatorname{corr}\left(y_{t}, \sigma_{s}\left(y_{t}\right)\right)=-.48\right)$, and has a standard deviation, expressed in log percentage points, that is nearly 5 times greater than that of productivity, $\sigma_{s}(y) / \sigma_{\epsilon}=4.77$. Define $\bar{\sigma}_{s} \equiv 4.77$ and denote the deviations of productivity as $l_{y}$. The borrowing cost can then be written as follows,

$$
\begin{gathered}
\kappa(y)=\bar{r}\left(1-\sigma_{s}(y)\right) \bar{\kappa} \\
\sigma_{s}(y)=\bar{\sigma}_{s} l_{y} \\
\ln (\kappa(y))=\ln (\bar{r} \bar{\kappa})+\ln \left(1-\sigma_{s}(y)\right) \\
\approx \ln (\bar{r} \bar{\kappa})-\sigma_{s}(y) \\
\approx \ln (\bar{r} \bar{\kappa})-\bar{\sigma}_{s} l_{y}
\end{gathered}
$$

Let $l_{\kappa}$ be $\log$ deviations of the vacancy posting cost. Then to log deviation is proportional to that of output, as desired:

$$
\Delta \ln (\bar{\kappa}) \approx \bar{\sigma}_{s} \Delta l_{y}
$$

As a result, the free entry condition is now given as follows:

$$
\theta(w ; \Omega)=p_{V}^{-1}\left(\frac{\kappa(y)}{J(w ; \Omega)}\right) \text { if } \theta(w ; \Omega)>0
$$

The model's implied Beveridge curve with cyclical vacancy posting costs, inclusive of the experiment (see Section 10.1), is given by Figure 26 (the data is in Figure 25). The circles represent the recession simulated in the model, and clearly the Beveridge curve shifts outward. In the default economy, this shift is closer to the 45 degree line, generating a more positive correlation between $\mathrm{v}$ and $\mathrm{u}$. 
Figure 25:

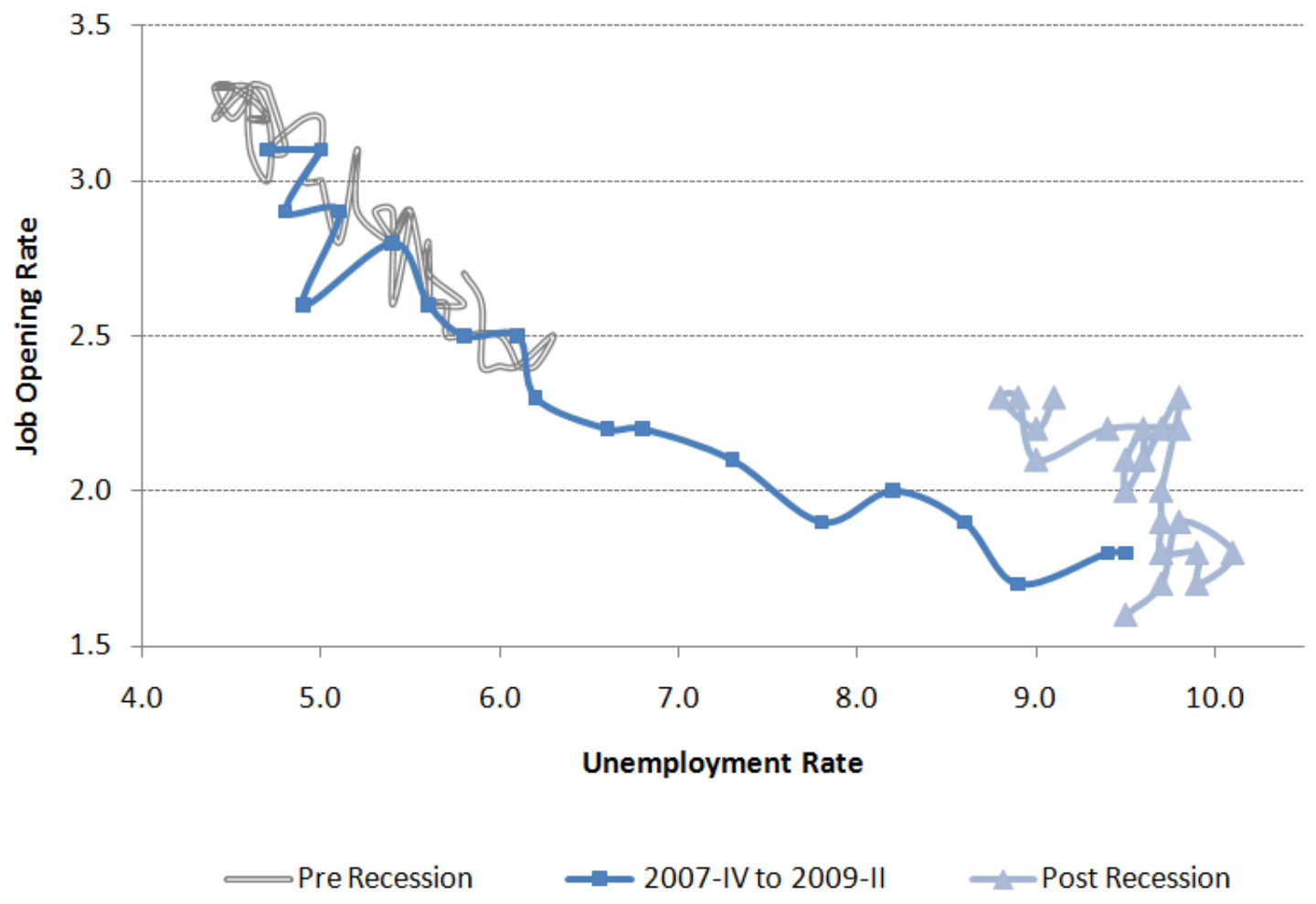

Figure 26:

Beveridge Curve, Vacancy Shocks
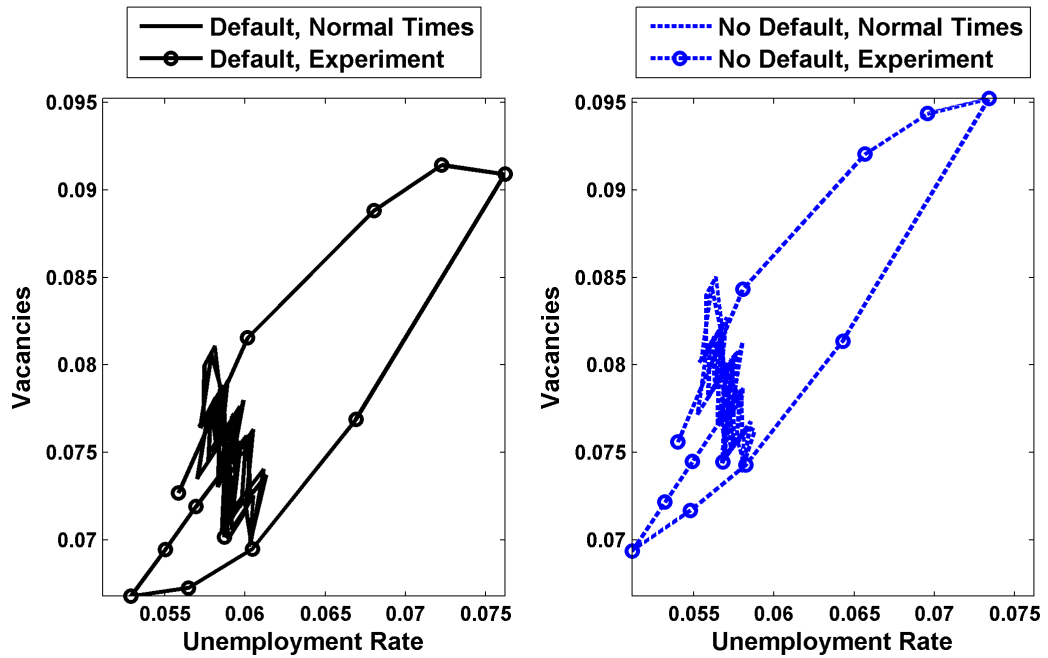


\section{B Proofs}

Several assumptions are necessary for the proofs that follow:

\section{A.1 Boundedness:}

i. The support of $y$ is bounded above and below $y \in[\underline{y}, \bar{y}] \equiv Y \subset \mathbb{R}_{++}$

ii. The choice of assets is disconnected and bounded above and below $b \in\left[\underline{b}_{n e g}, \bar{b}_{n e g}\right] \cup$ $\left[\underline{b}_{p o s}, \bar{b}_{\text {pos }}\right] \equiv B \subset \mathbb{R}$, and $\bar{b}_{\text {neg }}<<0 \leq \underline{b}_{\text {pos }}$

iii. Wages are bounded above and below, $w \in \mathcal{W} \equiv[\underline{w}, \bar{w}] \subset \mathbb{R}_{++}$

iv. Unemployment benefits are bounded above and below, $z \in Z \equiv[\underline{z}, \gamma \bar{w}] \subset \mathbb{R}_{++}$

v. The credit score is a well defined probability, $f \in[0,1] \equiv F$

vi. Consumption lies in the set $c \in C \equiv\left[\underline{z}+\underline{r} \underline{b}_{n e g}, \bar{w}+\bar{b}_{\text {pos }}\right] \subseteq \mathbb{R}_{++}$where $\underline{z}+\bar{r} \underline{b}_{n e g}>0$ which implies $\underline{z}+\underline{r}_{n e g}>0$.

vii. The repayment choice lies in the set $r \in R \equiv[\underline{r}, \bar{r}] \subseteq(0,1]$.

\section{A.2 Corner Conditions and Concavity:}

i. The utility function is twice continuously differentiable, $u^{\prime \prime}<0, u^{\prime}>0, \lim _{c \rightarrow 0} u^{\prime}(c)=$ $+\infty$, and $\lim _{c \rightarrow+\infty} u^{\prime}(c)=0$.

\section{A.3 Incentive Compatibility:}

i. (IC-High) Pick $\underline{x} \in \mathbb{R}_{--}$such that,

$$
\underline{x}<\underbrace{u\left(\underline{z}+\bar{r} \underline{b}_{n e g}\right)}_{\text {Repay }}-\underbrace{u\left(\underline{z}+\underline{r} \underline{b}_{n e g}\right)}_{\text {Default }}
$$

A fixed penalty of $x_{H}=\underline{x}$ if $r<\bar{r}$ deters the high types from default when they are most likely to default (with maximum borrowing and low benefits). Under assumptions A.1 and A.2, this number exists and is finite.

ii. (IC-Low) Let $\underline{b}_{n e g}=\underline{z} / \bar{r}+\epsilon$ for a small number $\epsilon$. Pick $\bar{b}_{n e g}, \pi_{H H}$, and $\pi_{L H}$ such that $\frac{\bar{b}_{n e g}\left(1+r_{f}\right)}{\underline{b}_{n e g}} \geq \bar{r}\left(\pi_{H H}-\pi_{L H}\right)+\underline{r}\left(\pi_{L H}-\pi_{H H}\right)$. Such a value exists for $\bar{b}_{n e g}$ for a trivially close pair of $\left(\pi_{H H}, \pi_{L H}\right)$. This guarantees that if $x_{L}(r)=0, \forall r \in R$, then myopic low types always default, even on the smallest loan $\bar{b}_{\text {neg }}$,

$$
\underbrace{w-b+\frac{\pi_{H H} \bar{r}+\left(1-\pi_{H H}\right) \underline{r}_{b}}{1+r_{f}} \underline{b e g}_{n e g}}_{\text {Repay }} \leq \underbrace{w+\frac{\pi_{L H} \bar{r}+\left(1-\pi_{L H}\right) \underline{r}_{b}}{1+r_{f}} \underline{n e g}_{n}}_{\text {Default }}
$$

A.4 Invertability: $q_{V}: \mathbb{R} \rightarrow[0,1]$ is invertible 
Lemma 6.1: By construction, the model satisfies assumptions (1)-(3). Under the additional requirements that $q_{V}: \mathbb{R} \rightarrow[0,1]$ is invertible and both $\mathcal{W} \subseteq \mathbb{R}_{++}$(the wage domain) and $Y \subseteq \mathbb{R}$ (the aggregate shock domain) are bounded above and below, there is a unique solution to the firm's problem that does not depend on the aggregate distribution and the implied market tightness is independent of the distribution of agents across states.

Proof.

Step 1: Show the firm problem admits a solution independent of the distribution of agents across states.

Define $\Gamma_{I}$ to be the set of bounded functions that map from $\mathcal{W} \times Y$ into $\mathbb{R}$. Define the metric space $\left(\Gamma_{I},\|\cdot\|_{\infty}\right)$ where $\|f\|_{\infty}=\sup _{(w, y) \in \mathcal{W} \times Y}|f(w, y)|$, and define the usual Bellman operator $T^{J}: \Gamma_{I} \rightarrow \Gamma_{I}$ :

$$
T^{J}(J(w ; y))=y-w+\beta \mathbb{E}_{y^{\prime}}\left[\left(1-\delta\left(y^{\prime}, w\right)\right) J\left(w ; y^{\prime}\right)\right]
$$

To show that $T^{J}$ admits a fixed point independent of the distribution of agents across types, I will show self-mapping, monotonicity, and discounting in order to appeal to Blackwell's sufficient conditions for a contraction mapping.

(1) Self-mapping- $J \in \Gamma_{I} \Longrightarrow T^{J}(J) \in \Gamma_{I}$. Since $T^{J}(J)$ is an affine combination of functions in $\Gamma_{I}, T^{J}(J) \in \Gamma_{I}$. Thus $T^{J}: \Gamma_{I} \rightarrow \Gamma_{I}$.

(2) Monotonicity- $\nu, \omega \in \Gamma_{I}$ and $\nu(x) \leq \omega(x) \forall x \in \Gamma_{I} \quad \Longrightarrow \quad T^{J}(\nu) \leq T^{J}(\omega)$. To show monotonicity, let $\nu(w ; y) \leq \omega(w ; y) \quad \forall(w, y) \in \mathcal{W} \times Y$ where $\nu, \omega \in \Gamma_{I}$. Suppressing the arguments of the inputs,

$$
\begin{aligned}
T^{J}(\nu) & =y-w+\beta \mathbb{E}_{y^{\prime}}\left[\left(1-\delta\left(y^{\prime}, w\right)\right) \nu\right] \\
& \leq y-w+\beta \mathbb{E}_{y^{\prime}}\left[\left(1-\delta\left(y^{\prime}, w\right)\right) \omega\right] \\
& =T^{J}(\omega)
\end{aligned}
$$

The first line is the definition of $T^{J}$, the second line follows by hypothesis, and the last line mimics the first.

(3) Discounting- $a>0$ and $\nu \in \Gamma_{I} \Longrightarrow T(\nu+a) \leq T(\nu)+\beta a$ for some $\beta \in(0,1)$. To show discounting, let $a \geq 0$,

$$
\begin{aligned}
T^{J}(\nu+a) & =y-w+\beta \mathbb{E}_{y^{\prime}}\left[\left(1-\delta\left(y^{\prime}, w\right)\right)(\nu+a)\right] \\
& =y-w+\mathbb{E}_{y^{\prime}}\left[\beta\left(1-\delta\left(y^{\prime}, w\right)\right) \nu+\beta\left(1-\delta\left(y^{\prime}, w\right)\right) a\right] \\
& \leq y-w+\beta \mathbb{E}_{y^{\prime}}\left[\left(1-\delta\left(y^{\prime}, w\right)\right) \nu\right]+\beta a
\end{aligned}
$$


The first line is the definition of $T^{J}$, the second line is just a rearrangement, and the third line notes that $\left(1-\delta\left(y^{\prime}, w\right)\right) \leq 1, \forall\left(y^{\prime}, w\right) \in Y \times \mathcal{W}$ and then pulling the constant out of the expectation operator. Thus $T^{J}$ satisfies Blackwell's sufficient conditions for a contraction mapping and therefore $T^{J}$ has a unique fixed point, $J^{*} \in \Gamma_{I}, J^{*}: \mathcal{W} \times Y \rightarrow \mathbb{R}$.

Step 2: Solve for the implied equilibrium market tightness and show it is independent of the distribution of agents across types.

Let $\theta^{*}$ be the market tightness implied by $J^{*}: \mathcal{W} \times Y \rightarrow \mathbb{R}$ in the equation below (which uses assumptions (1)-(3) and invertibility)

$$
\theta^{*}=p_{V}^{-1}\left(\frac{\kappa(y)}{J^{*}}\right)
$$

Clearly, the market tightness implied by the firm's problem is independent of the distribution across types, $\theta^{*}: \mathcal{W} \times Y \rightarrow[0,1]$

Proposition 6.2: By construction, the model satisfies assumptions (1)-(4). Let $\beta_{L}=0$ and

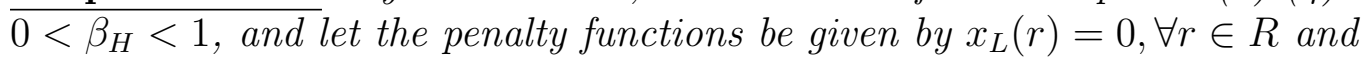

$$
x_{H}(r)= \begin{cases}\underline{x}, & \text { if } r<\bar{r} \text { Note }: \underline{x}<0 \text { given by A.3 } \\ 0, & \text { if } r=\bar{r}\end{cases}
$$

Under the additional assumptions A.1-A.4, a Perfectly Separating Bayesian Block Recursive Equilibrium exists where beliefs are given by,

$$
\hat{g}(r, f, b) \equiv \begin{cases}\pi_{L H}, & \text { if } b<0 \& r<\bar{r} \\ \pi_{H H}, & \text { if } b<0 \& r=\bar{r} \\ f \pi_{H H}+(1-f) \pi_{L H}, & \text { Otherwise }\end{cases}
$$

and bond prices are given by $\hat{q}\left(w, b^{\prime}, f^{\prime}\right) \equiv \frac{f^{\prime} \bar{r}+\left(1-f^{\prime}\right) \underline{r}}{\left(1+r_{f}\right)}$.

Proof.

Step 1: Solve for the equilibrium market tightness.

Apply Proposition 6.1 to find the unique $\theta^{*}: \mathbb{R}_{++} \times Y \rightarrow[0,1]$.

Step 2: Solve the household problem taking beliefs $\hat{g}: R \times B \times F \rightarrow[0,1]$, the market tightness $\theta^{*}: \mathbb{R}_{++} \times Y \rightarrow[0,1]$, and the bond price $\hat{q}: \mathbb{R}_{++} \times B \times F \rightarrow\left[\underline{r} /\left(1+r_{f}\right), 1 /\left(1+r_{f}\right)\right]$ as given, each of which is independent of the aggregate distribution. 
(A) Rewrite the household's problem: Let the state vector be given by $x=(e, w, b, f, i ; y)$, which is independent of $\mu$, and let tomorrow's state vector be given by,

$$
x^{\prime}=\left(e^{\prime}, w^{\prime}, b^{\prime}, \hat{g}(r, f, b), i^{\prime} ; y^{\prime}\right) \in\{W, U\} \times \mathbb{R}_{++} \times \mathbb{R} \times[0,1] \times\{H, L\} \times Y \equiv D_{x}^{I}
$$

The superscript $I$ means the domain is Independent of the distribution $\mu$. In terms of vector notation, $x(j)$ denotes element $j$ of the state vector $x$ and $1(\cdot)$ is the indicator function. Denote the budget correspondence $\Gamma: D_{x}^{I} \rightarrow R \times B$, which is independent of type other than through $f$, as $\Gamma(x)=\left\{\left(r, b^{\prime}\right) \in R \times B: c\left(x, r, b^{\prime}\right) \geq 0\right\}$. So long as the agent can have positive consumption after borrowing the maximum the period before and having lost unemployment benefits (losing benefits means $z=\underline{z}$ ), $-\underline{r} \underline{b}_{n e g}<\underline{z}, \Gamma(x)$ is non-empty $\forall x \in D_{x}^{I}$. Using this notation, rewrite the household's problem:

$$
\begin{gathered}
V(x)=\max _{\left(r, b^{\prime}\right) \in \Gamma(x)} u\left(c\left(x, r, b^{\prime}\right)\right)+x_{i}(r)+\beta_{i}\left[\pi_{i i}\left[1(x(1)=W) E_{x^{\prime} \mid i, W} V\left(x^{\prime}\right)+1(x(1)=U) E_{x^{\prime} \mid i, U} V\left(x^{\prime}\right)\right]\right. \\
\left.+\pi_{i j}\left[1(x(1)=W) E_{x^{\prime} \mid j, W} V\left(x^{\prime}\right)+1(x(1)=U) E_{x^{\prime} \mid j, U} V\left(x^{\prime}\right)\right]\right]
\end{gathered}
$$

such that

$$
c\left(x, r, b^{\prime}\right)=1(x(1)=W)\left(w+r b-\hat{q}\left(w, b^{\prime}, f^{\prime}\right)\right)+1(x(1)=U)\left(z+r b-\hat{q}\left(z, b^{\prime}, f^{\prime}\right)\right)
$$

For the employed agents, the expectations are independent of the aggregate distribution

$$
\begin{aligned}
E_{x^{\prime} \mid i, W} V\left(x^{\prime}\right) & \equiv E\left[\delta\left(y^{\prime}, w\right) V\left(U, \gamma w, b^{\prime}, \hat{g}(r, f, b), i ; y^{\prime}\right)\right. \\
& \left.+\left(1-\delta\left(y^{\prime}, w\right)\right) V\left(E, w, b^{\prime}, \hat{g}(r, f, b), i ; y^{\prime}\right)\right]
\end{aligned}
$$

And likewise, the unemployed agent's expectations are independent of the aggregate state

$$
\begin{aligned}
E_{x^{\prime} \mid i, U} V\left(x^{\prime}\right) & \equiv E\left[\max _{\tilde{w}} p_{U}\left(\theta^{*}\left(\tilde{w} ; y^{\prime}\right)\right) V\left(E, \tilde{w}, b^{\prime}, \hat{g}(r, f, b), i ; y^{\prime}\right)\right. \\
& \left.+\left(1-p_{U}\left(\theta^{*}\left(\tilde{w} ; y^{\prime}\right)\right)\right) V\left(U, z^{\prime}, b^{\prime}, \hat{g}(r, f, b), i ; y^{\prime}\right)\right]
\end{aligned}
$$

(B) Establish Blackwell's Sufficient Conditions for a Contraction Mapping: Define the metric space $\left(X\left(D_{x}^{I}\right),\|\cdot\|_{\infty}\right)$ where $\|f\|_{\infty}=\sup _{x \in D_{x}^{I}}|f(x)|$ and $X\left(D_{x}^{I}\right)$ is the set of all bounded functions that map $D_{x}^{I}$ into $\mathbb{R}$. Define the usual Bellman operator $T^{V}: X \rightarrow X$, subject to (30) - (32), as follows:

$$
\begin{gathered}
T^{V}(V(x))=\max _{\left(r, b^{\prime}\right) \in \Gamma(x)} u\left(c\left(x, r, b^{\prime}\right)\right)+x_{i}(r)+\beta_{i}\left[\pi_{i i}\left[1(x(1)=W) E_{x^{\prime} \mid i, W} V\left(x^{\prime}\right)+1(x(1)=U) E_{x^{\prime} \mid i, U} V\left(x^{\prime}\right)\right]\right. \\
\left.+\pi_{i j}\left[1(x(1)=W) E_{x^{\prime} \mid j, W} V\left(x^{\prime}\right)+1(x(1)=U) E_{x^{\prime} \mid j, U} V\left(x^{\prime}\right)\right]\right]
\end{gathered}
$$

To show that this problem admits a fixed point in $X$, I must establish self-mapping, monotonicity, and discounting. 
(1) Self-mapping- $V \in X \Longrightarrow T^{V}(V) \in X$. This amounts to showing that $T^{V}(\cdot)$ preserves the bounds for any initial guess $v \in X$. Given assumptions A.1-A.3, and the bond functions and penalty functions specified in the hypothesis, the contemporaneous flow utility is bounded above and below by $u_{\min }=u\left(\underline{z}+\bar{r} \underline{b}_{n e q}\right)+\underline{x}$ and $u_{\max }=u\left(\bar{w}+\bar{b}_{\text {pos }}\right)$ for any feasible choice. Since any guess $V(x) \in X$ is bounded by hypothesis and the contemporaneous flow utility is bounded over the feasible choice set, it must be the case that $T(V(x))$ is also bounded.

(2) Monotonicity- $v, w \in X$ and $v(x) \leq w(x) \forall x \in D_{x}^{I} \quad \Longrightarrow \quad T^{V}(v) \leq T^{V}(w)$. Monotonicity is also straightforward to prove. Assume $v, w \in X$ and $v(\bar{x}) \leq w(x)$ $\forall x \in D_{x}^{I}$.

$$
\begin{aligned}
T^{V}(v) & =\max _{\left(r, b^{\prime}\right) \in \Gamma(x)} u\left(c\left(x, r, b^{\prime}\right)\right)+x_{i}(r)+\beta_{i}\left[\pi_{i i}\left[1(x(1)=W) E_{x^{\prime} \mid i, W} v\left(x^{\prime}\right)+1(x(1)=U) E_{x^{\prime} \mid i, U} v\left(x^{\prime}\right)\right]\right. \\
& \left.+\pi_{i j}\left[1(x(1)=W) E_{x^{\prime} \mid j, W} v\left(x^{\prime}\right)+1(x(1)=U) E_{x^{\prime} \mid j, U} v\left(x^{\prime}\right)\right]\right] \\
& \leq \max _{\left(r, b^{\prime}\right) \in \Gamma(x)} u\left(c\left(x, r, b^{\prime}\right)\right)+x_{i}(r)+\beta_{i}\left[\pi_{i i}\left[1(x(1)=W) E_{x^{\prime} \mid i, W} w\left(x^{\prime}\right)+1(x(1)=U) E_{x^{\prime} \mid i, U} w\left(x^{\prime}\right)\right]\right. \\
& \left.+\pi_{i j}\left[1(x(1)=W) E_{x^{\prime} \mid j, W} w\left(x^{\prime}\right)+1(x(1)=U) E_{x^{\prime} \mid j, U} w\left(x^{\prime}\right)\right]\right] \\
& =T^{V}(w)
\end{aligned}
$$

(3) Discounting- $a>0$ and $v \in X \Longrightarrow T^{V}(v+a) \leq T^{V}(v)+\beta a$ for some $\beta \in(0,1)$. For discounting, suppose $a>0$ and $v \in X$.

$$
\begin{aligned}
T^{V}(v+a)= & \max _{\left(r, b^{\prime}\right) \in \Gamma(x)} u\left(c\left(x, r, b^{\prime}\right)\right)+x_{i}(r)+\beta_{i}\left[\pi _ { i i } \left[1(x(1)=W) E_{x^{\prime} \mid i, W}\left(v\left(x^{\prime}\right)+a\right)+1(x(1)=U) E_{x^{\prime} \mid i, U}\left(v\left(x^{\prime}\right)+a\right.\right.\right. \\
& \left.+\pi_{i j}\left[1(x(1)=W) E_{x^{\prime} \mid j, W}\left(v\left(x^{\prime}\right)+a\right)+1(x(1)=U) E_{x^{\prime} \mid j, U}\left(v\left(x^{\prime}\right)+a\right)\right]\right] \\
& \leq \max _{\left(r, b^{\prime}\right) \in \Gamma(x)} u\left(c\left(x, r, b^{\prime}\right)\right)+x_{i}(r)+\beta_{i}\left[\pi_{i i}\left[1(x(1)=W) E_{x^{\prime} \mid i, W} v\left(x^{\prime}\right)+1(x(1)=U) E_{x^{\prime} \mid i, U} v\left(x^{\prime}\right)\right]\right. \\
& \left.+\pi_{i j}\left[1(x(1)=W) E_{x^{\prime} \mid j, W} v\left(x^{\prime}\right)+1(x(1)=U) E_{x^{\prime} \mid j, U} v\left(x^{\prime}\right)\right]\right]+\beta a \\
& =T^{V}(v)+\beta a
\end{aligned}
$$

Appealing to Blackwell's sufficient conditions, $T^{V}(\cdot)$ satisfies (1)-(3) and is thus a contraction mapping, therefore the contraction mapping theorem implies that $T^{V}(\cdot)$ has a unique fixed point in $X$, i.e. $T^{V}\left(V^{*}\right)=V^{*}$ where $V^{*}: D_{x}^{I} \rightarrow \mathbb{R}$.

Step 3: Check equilibrium repayment behavior is consistent with beliefs and bond prices.

$V^{*}: D_{x}^{I} \rightarrow \mathbb{R}$ is independent of the distribution, thus the repayment choices associated with $V^{*}$ are independent of the distribution, $r_{e}^{i}: \mathcal{W} \times B \times F \times Y \rightarrow R$ for $i \in\{H, L\}$ and $e \in\{W, U\}$. However, this is not enough to prove the existence of the posited equilibrium 
since the repayment choices need to be consistent with beliefs and bond prices. There are two potential places in the state space in which inconsistencies can occur:

i. High types that enter the period with the lowest wages and maximum amount of debt are the most likely to default.

ii. Low types that enter the period with the highest wage and smallest amount of debt are the most likely to repay; note that even with $\beta_{L}=0$, the intratemporally updated credit score stops low types from defaulting on small amounts of debts, i.e. low types will repay debts $\hat{b}$ such that $\hat{b} \in\left[\bar{b}_{n e g}, 0\right)$.

I will now address these issues and make sure the assumptions laid out in the hypothesis are enough to align each type's behavior with beliefs and bond prices.

(A) Check Incentive Compatibility Among Low Types: Low types will default so long as today's gains from default, less the change in the cost of credit today, is positive. Therefore, the choice is to compare consumption today with default versus consumption tomorrow without default. For a low-type agent that enters the period with debt, the components of consumption are (i) the wage which is unchanged by default behavior (ii) past debts that are either repaid or defaulted upon, and (iii) future borrowings where the bond price which is $\frac{\pi_{H H} \bar{r}+\left(1-\pi_{H H}\right) \underline{r}}{1+r_{f}}$ if the agents repays (since this reveals a high type agent) and $\frac{\pi_{L H} \bar{r}+\left(1-\pi_{L H}\right) \underline{r}}{1+r_{f}}$ if the agent picks $r<\bar{r}$. Consider an employed agent with $b<0, \hat{q}\left(w, b^{\prime}, f^{\prime}\right)=\frac{f^{\prime} \bar{r}+\left(1-f^{\prime}\right) \underline{r}}{\left(1+r_{f}\right)}$ and who optimally chooses $b^{\prime}=\underline{b}_{n e g}{ }^{55}$

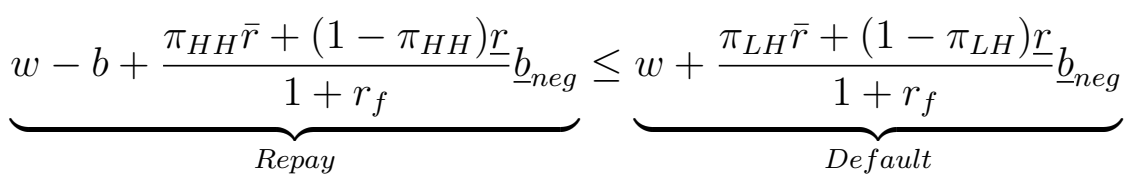

Imposing the smallest possible amount of debt $b=\bar{b}_{\text {neg }}$ (recall $b$ is negative when borrowing, and $b=\bar{b}_{n e g}$ is the case in which low types are most likely to deviate from the equilibrium action and decide to repay), the above condition yields

$$
\frac{\bar{b}_{n e g}\left(1+r_{f}\right)}{\underline{b}_{n e g}} \geq \bar{r}\left(\pi_{H H}-\pi_{L H}\right)+\underline{r}\left(\pi_{L H}-\pi_{H H}\right)
$$

Therefore, the low type's actions are consistent with the beliefs and the bond price. A similar argument holds for the unemployed.

(B) Check Incentive Compatibility Among High Types: To ensure the high types always want to repay, consider the payment decision of a high-type agent that has the lowest

\footnotetext{
${ }^{55}$ Note that since $\hat{q}\left(w, b^{\prime}, f^{\prime}\right)=\frac{f^{\prime} \bar{r}+\left(1-f^{\prime}\right) \underline{r}}{\left(1+r_{f}\right)}$ is independent of $b$ and $\beta_{L}=0$, the optimal choice of the low type is $b^{\prime}=\underline{b}_{n e g}$.
} 
possible benefits and maximum debt. Consider $b^{\prime}=0$ which is the case that the agent that is least likely to repay. A high type agent will repay so long as

$$
0<\underbrace{u\left(\underline{z}+\bar{r} \underline{b}_{n e g}\right)}_{\text {Repay }}-\underbrace{\left(u\left(\underline{z}+\underline{r}_{n e g}\right)+\underline{x}\right)}_{\text {Default }}
$$

Thus, pick $\underline{x} \in \mathbb{R}_{--}$such that,

$$
\underline{x}<u\left(\underline{z}+\bar{r} \underline{b}_{n e g}\right)-u\left(\underline{z}+\underline{r} \underline{b}_{n e g}\right)
$$

This penalty will deter the high types from default when they are most likely to default (with maximum borrowing and low benefits). Under assumptions A.1 and A.2, this number exists and is finite.

Thus the repayment behavior of the household is consistent with bond prices and beliefs.

Lemma 6.3: Let $r \in R \equiv[\underline{r}, \bar{r}]$, and assume the utility function is twice continuously differentiable, $u^{\prime \prime}<0, u^{\prime}>0, \lim _{c \rightarrow 0} u^{\prime}(c)=+\infty$, $\lim _{c \rightarrow+\infty} u^{\prime}(c)=0$, and assume that the penalty function is also twice continuously differentiable $x_{i}^{\prime \prime}<0, x_{i}^{\prime}>0, \lim _{r \rightarrow \underline{r}} x^{\prime}(r)=-\infty$, $\lim _{r \rightarrow \bar{r}} x^{\prime}(r)=0$ and $x_{i, 1}(r) \neq x_{j, 1}(r) \forall r \in R$, no Pooling Bayesian Recursive Equilibrium with borrowing exists (Note: This obtains regardless of off-equilibrium path beliefs).

Proof. I proceed by contradiction. Suppose that a Pooling Bayesian Recursive Equilibrium exists with positive lending.

Step 1: Show that with pooling (when both repayment policies are exactly the same), repayment behavior reveals nothing about the type, thus credit scores are constant across every possible point in the state space.

By assumption, $r_{U}^{L}(z, b, f ; \Omega)=r_{U}^{H}(z, b, f ; \Omega)=r_{U}^{*}(z, b, f ; \Omega)$ for unemployed agents and for employed agents $r_{W}^{L}(w, b, f ; \Omega)=r_{W}^{H}(w, b, f ; \Omega)=r_{W}^{*}(w, b, f ; \Omega)$. Rewrite (17) at follows (the summation is for $e \in\{W, U\}$ )

$\hat{f}=\frac{f \cdot \sum_{e} \operatorname{Pr}(e) \cdot \operatorname{Pr}\left(r_{e}^{H}(\hat{w}, b, f ; \Omega)=r^{o b s} \mid e, H, b, f, r^{o b s}, \Omega\right)}{f \cdot \sum_{e} \operatorname{Pr}(e) \cdot \operatorname{Pr}\left(r_{e}^{H}(\hat{w}, b, f ; \Omega)=r^{o b s} \mid e, H, b, f, r^{o b s}, \Omega\right)+(1-f) \cdot \sum_{e} \operatorname{Pr}(e) \cdot \operatorname{Pr}\left(r_{e}^{L}(\hat{w}, b, f ; \Omega)=r^{o b s} \mid e, L, b, f, r^{o b s}, \Omega\right)}$

where $r_{e}^{i(-1)}$ is the inverse of the type $i$ repayment function with respect to the wage (or benefits in the case of an unemployed agent) argument. Using equation (38) and the hypothesis, it is clear that the repayment behavior provides no new information about the type:

$$
\hat{f}=\frac{f \cdot \sum_{e} \operatorname{Pr}(e) \cdot \operatorname{Pr}\left(r_{e}^{*}(\hat{w}, b, f ; \Omega)=r^{o b s} \mid e, H, b, f, r^{o b s}, \Omega\right)}{f \cdot \sum_{e} \operatorname{Pr}(e) \cdot \operatorname{Pr}\left(r_{e}^{*}(\hat{w}, b, f ; \Omega)=r^{o b s} \mid e, H, b, f, r^{o b s}, \Omega\right)+(1-f) \cdot \sum_{e} \operatorname{Pr}(e) \cdot \operatorname{Pr}\left(r_{e}^{*}(\hat{w}, b, f ; \Omega)=r^{o b s} \mid e, L, b, f, r^{o b s}, \Omega\right)}
$$




$$
\begin{aligned}
& \hat{f}=\frac{f}{f+(1-f) \cdot \frac{\sum_{e} \operatorname{Pr}(e) \cdot \operatorname{Pr}\left(r_{e}^{*}(\hat{w}, b, f ; \Omega)=r^{o b s} \mid e, i=L, b, f, r^{o b s}, \Omega\right)}{\sum_{e} \operatorname{Pr}(e) \cdot \operatorname{Pr}\left(r_{e}^{*}(\hat{w}, b, f ; \Omega)=r^{o b s} \mid e, i=H, b, f, r^{o b s}, \Omega\right)}} \\
& =f
\end{aligned}
$$

As a result, $f$ is a constant in a pooling equilibrium.

Step 2: Show that if credit scores have no informational content and are constant, bond prices do not depend on the credit score.

Likewise, the bond price function, given by (14) and (16) does not depend on the credit score. Take the numerator of the employed bond price for example, expected repayment is independent of $f$ :

$$
\begin{aligned}
\hat{r}_{e}(w, b, f ; \Omega) & =(1-f) \cdot r_{e}^{L}(w, b, f ; \Omega)+f \cdot r_{e}^{H}(w, b, f ; \Omega) \\
& =(1-f) \cdot r_{e}^{*}(w, b, f ; \Omega)+f \cdot r_{e}^{*}(w, b, f ; \Omega) \\
& =r_{e}^{*}(w, b, f ; \Omega) \\
& =\hat{\hat{r}}_{e}^{*}(w, b ; \Omega), \quad e \in\{W, U\}
\end{aligned}
$$

Where the second line uses the hypothesis, and the last line supresses the constant $f$ by renaming $r_{e}^{*}(w, b, f ; \Omega)=\hat{\hat{r}}_{e}^{*}(w, b ; \Omega)$. With this notation in hand, the bond price for employed agents is given as follows (a similar argument holds for the unemployed value function):

$$
q_{W}\left(w, b^{\prime} ; \Omega\right)=\frac{\mathbb{E}\left[\left(1-\delta\left(y^{\prime}, w\right)\right) \hat{\hat{r}}_{W}^{*}(w, b, f ; \Omega)+\delta\left(y^{\prime}, w\right) \hat{\hat{r}}_{U}^{*}\left(z^{\prime}, b^{\prime} ; \Omega^{\prime}\right)\right]}{\left(1+r_{f}\right)} \text { for } b^{\prime}<0, b^{\prime} \in B
$$

Step 3: Show that if credit scores have no informational content and are constant, the assumed pooling equilibrium breaks down.

Now, in order for the assumed pooling Bayesian Recursive Equilibrium to exist with positive lending, it must be the case that given the above updating rule and bond price, the household picks $r_{e}$ such that $r_{e}=r_{e}^{*}$. However, lets return to the definition of a Bayesian Recursive Equilibrium. If households take as given the f-independent bond price and updating function, the optimal choice of a low type household is different from the optimal choice of a high type household, by hypothesis. To see this, take first order conditions for the household's repayment choice, $r \in[\underline{r}, \bar{r}]$, given the $f$-independent bond price and credit score updating function:

$$
x_{i, 1}(r) \leq-u_{1}(c) b \text { for } i \in\{H, L\}, \forall b<0 \text {, with equality if } r<\underline{r}
$$

Under the assumptions placed on the curvature of the penalty function and utility function and as long as $x_{i, 1}(r) \neq x_{j, 1}(r)$, then the repayment decision has an interior solution for both types and $r^{L} \neq r^{H}$, a contradiction. 
Proposition 6.4: Assume for $i \in\{H, L\}$,

$$
x_{i}(r)= \begin{cases}-\infty, & \text { if } r<\bar{r} \\ 0, & \text { if } r=\bar{r}\end{cases}
$$

Under additional assumptions A.1, A.2, and A.4, a Pooling Bayesian Block Recursive Equilibrium with borrowing exists where $q^{*}=1 /\left(1+r_{f}\right)$.

Proof. Apply Lemma 6.1 to find $\theta^{*}$ which is independent of the distribution. Credit scores contain no information and are constant (see Lemma 6.3), and the bond price is also constant since there is no default. Thus the household's problem, after being rewritten and solved exactly the same as Proposition 6.2, will admit a solution independent of the distribution.

Now in order to check the above solution is consistent with the asserted prices and constant beliefs, take first order conditions for repayment. The corner solution for the repayment choice is obtained by letting $x_{H}(r) \rightarrow-\infty$ and $x_{L}(r) \rightarrow-\infty \quad \forall r \in R \backslash\{\bar{r}\}$, and thus Equation 40 holds trivially for both types given the flat updating rule. With this optimal full-repayment policy in hand, the bond price is simply the risk free rate $q^{*}=1 /\left(1+r_{f}\right)$ across both employment status.

\section{Alternate Measures of Continuous Default}

Figures 27 and 28 illustrate the histogram and density of the fraction of total credit card balance that is past due, respectively. A similar pattern emerges as before; there are very few binary defaults. The median amount of total credit balance defaulted upon is $7.5 \%$ and the mean is $24.0 \%$. Overall, across all types of debts, the median default is $\$ 1186.5$ in 2005 dollars and the mean default is $\$ 4000.9$ in 2005 dollars. Figures 29 and 30 show the same histogram and density of the fraction of open accounts that are 60+ days past due or have had a major derogatory event (like bankruptcy), within the last 24 months, and have been updated within the last 3 months. Once again, a similar pattern emerges. 
Figure 27:

Percent of Total Balance Past Due on Bankcards, at Time of Default

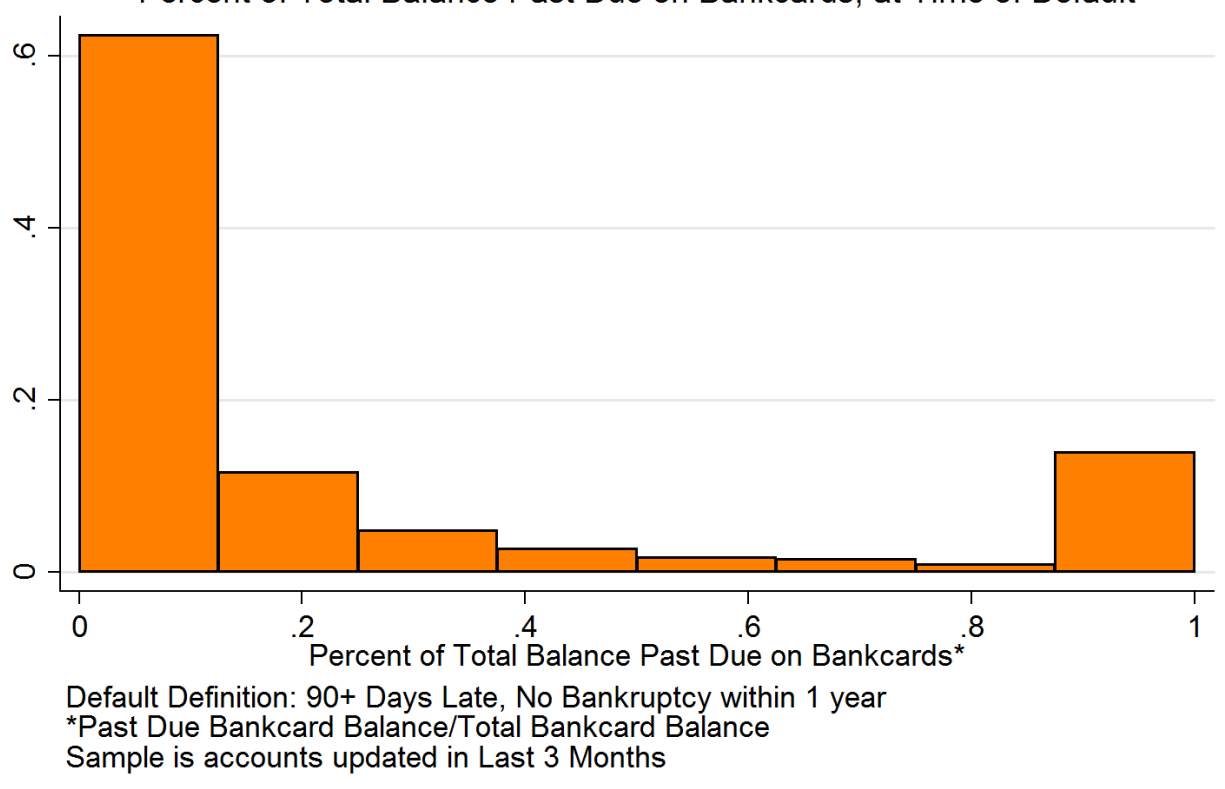

Figure 28:

Density for Percent of Total Balance Past Due on Bankcards, Window Around Default - 1Q Before Default $\quad$ Quarter of Default $\quad \cdots \quad 1 Q$ After Default

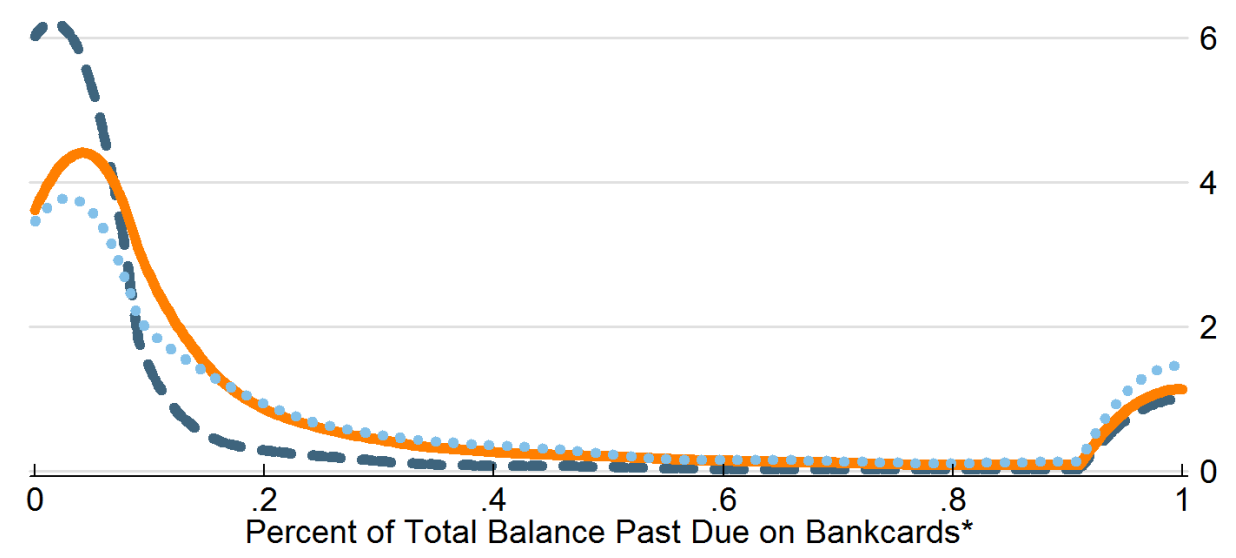

Default Definition: 90+ Days Late, No Bankruptcy within 1 year

*Past Due Bankcard Balance/Total Bankcard Balance

Sample is accounts updated in Last 3 Months 
Figure 29:

Fraction of Accounts 60+ Days Late, at Time of Default

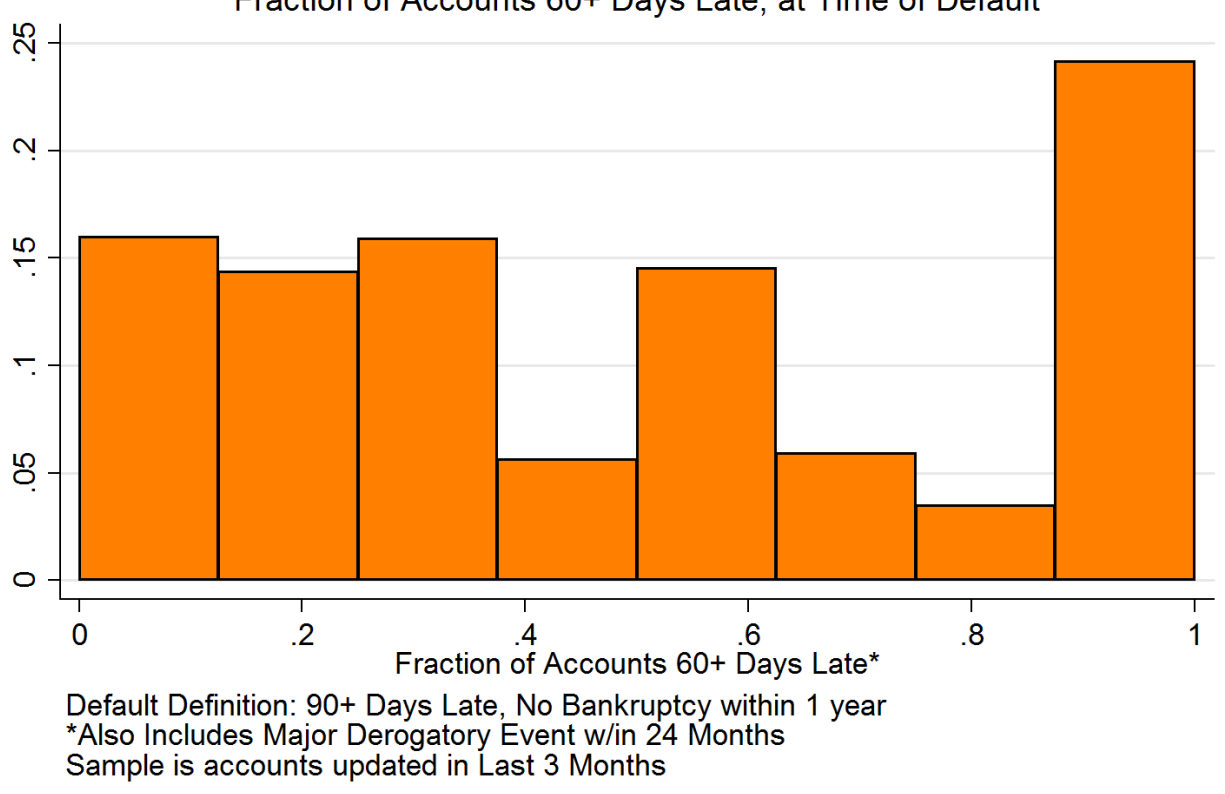

Figure 30:

Density for Fraction of Accounts 60+ Days Late, Window Around Default

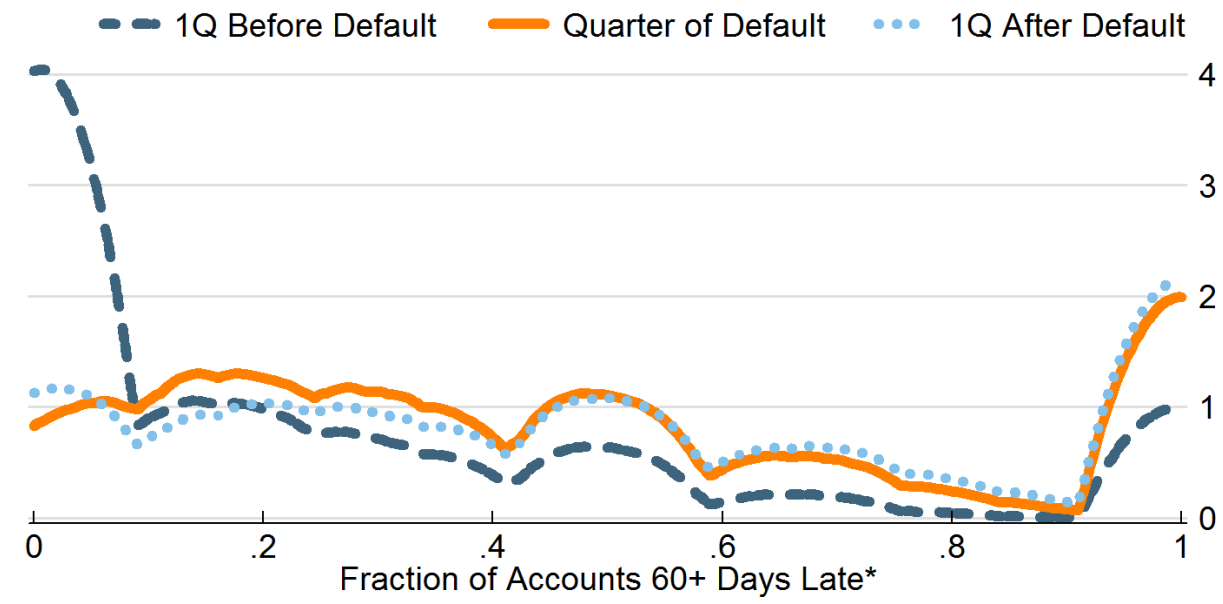

Default Definition: 90+ Days Late, No Bankruptcy within 1 year

*Also Includes Major Derogatory Event w/in 24 Months

Sample is accounts updated in Last 3 Months 


\section{Distortionary Policies}

Credit, in its standard form, is the way markets allocate scarce resources, and so when the government implements policies that directly change the incentives to extend credit, there are adverse (real) implications. Following the credit bust, the government responded by regulating various markets where were often times mistargeted. Among those regulations, there were several policies that furthered the severity of the contraction and, as will the be the subject of this paper, the recovery by limiting the efficient provision and reallocation of consumer credit:

- The Robo-Signing Lawsuit

- The Mortgage Servicer Settlement

- The Credit CARD Act of 2009

- The Home Affordable Modification Program

- The Hardest Hit Program

- The State Foreclosure Moratoria

- Dodd Frank (TBA)

Credit Cardholders' Bill of Rights (The Credit Card Accountability Responsibility and Disclosure Act of 2009 or Credit CARD Act of 2009)

- "Customers who have been subject to a rate increase and then pay on time for six consecutive months must have their interests rates returned to the rate it was before the rate increase. Requires creditors to review payment history each six months and to determine if a rate decrease should apply."

- No interest rate increases for the first year. Your credit card company cannot increase your rate for the first 12 months after you open an account. There are some exceptions:

(i) If your card has a variable interest rate tied to an index; your rate can go up whenever the index goes up.

(ii) If there is an introductory rate, it must be in place for at least 6 months; after that your rate can revert to the "go-to" rate the company disclosed when you got the card.

(iii) If you are more than 60 days late in paying your bill, your rate can go up.

The following is quoted from "Executive Summary of Multistate Federal Settlement of Foreclosure Misconduct Claims" which is a summary of the mortgage servicer settlement: 
- "Borrowers must be sent a pre-foreclosure notice that will include a summary of loss mitigation options offered, an account summary, description of facts supporting lenders right to foreclose, and a notice that the borrower may request a copy of the loan note and the identity of the investor holding the loan.

- Borrowers must be thoroughly evaluated for all available loss mitigation options before foreclosure referral, and banks must act on loss mitigation applications before referring loans to foreclosure; i.e. "dual tracking" will be restricted.

- Denials of loss mitigation relief must be automatically reviewed, with a right to appeal for borrowers."

- "Banks are required to designate an employee as a continuing single point of contact to assist borrowers seeking loss mitigation assistance.

- Banks must maintain adequate trained staff to handle the demand for loss mitigation relief.

- Servicers are required to expedite and facilitate short sales of distressed properties.

- Restrictions are imposed on default fees, late fees, third-party fees, and force-placed insurance." 


\section{E Cure Rates}

The following table shows the rate at which consumers transit from the row state to the column state (i.e. 2.69 percent of those with no credit begin the quarter with a current credit card). The accounts are not updated every quarter, thus you end up with what look like erroneous transitions. The cure rates are the transitions from late (90 or $120+$ days late) to current, and FC stands for foreclosure. Derogatory is a discretionary classification of persistently late accounts.

\begin{tabular}{|c|c|c|c|c|c|c|c|c|}
\hline \multicolumn{9}{|c|}{ Post 2005} \\
\hline \multicolumn{9}{|c|}{ Credit } \\
\hline & No Credit & Current & 30 & 60 & 90 & $120+$ & Derogatory & Bankruptcy \\
\hline No Credit & 96.5 & 2.69 & 0.06 & 0.02 & 0.01 & 0.08 & 0.55 & 0.1 \\
\hline Current & 1.54 & 95.9 & 1.13 & 0.63 & 0.42 & 0.11 & 0.17 & 0.1 \\
\hline 30 & 2.37 & 45.08 & 13.28 & 6.6 & 5.98 & 22.56 & 3.33 & 0.8 \\
\hline 60 & 3.54 & 23.48 & 5.98 & 7.32 & 5.92 & 44.15 & 8.4 & 1.2 \\
\hline 90 & 4.59 & 15.14 & 3.33 & 2.73 & 4.83 & 39.32 & 28.73 & 1.34 \\
\hline $120+$ & 8.32 & 11.26 & 1.53 & 1.27 & 1.24 & 16.77 & 58.19 & 1.42 \\
\hline Derogatory & 11.01 & 3.28 & 0.18 & 0.19 & 0.15 & 0.56 & 83.9 & 0.73 \\
\hline Bankruptcy & 16.19 & 14.2 & 0.4 & 0.33 & 0.19 & 0.52 & 4.32 & 63.84 \\
\hline \multicolumn{9}{|c|}{ Mortgage } \\
\hline & No Credit & Current & 30 & 60 & 90 & $120+$ & Derogatory & $\begin{array}{l}\text { Bankruptcy } \\
\text { (FC) }\end{array}$ \\
\hline No Credit & 98.59 & 1.29 & 0.03 & 0.01 & 0.01 & 0.02 & 0.02 & 0.03 \\
\hline Current & 3.52 & 94.32 & 1.45 & 0.36 & 0.16 & 0.05 & 0.05 & 0.1 \\
\hline 30 & 5.13 & 36.29 & 31.05 & 13.24 & 5.13 & 5.33 & 3.31 & 0.54 \\
\hline 60 & 5.53 & 17.62 & 15.74 & 18.38 & 12.26 & 18.67 & 10.67 & 1.13 \\
\hline 90 & 8.53 & 14.34 & 4.38 & 6.61 & 10.84 & 32.59 & 20.8 & 1.91 \\
\hline $120+$ & 9.43 & 9.91 & 1.52 & 1.32 & 1.24 & 59.8 & 15.11 & 1.67 \\
\hline Derogatory & 18.17 & 5.31 & 0.87 & 0.56 & 0.23 & 6.9 & 65.33 & 2.64 \\
\hline $\begin{array}{l}\text { Bankruptcy } \\
\text { (FC) }\end{array}$ & 19.77 & 2.92 & 0.29 & 0.07 & 0.04 & 0.97 & 1.37 & 74.57 \\
\hline
\end{tabular}

